\title{
Spatial Distribution of Amino Acids of the SARS-CoV2 Proteins
}

\author{
Ranjeet Kumar Rout ${ }^{\mathrm{a}}$, Sk. Sarif Hassan ${ }^{\mathrm{b}, *}$ \\ ${ }^{a}$ Department of Computer Science $\&$ Engineering, National Institute of Technology, \\ Hazratbal, Srinagar, India \\ ${ }^{b}$ Department of Mathematics, Pingla Thana Mahavidyalaya, Paschim Medinipur-721140, \\ India
}

\begin{abstract}
The world is now undergoing through a global emergency due to COVID-19 which needs immediate remedies in order to strengthen the healthcare facility to save the nations. Looking towards to the remedies, research on different aspects including the genomic and proteomic level characterizations of the SARS-CoV2 are necessarily important. In this present study, the spatial representation/composition of twenty amino acids across the primary protein sequences of SARSCoV2 have been looked into through different parameters viz. Shannon entropy, Hurst exponent in order to fetch the autocorrelation and amount of information over the spatial representations. Also frequency distribution of each of the amino acids over the protein sequences have been chalked out.
\end{abstract}

Keywords: Shannon entropy, Hurst exponent, Amino acid, Frequency distribution, \& SARS-CoV2.

\section{Introduction}

Global emergency due to the COVID-19 is making life hard throughout the globe [1, 2, 3]. The largest genomes (of size approximately $30 \mathrm{~kb}$ ) for RNA viruses so far is known as the SARS-CoV2 [4, 5]. CoVs are classified into three

\footnotetext{
* Corresponding author

Email addresses: ranjeetkumarrout@nitsri.net (Ranjeet Kumar Rout), sarimif@gmail.com (Sk. Sarif Hassan )
} 
5 different classes such as $\alpha$-CoVs, $\beta$-CoVs and $\gamma$-CoVs based on the genetic and antigenic criteria 6, 7]. The SARS-COV2 is classified into the $\beta$-CoV group [8]. Quite a good number of untiring research activities across the world have been carried out [9, 10, 11]. Everyday, new genome sequences as well as primary protein sequences of SARS-CoV2 are being included in the databases viz. NCBI virus database [12, 13. In the current scenario, no antiviral drugs with proven efficacy nor are there vaccines for the CoV2 prevention exist [14, 15]. Also, the researchers have not gained yet the clear molecular biology of SARSCoV2 infection [16]. Everyday our world is now experiencing the pandemic side of the COVID-19 which certainly questing for in depth knowledge of the virus and its infection mechanism and other aspects. In the present state of art, viral infection mechanism is not fully understood though various proteinprotein interactions (PPIs) of virus and host are known [17, 18. So identifying interactions between the SARS-CoV2 virus proteins and host proteins helps understand the mechanism of viral infection and develop treatments and vaccines [19. Understanding these SARS-CoV2 proteins is one of the primary aims to get a clarity of the PPIs between the virus proteins and host proteins [20]. The protein fold depends on by the number, spatial arrangement and topological connectivity of secondary structure elements (SSEs) 21]. Biologists yet to understand the spatial arrangement of secondary structure elements (SSEs) [22].

${ }_{25}$ The geometric three dimensional structure of a protein depends on the spatial arrangement of the SSEs which has been studied in [23]. So the spatial distribution as well as presence/absence of different amino acids over a primary protein sequence of SARS-CoV2 are significantly important to reveal. It is needless to mention that the spatial arrangement uncovers the rules that govern the folding of polypeptide chains 24]. Alternation of amino acids over the primary sequence might affect the function of a protein. Also the primary sequence of a protein reveals the molecular events in evolution. The spatial arrangement of amino acids determines the conformability of proteins too [25, 26].

In this present study, spatial composition of twenty amino acids across the primary proteins of SARS-CoV2 have been looked into through parameters viz. 
Hurst exponent and Shannon entropy. Also frequency analysis of the amino acids over the proteins have been chalked out. It is noted that authors have done similar analysis for the 89 genomes of SARS-CoV2 [27].

\subsection{Database used and Specifications}

For this present study, as on date 24th March, 2020, there are 944 primary protein sequences of the SARS-CoV2 in the NCBI Virus Database (https: //www.ncbi.nlm.nih.gov/labs/virus/vssi/), which have been considered [28]. It is noted that out of all these 944 sequences only 105 sequences are distinct although these sequence data have been taken from wide ranges of geographic locations over the world. The complete list of 105 distinct sequences which we name as $N 1, N 2, \ldots, N 105$ with their corresponding accessions is given at the end of the article in the Table 51, 52, 53, 54 and 55. These 105 distinct proteins sequences are taken for the present study.

There are twenty amino acids of three different types as described below:

- Essential amino acids: H, I, K, L, M, F, T, W and V.

- Conditionally Essential: R, C, Q, G, P and Y.

- Non-Essential: A, D, N, E, S.

Replication of a virus depends on the availability of amino acids [29]. Amino acids play a crucial role in virus-related infections as amino acids are necessarily required for protein synthesis [30. The absence of essential amino acids may result in empty virus particles that are free of viral nucleic acids [31. The conditionally essential amino acid Arginine (R) is very much needed for the replication of viruses and progression of viral infections. The basic backbone of the amino acids are carbon atom $(\mathrm{C})$ attached to a carboxyl group (-COOH), ${ }_{60}$ an amino group, (-NH2), a Hydrogen, and another group of atoms (R). The $\mathrm{R}$ group gives the amino acid its unique characteristics, and allows it to react with other amino acids in unique ways. Based on the structure and general chemical characteristics of $\mathrm{R}$ groups of the amino acids the following well known classification is given in the following: 
- Hydroxyl: S, C, T, M

- Cyclic: P

- Aromatic: F, Y, W

- Basic: H, K, R

- Acidic: D, Q, Z, N

Hereby we order these amino acids as $A_{1}, A_{2}, A_{3}, \ldots A_{20}$ corresponding to A, C, F, G, H, I, L, M, N, P, Q, S, T, V, W, Y, D, E, K and R respectively.

Every primary protein sequence has been decomposed into twenty different binary sequences of $0^{\prime} s$ and $1^{\prime} s$, which is formed by the following rule:

75 Given a primary protein sequences of SARS-CoV2, for every amino acid $A_{i} \in$ $\{A, C, F, G, H, I, L, M, N, P, Q, S, T, V, W, Y, D, E, K, R\}$ for $i=1$ to 20 , put one wherever $A_{i}$ is present and elsewhere put zero.

Consequently, for every given primary protein sequence $N j$ for all $j=$ $1,2, \ldots 105$, there would be twenty binary sequences $B_{i_{j}}$ corresponding to twenty different amino acids $A_{i}$ for all $i=1,2, \ldots 20$.

The length of these complete 105 primary protein sequences is widely varying from 13 to 7097. There is one complete SARS-CoV2 protein sequence N99 of the smallest length 13 and one protein sequence N26 of the largest length 7097 . There are $6,3,8,10,3$, and 48 sequences of lengths 121, 275, 419, 1273, 4405 and 7096 respectively and rest sequences are of unique length ranges from the smallest to largest. So typically all these 105 sequences can be grouped into six groups excluding individual sequences of different unique length. The complete list of 105 proteins with their corresponding length are given in the Table 1. 
Table 1: Length of the 105 primary protein sequences

\begin{tabular}{|c|c|c|c|c|c|c|c|}
\hline Seq & Length & Seq & Length & Seq & Length & Seq & Length \\
\hline N99 & 13 & N90 & 419 & $\mathrm{~N} 12$ & 7088 & N41 & 7096 \\
\hline N80 & 38 & N91 & 419 & N13 & 7091 & N42 & 7096 \\
\hline N81 & 43 & N92 & 419 & N44 & 7095 & N43 & 7096 \\
\hline N68 & 61 & N93 & 419 & N14 & 7096 & N45 & 7096 \\
\hline N96 & 75 & N94 & 419 & N16 & 7096 & N46 & 7096 \\
\hline N97 & 75 & N95 & 419 & N17 & 7096 & N47 & 7096 \\
\hline $\mathrm{N} 103$ & 83 & N7 & 500 & N18 & 7096 & N48 & 7096 \\
\hline N98 & 113 & N1 & 527 & N19 & 7096 & N49 & 7096 \\
\hline N82 & 121 & N5 & 601 & N2O & 7096 & N50 & 7096 \\
\hline N83 & 121 & N6 & 638 & N21 & 7096 & N51 & 7096 \\
\hline N84 & 121 & N100 & 932 & $\mathrm{~N} 22$ & 7096 & N52 & 7096 \\
\hline N85 & 121 & N70 & 1272 & $\mathrm{~N} 23$ & 7096 & N53 & 7096 \\
\hline N86 & 121 & N69 & 1273 & N24 & 7096 & N54 & 7096 \\
\hline N87 & 121 & N71 & 1273 & N25 & 7096 & N55 & 7096 \\
\hline N2 & 139 & N72 & 1273 & N27 & 7096 & N56 & 7096 \\
\hline N15 & 180 & N73 & 1273 & N28 & 7096 & N57 & 7096 \\
\hline N3 & 198 & N74 & 1273 & $\mathrm{~N} 29$ & 7096 & N59 & 7096 \\
\hline N8 & 222 & N75 & 1273 & N30 & 7096 & N60 & 7096 \\
\hline N9 & 275 & N76 & 1273 & N31 & 7096 & N61 & 7096 \\
\hline N10 & 275 & N77 & 1273 & N33 & 7096 & N62 & 7096 \\
\hline N11 & 275 & N78 & 1273 & N34 & 7096 & N63 & 7096 \\
\hline N101 & 290 & N79 & 1273 & N35 & 7096 & N64 & 7096 \\
\hline N105 & 298 & N4 & 1945 & N37 & 7096 & N65 & 7096 \\
\hline $\mathrm{N} 102$ & 306 & N32 & 4405 & N38 & 7096 & N66 & 7096 \\
\hline N104 & 346 & N36 & 4405 & N39 & 7096 & N67 & 7096 \\
\hline N88 & 419 & N58 & 4405 & N40 & 7096 & N26 & 7097 \\
\hline N89 & 419 & & & & & & \\
\hline
\end{tabular}

\section{Methods}

90 In characterizing the amino acids spatial distribution over the primary protein sequences of SARS-CoV2, the three parameters Hurst Exponent, Shannon Entropy are used. In addition amino acid density/frequency analysis is also being carried out. Following these methods are described briefly. Similar works based on these methods are done in [32, 33, 34].

\subsection{Hurst Exponent}

Fractality (an organized form of nonlinearity) is naturally characterised using fractal dimension. In the case of one dimensional sequence, the fractal dimension (D) and the Hurst Exponent (HE) are linearly related as $D+H=2$ [35, 36]. The Hurst exponent measures the autocorrelation in the sequences [37. The 

less than 0.5 and for positively correlated sequences the HE ranges between 0.5 to 1 . If $\mathrm{HE}=0.5$, then the sequence clearly depicts its randomness with white noise.

The HE of a binary sequence $s_{n}$ is defined as

$$
\left(\frac{n}{2}\right)^{H E}=\frac{X(n)}{Y(n)}
$$

where

$$
Y(n)=\sqrt{\frac{1}{n} \sum_{i=1}^{n}\left(s_{i}-m\right)}
$$

and $X(n)=\max T(i, n)-\min T(i, n)$, where

$$
T(i)=\sum_{j=1}^{n}\left(s_{i}-t\right)
$$

and

$$
t=\sqrt{\frac{1}{n} \sum_{i=1}^{n} s_{i}}
$$

The auto correlation of the binary representations of each of the amino acids over the SARS-CoV2 protein sequences are obtained through the Hurst exponent.

\subsection{Shannon entropy}

There are two kinds of Shannon entropy we wish to determine in this present study.

- Binary Shannon Entropy: The Shannon entropy (SE) measures information entropy of a Bernoulli process with probability $p$ of the two outcomes $(0 / 1)$. It is defined as

$$
S E=-\sum_{i=1}^{2} p_{i} \log _{2}\left(p_{i}\right)
$$

where $p_{1}=\frac{k}{2^{l}}$ and $p_{2}=\frac{l-k}{2^{l}}$; here $l$ is the length of the binary sequence and $k$ is the number of 1 's in the binary sequence of length $l$ [38]. The binary 
Shannon entropy is a measure of the uncertainty in a binary sequence. Whenever the probability $p=0$, the event is certain never to occur, and so there is no uncertainty, leading to an entropy of 0 . Similarly, if the probability $p=1$, the result is certain, so the entropy must be 0 . When $p=0.5$, the uncertainty is at a maximum and consequently the $\mathrm{SE}$ is 1.

- Amino Acid Conservation Shannon Entropy: Protein Post Translational Modification (PTM) important biological mechanism for expanding the genetic code [39, 40]. To the find the conservation of amino acids in primary protein sequences, Shannon entropy is deployed. For a given protein sequence, the SE is calculated as follows:

$$
S E=-\sum_{i=1}^{20} p_{A_{i}} \log _{2}\left(p_{A_{i}}\right)
$$

where $p_{A_{i}}$ represents the occurrence frequency of amino acid $A_{i}$ in the sequence.

\subsection{Amino Acid Density}

Over the primary protein sequences of SARS-CoV2, we wish to explore the amino acid frequency distributions and corresponding statistical descriptions [41]. The density of the amino acids over a primary protein sequence can also be found using the following formula:

$$
D\left(A_{i}\right)=\frac{F\left(A_{i}\right)}{L(P)} \times 100 \%
$$

where $A_{i}$ is an amino acid present in the primary protein sequence $P, L(P)$ is the length of the sequence $P$ and $F\left(A_{i}\right)$ is the frequency of the amino acid $A_{i}$ in the sequence $P$. This amino acid density would clarify the richness of essential amino acids in contrast to others.

\section{Results}

In this section, first the positive/negative trend of the spatial distribution of the twenty amino acids over the protein sequences of SARS-CoV2 through Hurst 
exponent are reported. The Hurst exponent also would imply the fractality (organized non-linearity) of the spatial representations as mentioned earlier. In addition, the amount of uncertainty of presence/absence of the amino acids over the protein sequences is determined through Shannon entropy. Also the amino acid conservation information is determined through the Shannon entropy. At last, the frequency distributions of all the amino acids over the protein sequences of SARS-CoV2 are given. It is noted that fourteen (14) SARS-CoV protein sequences have been taken for comparative investigations with the 105 SARS$\mathrm{CoV} 2$ proteins.

\subsection{Hurst Exponent of $B_{1_{j}}$ for $j=1,2, \ldots 105$ and Classification}

For the amino acid $A_{1}(A)$ the Hurst exponent(HE) for the 105 binary sequences $B_{1_{j}}$ for $j=1,2, \ldots 105$ have been determined. The plot of the HE for the binary sequences has been plotted and corresponding histogram is also given in the Fig 1. The HE of the binary representations of ordering of the amino acid $A_{1}$ over all the primary protein sequences would reveal the autocorrelation of the amino acid.
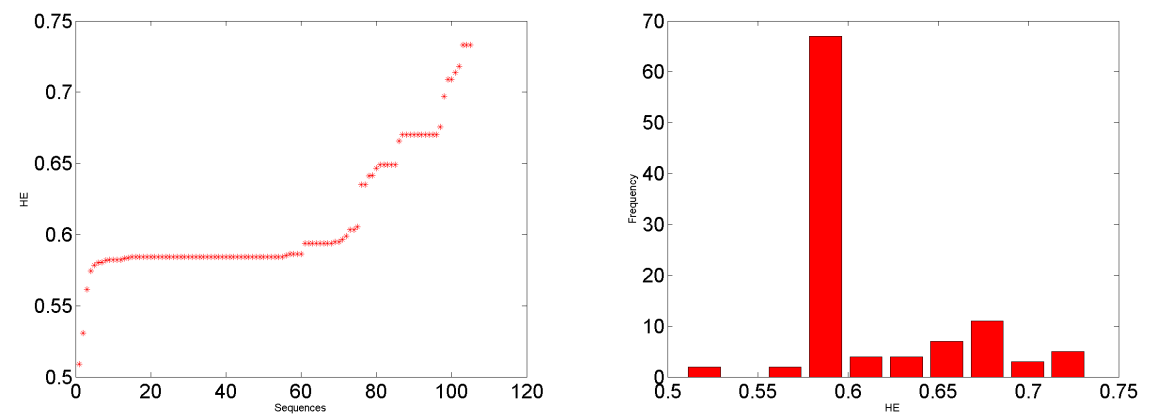

Figure 1: Plot of the HEs and corresponding histogram of all the binary sequences $B_{1_{j}}$ for $j=1,2, \ldots 105$ corresponding to the amino acid $A_{1}(A)$. 
Table 2: HE of $105 B_{1_{j}}$ for $j=1,2, \ldots 105$ corresponding to the amino acid $A_{1}(A)$.

\begin{tabular}{|c|c|c|c|c|c|c|c|c|c|c|c|}
\hline Seq & $\mathrm{HE}$ & C & Seq & $\mathrm{HE}$ & C & Seq & $\mathrm{HE}$ & C & Seq & $\mathbf{H E}$ & C \\
\hline N80 & 0.509 & 3 & N31 & 0.584 & 7 & N26 & 0.584 & 7 & N83 & 0.649 & 5 \\
\hline $\mathrm{N} 4$ & 0.531 & 3 & N33 & 0.584 & 7 & N8 & 0.585 & 7 & N84 & 0.649 & 5 \\
\hline N103 & 0.562 & 6 & N34 & 0.584 & 7 & $\mathrm{~N} 22$ & 0.586 & 7 & N85 & 0.649 & 5 \\
\hline N87 & 0.574 & 7 & N35 & 0.584 & 7 & N59 & 0.586 & 7 & N86 & 0.649 & 5 \\
\hline N105 & 0.578 & 7 & N37 & 0.584 & 7 & N65 & 0.586 & 7 & N74 & 0.666 & 1 \\
\hline $\mathrm{N} 20$ & 0.580 & 7 & N38 & 0.584 & 7 & N29 & 0.586 & 7 & N70 & 0.670 & 1 \\
\hline N7 & 0.581 & 7 & N39 & 0.584 & 7 & N88 & 0.594 & 2 & N69 & 0.670 & 1 \\
\hline N81 & 0.582 & 7 & $\mathrm{~N} 40$ & 0.584 & 7 & N89 & 0.594 & 2 & N71 & 0.670 & 1 \\
\hline N48 & 0.582 & 7 & N41 & 0.584 & 7 & N90 & 0.594 & 2 & N72 & 0.670 & 1 \\
\hline N50 & 0.582 & 7 & $\mathrm{~N} 42$ & 0.584 & 7 & N91 & 0.594 & 2 & N73 & 0.670 & 1 \\
\hline N61 & 0.582 & 7 & N45 & 0.584 & 7 & N92 & 0.594 & 2 & N75 & 0.670 & 1 \\
\hline N43 & 0.582 & 7 & N46 & 0.584 & 7 & N93 & 0.594 & 2 & N76 & 0.670 & 1 \\
\hline $\mathrm{N} 12$ & 0.583 & 7 & $\mathrm{~N} 47$ & 0.584 & 7 & N94 & 0.594 & 2 & N77 & 0.670 & 1 \\
\hline N13 & 0.584 & 7 & N49 & 0.584 & 7 & N95 & 0.594 & 2 & N78 & 0.670 & 1 \\
\hline N44 & 0.584 & 7 & N51 & 0.584 & 7 & N32 & 0.595 & 2 & N79 & 0.670 & 1 \\
\hline N14 & 0.584 & 7 & N52 & 0.584 & 7 & N36 & 0.595 & 2 & N101 & 0.676 & 1 \\
\hline N16 & 0.584 & 7 & N53 & 0.584 & 7 & N58 & 0.597 & 2 & N98 & 0.697 & 8 \\
\hline N17 & 0.584 & 7 & N54 & 0.584 & 7 & N68 & 0.599 & 2 & N96 & 0.709 & 10 \\
\hline N18 & 0.584 & 7 & N55 & 0.584 & 7 & N1 & 0.603 & 2 & N97 & 0.709 & 10 \\
\hline N19 & 0.584 & 7 & N56 & 0.584 & 7 & N5 & 0.604 & 2 & N2 & 0.714 & 9 \\
\hline N21 & 0.584 & 7 & N57 & 0.584 & 7 & N6 & 0.605 & 2 & N99 & 0.718 & 9 \\
\hline $\mathrm{N} 23$ & 0.584 & 7 & N60 & 0.584 & 7 & N100 & 0.635 & 5 & N9 & 0.733 & 4 \\
\hline N24 & 0.584 & 7 & N62 & 0.584 & 7 & N104 & 0.635 & 5 & N10 & 0.733 & 4 \\
\hline N25 & 0.584 & 7 & N63 & 0.584 & 7 & N3 & 0.641 & 5 & N11 & 0.733 & 4 \\
\hline $\mathrm{N} 27$ & 0.584 & 7 & N64 & 0.584 & 7 & $\mathrm{~N} 102$ & 0.642 & 5 & & & \\
\hline N28 & 0.584 & 7 & N66 & 0.584 & 7 & N15 & 0.647 & 5 & & & \\
\hline N30 & 0.584 & 7 & N67 & 0.584 & 7 & N82 & 0.649 & 5 & & & \\
\hline
\end{tabular}

Here the HE of the 105 binary representation of the amino acid $A_{1}$ is ranging from 0.509 to 0.7331 with standard deviation 0.04512. Based on the HEs of the binary sequences all these 105 primary protein sequences of SARS-CoV2, ten clustered $(\mathrm{C})$ are formed as presented in the Table 2.

The cluster 3 contains two sequences having HE approximately 0.5 which depicts the random walk/Brownian motion like character of the ordering of the amino acid $A_{1}$ over the the sequences N4 and N80. It is noted that all the $B_{1_{j}}$ for $j=1,2, \ldots 105$ except $\mathrm{N} 4$ and N80 are trending (persistent) sequences of ordering of the amino acid $A_{1}$ over all the 103 primary protein sequences. Out of all, there are $57 B_{1_{j}}$ for different values of $j$ having HE at fixed at 0.58 and belonging to the cluster 7 . So the amino acid $A_{1}$ is orderly placed in a persistent manner (not too persistent through) over most of the primary 
160

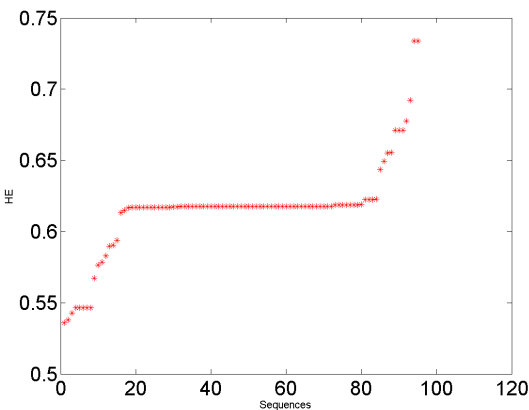

Figure 2: Plot of the HEs and corresponding histogram of all the binary sequences $B_{2}$ for $j=1,2, \ldots 105$ corresponding to the amino acid $A_{2}(A)$. 
Table 3: HE of $105 B_{2_{j}}$ for $j=1,2, \ldots 105$ corresponding to the amino acid $A_{2}(C)$.

\begin{tabular}{|c|c|c|c|c|c|c|c|c|c|c|c|}
\hline Seq & HE & C & Seq & HE & C & Seq & HE & C & Seq & HE & C \\
\hline N68 & * & 2 & N73 & 0.617 & 1 & N45 & 0.618 & 1 & N32 & 0.623 & 1 \\
\hline N88 & * & 2 & N74 & 0.617 & 1 & N46 & 0.618 & 1 & N36 & 0.623 & 1 \\
\hline N89 & * & 2 & N75 & 0.617 & 1 & N47 & 0.618 & 1 & N58 & 0.623 & 1 \\
\hline N90 & * & 2 & N76 & 0.617 & 1 & N48 & 0.618 & 1 & N102 & 0.623 & 1 \\
\hline N91 & * & 2 & N77 & 0.617 & 1 & N49 & 0.618 & 1 & N4 & 0.644 & 8 \\
\hline N92 & * & 2 & N78 & 0.617 & 1 & N50 & 0.618 & 1 & N2 & 0.649 & 8 \\
\hline N93 & * & 2 & N79 & 0.617 & 1 & N51 & 0.618 & 1 & N1 & 0.655 & 8 \\
\hline N94 & * & 2 & N70 & 0.617 & 1 & N52 & 0.618 & 1 & N6 & 0.655 & 8 \\
\hline N95 & * & 2 & $\mathrm{~N} 13$ & 0.617 & 1 & N53 & 0.618 & 1 & N9 & 0.671 & 5 \\
\hline N99 & * & 2 & N44 & 0.617 & 1 & N54 & 0.618 & 1 & N10 & 0.671 & 5 \\
\hline N100 & 0.536 & 3 & N3 & 0.617 & 1 & N55 & 0.618 & 1 & N11 & 0.671 & 5 \\
\hline $\mathrm{N} 105$ & 0.538 & 3 & N14 & 0.618 & 1 & N56 & 0.618 & 1 & N5 & 0.678 & 10 \\
\hline N103 & 0.543 & 3 & N16 & 0.618 & 1 & N57 & 0.618 & 1 & N101 & 0.692 & 9 \\
\hline $\mathrm{N} 82$ & 0.547 & 3 & $\mathrm{~N} 17$ & 0.618 & 1 & N59 & 0.618 & 1 & N96 & 0.734 & 4 \\
\hline N83 & 0.547 & 3 & $\mathrm{~N} 18$ & 0.618 & 1 & N60 & 0.618 & 1 & N97 & 0.734 & 4 \\
\hline N84 & 0.547 & 3 & N19 & 0.618 & 1 & N61 & 0.618 & 1 & & & \\
\hline N85 & 0.547 & 3 & $\mathrm{~N} 20$ & 0.618 & 1 & N62 & 0.618 & 1 & & & \\
\hline N86 & 0.547 & 3 & $\mathrm{~N} 21$ & 0.618 & 1 & N63 & 0.618 & 1 & & & \\
\hline N7 & 0.567 & 6 & $\mathrm{~N} 23$ & 0.618 & 1 & N64 & 0.618 & 1 & & & \\
\hline N15 & 0.576 & 6 & $\mathrm{~N} 24$ & 0.618 & 1 & N65 & 0.618 & 1 & & & \\
\hline N8 & 0.578 & 6 & $\mathrm{~N} 27$ & 0.618 & 1 & N66 & 0.618 & 1 & & & \\
\hline N87 & 0.583 & 7 & N28 & 0.618 & 1 & N67 & 0.618 & 1 & & & \\
\hline N98 & 0.590 & 7 & N29 & 0.618 & 1 & $\mathrm{~N} 22$ & 0.619 & 1 & & & \\
\hline N104 & 0.590 & 7 & N30 & 0.618 & 1 & N25 & 0.619 & 1 & & & \\
\hline N81 & 0.594 & 7 & N33 & 0.618 & 1 & N31 & 0.619 & 1 & & & \\
\hline N80 & 0.613 & 1 & N34 & 0.618 & 1 & N39 & 0.619 & 1 & & & \\
\hline N72 & 0.615 & 1 & N35 & 0.618 & 1 & $\mathrm{~N} 40$ & 0.619 & 1 & & & \\
\hline $\mathrm{N} 12$ & 0.617 & 1 & N37 & 0.618 & 1 & N41 & 0.619 & 1 & & & \\
\hline N69 & 0.617 & 1 & N38 & 0.618 & 1 & $\mathrm{~N} 42$ & 0.619 & 1 & & & \\
\hline N71 & 0.617 & 1 & $\mathrm{~N} 43$ & 0.618 & 1 & $\mathrm{~N} 26$ & 0.619 & 1 & & & \\
\hline
\end{tabular}

Here the $\mathrm{HE}$ of the 105 binary representation of the amino acid $A_{2}$ is ranging from 0.536 to 0.7338 with standard deviation 0.04512. Based on the HEs of the binary sequences all these 105 primary protein sequences of SARS-CoV2, ten 175 clustered $(\mathrm{C})$ are formed as presented in the Table 3.

The cluster 2 contains ten sequences (N68, N88, N89, N90, N91, N92, N93, N94, N95 AND N99) having no HE $(*)$ which indicates that the corresponding binary sequences $B_{2_{68}}, B_{2_{88}}, B_{2_{89}}, B_{2_{90}}, B_{2_{91}}, B_{2_{92}}, B_{2_{93}}, B_{2_{94}}$ and $B_{2_{95}}$ respectively are completely free from the amino acid $A_{2}(\mathrm{C})$. The cluster 3 and 6 consist of 8 and 3 sequences respectively, whose HEs are approximately 0.5 which depicts the random walk/Brownian motion like character of the ordering of the amino acid $A_{2}$ over the the corresponding protein sequences. It is 
noted that almost all of these 105 SARS-CoV2 protein sequences are trending (persistent) sequences. Out of all, there are $69 B_{2_{j}}$ for different values of $j$ having $\mathrm{HE}$ at fixed at 0.61 varied by 0.01 and belonging to the cluster 1 . So the amino acid $A_{2}$ is orderly placed in a persistent manner over most of the primary protein sequences of SARS-CoV2 proteins. There is a cluster 4 consisting two binary representations having HE approximately 0.734 which indicates the positive autocorrelation (more persistent). It is noted that there are other sequences having same HE belonging to different other clusters as shown in the Table 3.

\subsection{Hurst Exponent of $B_{3_{j}}$ for $j=1,2, \ldots 105$ and Classification}

For the amino acid $A_{3}(F)$ the HE for the 105 binary sequences $B_{3_{j}}$ for $j=1,2, \ldots 105$ have been determined. The plot of the HE for the binary sequences has been plotted and corresponding histogram is also given in the Fig 3. The HE of the binary representations of ordering of the amino acid $A_{3}$ over all the primary protein sequences would reveal the autocorrelation of the amino acid.
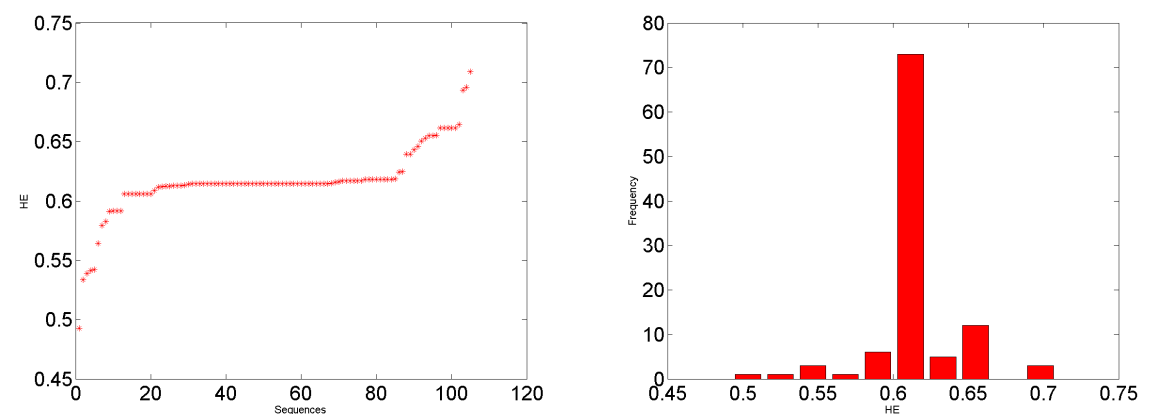

Figure 3: Plot of the HEs and corresponding histogram of all the binary sequences $B_{3_{j}}$ for $j=1,2, \ldots 105$ corresponding to the amino acid $A_{3}(F)$. 
Table 4: HE of $105 B_{3 j}$ for $j=1,2, \ldots 105$ corresponding to the amino acid $A_{3}(F)$.

\begin{tabular}{|c|c|c|c|c|c|c|c|c|c|c|c|}
\hline Seq & HE & C & Seq & $\mathrm{HE}$ & C & Seq & HE & C & Seq & HE & C \\
\hline N5 & 0.493 & 3 & $\mathrm{~N} 13$ & 0.614 & 8 & N55 & 0.615 & 8 & N96 & 0.640 & 1 \\
\hline N1 & 0.534 & 6 & N44 & 0.615 & 8 & N56 & 0.615 & 8 & N97 & 0.640 & 1 \\
\hline N6 & 0.539 & 6 & N14 & 0.615 & 8 & N57 & 0.615 & 8 & N7 & 0.643 & 10 \\
\hline $\mathrm{N} 3$ & 0.541 & 6 & N16 & 0.615 & 8 & N61 & 0.615 & 8 & N68 & 0.646 & 10 \\
\hline $\mathrm{N} 2$ & 0.542 & 6 & N17 & 0.615 & 8 & N63 & 0.615 & 8 & N101 & 0.650 & 10 \\
\hline N15 & 0.564 & 6 & N18 & 0.615 & 8 & N64 & 0.615 & 8 & N36 & 0.653 & 10 \\
\hline N102 & 0.579 & 5 & N19 & 0.615 & 8 & N65 & 0.615 & 8 & $\mathrm{~N} 32$ & 0.655 & 10 \\
\hline N104 & 0.582 & 5 & N21 & 0.615 & 8 & N66 & 0.615 & 8 & N58 & 0.655 & 10 \\
\hline N103 & 0.591 & 5 & $\mathrm{~N} 23$ & 0.615 & 8 & N67 & 0.615 & 8 & N99 & 0.656 & 10 \\
\hline N9 & 0.591 & 5 & N25 & 0.615 & 8 & $\mathrm{~N} 4$ & 0.615 & 8 & $\mathrm{~N} 82$ & 0.662 & 4 \\
\hline N10 & 0.591 & 5 & $\mathrm{~N} 28$ & 0.615 & 8 & $\mathrm{~N} 12$ & 0.616 & 8 & N83 & 0.662 & 4 \\
\hline N11 & 0.591 & 5 & N29 & 0.615 & 8 & $\mathrm{~N} 42$ & 0.616 & 8 & N84 & 0.662 & 4 \\
\hline N88 & 0.606 & 7 & N30 & 0.615 & 8 & $\mathrm{~N} 20$ & 0.617 & 8 & N85 & 0.662 & 4 \\
\hline N89 & 0.606 & 7 & N31 & 0.615 & 8 & $\mathrm{~N} 27$ & 0.617 & 8 & N86 & 0.662 & 4 \\
\hline N90 & 0.606 & 7 & N35 & 0.615 & 8 & N33 & 0.617 & 8 & N105 & 0.664 & 4 \\
\hline N91 & 0.606 & 7 & N37 & 0.615 & 8 & N34 & 0.617 & 8 & N8 & 0.694 & 2 \\
\hline N92 & 0.606 & 7 & N38 & 0.615 & 8 & N59 & 0.617 & 8 & N81 & 0.696 & 2 \\
\hline N93 & 0.606 & 7 & N39 & 0.615 & 8 & N62 & 0.617 & 8 & N80 & 0.709 & 9 \\
\hline N94 & 0.606 & 7 & N41 & 0.615 & 8 & N69 & 0.618 & 8 & & & \\
\hline N95 & 0.606 & 7 & N43 & 0.615 & 8 & N71 & 0.618 & 8 & & & \\
\hline N87 & 0.609 & 7 & N45 & 0.615 & 8 & N73 & 0.618 & 8 & & & \\
\hline $\mathrm{N} 26$ & 0.612 & 8 & $\mathrm{~N} 46$ & 0.615 & 8 & N74 & 0.618 & 8 & & & \\
\hline N78 & 0.612 & 8 & N47 & 0.615 & 8 & N75 & 0.618 & 8 & & & \\
\hline N51 & 0.612 & 8 & $\mathrm{~N} 48$ & 0.615 & 8 & N76 & 0.618 & 8 & & & \\
\hline N60 & 0.612 & 8 & N49 & 0.615 & 8 & N77 & 0.618 & 8 & & & \\
\hline $\mathrm{N} 22$ & 0.613 & 8 & N50 & 0.615 & 8 & N79 & 0.618 & 8 & & & \\
\hline $\mathrm{N} 24$ & 0.613 & 8 & N52 & 0.615 & 8 & N70 & 0.618 & 8 & & & \\
\hline $\mathrm{N} 40$ & 0.613 & 8 & N53 & 0.615 & 8 & $\mathrm{~N} 72$ & 0.624 & 1 & & & \\
\hline N98 & 0.613 & 8 & N54 & 0.615 & 8 & N100 & 0.625 & 1 & & & \\
\hline
\end{tabular}

Here the $\mathrm{HE}$ of the 105 binary representation of the amino acid $A_{3}$ is ranging 200 from 0.493 to 0.709 with standard deviation 0.0296. Based on the HEs of the binary sequences all these 105 primary protein sequences of SARS-CoV2, ten clustered $(\mathrm{C})$ are formed as presented in the Table 4.

The largest cluster contains 65 sequences having HE approximately 0.61 which says the binary representations $B_{3_{j}}$ for $j=1,2, \ldots 105$ for the amino acid $A_{3}$ are positively autocorrelated/persistent. There are other sequences belonging to the the cluster 7 and 10 having same HEs 0.606 and 0.655 respectively as shown in the Table 3 . 


\subsection{Hurst Exponent of $B_{4_{j}}$ for $j=1,2, \ldots 105$ and Classification}

For the amino acid $A_{4}(G)$ the $\mathrm{HE}$ for the 105 binary sequences $B_{4_{j}}$ for $j=1,2, \ldots 105$ have been determined. The plot of the HE for the binary sequences has been plotted and corresponding histogram is also given in the Fig 4. The HE of the binary representations of ordering of the amino acid $A_{4}$ over all the primary protein sequences would reveal the autocorrelation of the amino acid.

Here the $\mathrm{HE}$ of the 105 binary representation of the amino acid $A_{4}$ is ranging from 0.546 to 0.664 with standard deviation 0.0876. Based on the HEs of the binary sequences all these 105 primary protein sequences of SARS-CoV2, ten clustered $(\mathrm{C})$ are formed as presented in the Table 5.

There are two protein sequences N68 and N81 without any amino acid G (conditionally essential) as it can be seen in the Table 5. All the binary spatial distributions of the 105 proteins are having positive auto correlation and consequently persistent/trending. The most of the sequences (54 in number) are having HE 0.6 belonging to a cluster as shown in the Table 5 . The cluster 8 contains N7 and N99 which has the amino acid representations $B_{4_{7}}$ and $B_{4_{99}}$ 225 respectively having the highest $\mathrm{HE} 0.664$.
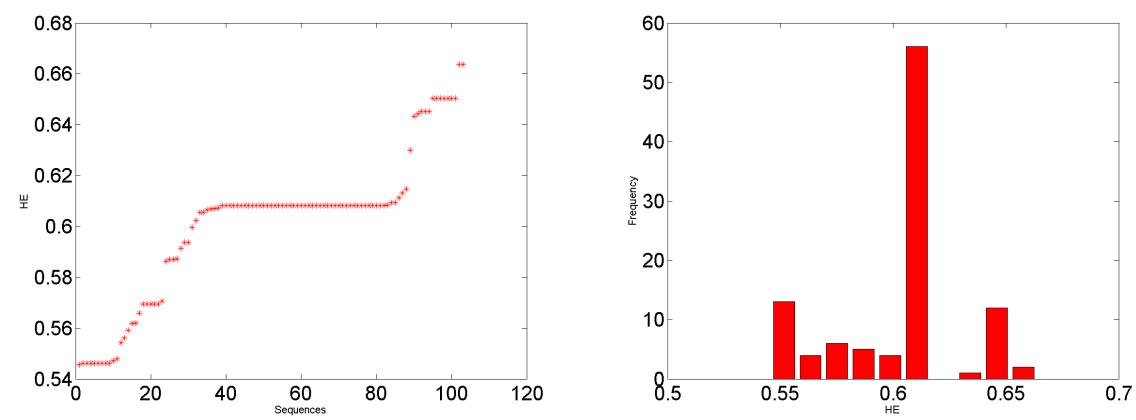

Figure 4: Plot of the HEs and corresponding histogram of all the binary sequences $B_{4_{j}}$ for $j=1,2, \ldots 105$ corresponding to the amino acid $A_{4}(G)$. 
Table 5: HE of $105 B_{4}$ for $j=1,2, \ldots 105$ corresponding to the amino acid $A_{4}(G)$.

\begin{tabular}{|c|c|c|c|c|c|c|c|c|c|c|c|}
\hline Seq & HE & C & Seq & HE & C & Seq & HE & C & Seq & HE & C \\
\hline N68 & * & 4 & N96 & 0.594 & 5 & N39 & 0.608 & 3 & N5 & 0.630 & 9 \\
\hline N81 & * & 4 & N97 & 0.594 & 5 & $\mathrm{~N} 40$ & 0.608 & 3 & N95 & 0.643 & 10 \\
\hline N70 & 0.546 & 6 & N10 & 0.600 & 7 & N41 & 0.608 & 3 & N87 & 0.644 & 10 \\
\hline N69 & 0.546 & 6 & N8 & 0.602 & 7 & $\mathrm{~N} 42$ & 0.608 & 3 & N32 & 0.645 & 10 \\
\hline N71 & 0.546 & 6 & N14 & 0.606 & 7 & N43 & 0.608 & 3 & N36 & 0.645 & 10 \\
\hline N72 & 0.546 & 6 & N60 & 0.606 & 7 & N45 & 0.608 & 3 & N58 & 0.645 & 10 \\
\hline N73 & 0.546 & 6 & $\mathrm{~N} 13$ & 0.606 & 3 & N46 & 0.608 & 3 & N88 & 0.650 & 2 \\
\hline N74 & 0.546 & 6 & $\mathrm{~N} 12$ & 0.607 & 3 & N47 & 0.608 & 3 & N89 & 0.650 & 2 \\
\hline N76 & 0.546 & 6 & N26 & 0.607 & 3 & N48 & 0.608 & 3 & N90 & 0.650 & 2 \\
\hline N78 & 0.546 & 6 & N15 & 0.607 & 3 & N49 & 0.608 & 3 & N91 & 0.650 & 2 \\
\hline N79 & 0.546 & 6 & N16 & 0.608 & 3 & N50 & 0.608 & 3 & N92 & 0.650 & 2 \\
\hline N105 & 0.547 & 6 & N17 & 0.608 & 3 & N51 & 0.608 & 3 & N93 & 0.650 & 2 \\
\hline N3 & 0.548 & 6 & N18 & 0.608 & 3 & N52 & 0.608 & 3 & N94 & 0.650 & 2 \\
\hline N77 & 0.554 & 6 & N19 & 0.608 & 3 & N55 & 0.608 & 3 & N7 & 0.664 & 8 \\
\hline N75 & 0.556 & 6 & $\mathrm{~N} 20$ & 0.608 & 3 & N56 & 0.608 & 3 & N99 & 0.664 & 8 \\
\hline N98 & 0.559 & 1 & $\mathrm{~N} 21$ & 0.608 & 3 & N57 & 0.608 & 3 & & & \\
\hline N100 & 0.562 & 1 & $\mathrm{~N} 22$ & 0.608 & 3 & N59 & 0.608 & 3 & & & \\
\hline N102 & 0.562 & 1 & $\mathrm{~N} 23$ & 0.608 & 3 & N61 & 0.608 & 3 & & & \\
\hline N2 & 0.566 & 1 & N24 & 0.608 & 3 & N62 & 0.608 & 3 & & & \\
\hline N82 & 0.569 & 1 & N25 & 0.608 & 3 & N63 & 0.608 & 3 & & & \\
\hline N83 & 0.569 & 1 & $\mathrm{~N} 27$ & 0.608 & 3 & N64 & 0.608 & 3 & & & \\
\hline N84 & 0.569 & 1 & N28 & 0.608 & 3 & N65 & 0.608 & 3 & & & \\
\hline N85 & 0.569 & 1 & N29 & 0.608 & 3 & N66 & 0.608 & 3 & & & \\
\hline N86 & 0.569 & 1 & N30 & 0.608 & 3 & N67 & 0.608 & 3 & & & \\
\hline N1 & 0.571 & 1 & N31 & 0.608 & 3 & N44 & 0.608 & 3 & & & \\
\hline N4 & 0.586 & 5 & N33 & 0.608 & 3 & N53 & 0.609 & 3 & & & \\
\hline N9 & 0.587 & 5 & N34 & 0.608 & 3 & N54 & 0.609 & 3 & & & \\
\hline N11 & 0.587 & 5 & N35 & 0.608 & 3 & N101 & 0.611 & 3 & & & \\
\hline N6 & 0.587 & 5 & N37 & 0.608 & 3 & N80 & 0.613 & 3 & & & \\
\hline N103 & 0.591 & 5 & N38 & 0.608 & 3 & N104 & 0.615 & 3 & & & \\
\hline
\end{tabular}

\subsection{Hurst Exponent of $B_{5 j}$ for $j=1,2, \ldots 105$ and Classification}

For the amino acid $A_{5}(H)$ the HE for the 105 binary sequences $B_{5_{j}}$ for $j=1,2, \ldots 105$ have been determined. The plot of the HE for the binary sequences has been plotted and corresponding histogram is also given in the Fig 5. The HE of the binary representations of ordering of the amino acid $A_{5}$ over all the primary protein sequences would reveal the autocorrelation of the amino acid. 

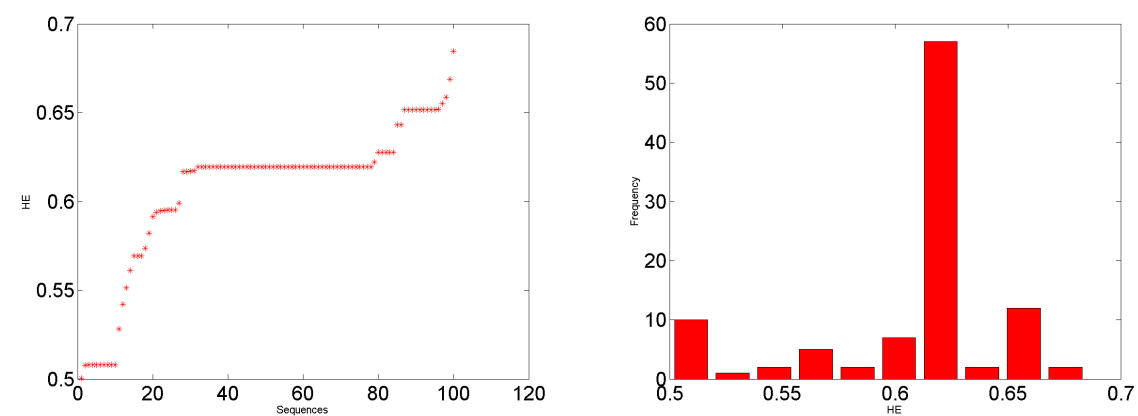

Figure 5: Plot of the HEs and corresponding histogram of all the binary sequences $B_{5_{j}}$ for $j=1,2, \ldots 105$ corresponding to the amino acid $A_{5}(G)$.

Here the HE of the 105 binary representation of the amino acid $A_{5}$ is ranging from 0.5 to 0.685 with standard deviation 0.136. Based on the HEs of the binary sequences all these 105 primary protein sequences of SARS-CoV2, ten clustered (C) are formed as presented in the Table 6 .

One of the essential amino acids $H$ does not present in the protein sequences N3, N80, N97, N98 and N99 of the SARS-CoV2 as found. The spatial organization of the amino acid $\mathrm{H}$ is absolutely random(does not either trending nor negatively autocorrelated) in the protein sequences N5, N15, N88, N89, N90, N91, N92, N93, N94 and N95 which belong to the cluster 2 as shown in the Table 6 . The largest cluster 8 contains 54 protein sequences where the amino acid $\mathrm{H}$ is spatially distributed with positive autocorrelation (i.e. trending sequence) with HE 0.619. Such a organized spatial distributions of the essential amino acid $\mathrm{H}$ over most of the protein sequences belonging to the cluster 8 is certainly noteworthy. 
Table 6: HE of $105 B_{5_{j}}$ for $j=1,2, \ldots 105$ corresponding to the amino acid $A_{5}(H)$.

\begin{tabular}{|c|c|c|c|c|c|c|c|c|c|c|c|}
\hline Seq & $\mathrm{HE}$ & C & Seq & HE & C & Seq & $\mathrm{HE}$ & C & Seq & $\mathrm{HE}$ & C \\
\hline N3 & * & 3 & N9 & 0.595 & 5 & N38 & 0.619 & 8 & N82 & 0.628 & 1 \\
\hline N80 & * & 3 & N10 & 0.595 & 5 & N39 & 0.619 & 8 & N83 & 0.628 & 1 \\
\hline N97 & * & 3 & N11 & 0.595 & 5 & N40 & 0.619 & 8 & N84 & 0.628 & 1 \\
\hline N98 & $*$ & 3 & N68 & 0.599 & 5 & N41 & 0.619 & 8 & N85 & 0.628 & 1 \\
\hline N99 & * & 3 & $\mathrm{~N} 21$ & 0.617 & 8 & $\mathrm{~N} 42$ & 0.619 & 8 & N86 & 0.628 & 1 \\
\hline N5 & 0.500 & 2 & N64 & 0.617 & 8 & N43 & 0.619 & 8 & N79 & 0.643 & 9 \\
\hline N15 & 0.508 & 2 & $\mathrm{~N} 13$ & 0.617 & 8 & $\mathrm{~N} 45$ & 0.619 & 8 & $\mathrm{~N} 2$ & 0.643 & 9 \\
\hline N88 & 0.508 & 2 & $\mathrm{~N} 12$ & 0.617 & 8 & N46 & 0.619 & 8 & N69 & 0.652 & 9 \\
\hline N89 & 0.508 & 2 & N26 & 0.619 & 8 & $\mathrm{~N} 47$ & 0.619 & 8 & N71 & 0.652 & 9 \\
\hline N90 & 0.508 & 2 & $\mathrm{~N} 14$ & 0.619 & 8 & $\mathrm{~N} 48$ & 0.619 & 8 & N72 & 0.652 & 9 \\
\hline N91 & 0.508 & 2 & N16 & 0.619 & 8 & N50 & 0.619 & 8 & N73 & 0.652 & 9 \\
\hline N92 & 0.508 & 2 & N17 & 0.619 & 8 & N51 & 0.619 & 8 & N74 & 0.652 & 9 \\
\hline N93 & 0.508 & 2 & N18 & 0.619 & 8 & N52 & 0.619 & 8 & N75 & 0.652 & 9 \\
\hline N94 & 0.508 & 2 & N19 & 0.619 & 8 & N53 & 0.619 & 8 & N76 & 0.652 & 9 \\
\hline N95 & 0.508 & 2 & N20 & 0.619 & 8 & N54 & 0.619 & 8 & N77 & 0.652 & 9 \\
\hline N7 & 0.528 & 6 & $\mathrm{~N} 22$ & 0.619 & 8 & N55 & 0.619 & 8 & N78 & 0.652 & 9 \\
\hline N100 & 0.542 & 6 & N23 & 0.619 & 8 & N56 & 0.619 & 8 & N70 & 0.652 & 9 \\
\hline N1 & 0.551 & 6 & $\mathrm{~N} 24$ & 0.619 & 8 & N57 & 0.619 & 8 & N6 & 0.655 & 9 \\
\hline N4 & 0.561 & 7 & N25 & 0.619 & 8 & N59 & 0.619 & 8 & N8 & 0.659 & 9 \\
\hline $\mathrm{N} 32$ & 0.569 & 7 & N27 & 0.619 & 8 & N60 & 0.619 & 8 & N101 & 0.669 & 4 \\
\hline N36 & 0.569 & 7 & $\mathrm{~N} 28$ & 0.619 & 8 & N61 & 0.619 & 8 & N81 & 0.685 & 10 \\
\hline N58 & 0.569 & 7 & N29 & 0.619 & 8 & N62 & 0.619 & 8 & & & \\
\hline N87 & 0.574 & 7 & N30 & 0.619 & 8 & N63 & 0.619 & 8 & & & \\
\hline N105 & 0.582 & 7 & N31 & 0.619 & 8 & N65 & 0.619 & 8 & & & \\
\hline N103 & 0.591 & 5 & N33 & 0.619 & 8 & N66 & 0.619 & 8 & & & \\
\hline N96 & 0.594 & 5 & N34 & 0.619 & 8 & N67 & 0.619 & 8 & & & \\
\hline N104 & 0.595 & 5 & N35 & 0.619 & 8 & N44 & 0.619 & 8 & & & \\
\hline N102 & 0.595 & 5 & N37 & 0.619 & 8 & N49 & 0.622 & 8 & & & \\
\hline
\end{tabular}

3.6. Hurst Exponent of $B_{6_{j}}$ for $j=1,2, \ldots 105$ and Classification

For the amino acid $A_{6}(I)$ the HE for the 105 binary sequences $B_{6_{j}}$ for $j=$ $1,2, \ldots 105$ have been determined. The plot of the HE for the binary sequences 250 has been plotted and corresponding histogram is also given in the Fig 6 . The HE of the binary representations of ordering of the amino acid $A_{6}$ over all the primary protein sequences would reveal the autocorrelation of the amino acid.

Here the HE of the 105 binary representation of the amino acid $A_{6}$ is ranging from 0.509 to 0.736 with standard deviation 0.0661. Based on the HEs of the 255 binary sequences all these 105 primary protein sequences of SARS-CoV2, ten clustered (C) are formed as presented in the Table 7. 

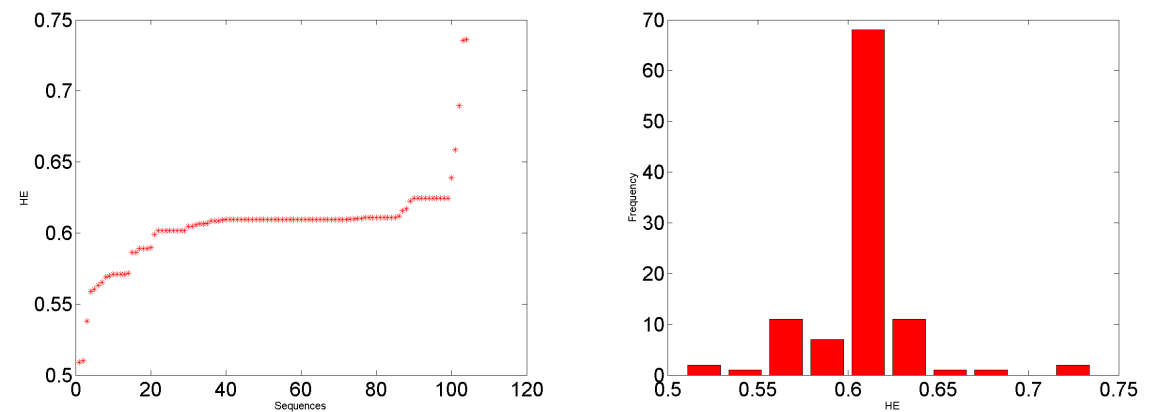

Figure 6: Plot of the HEs and corresponding histogram of all the binary sequences $B_{6_{j}}$ for $j=1,2, \ldots 105$ corresponding to the amino acid $A_{6}(I)$.

Table 7: HE of $105 B_{6_{j}}$ for $j=1,2, \ldots 105$ corresponding to the amino acid $A_{6}(I)$.

\begin{tabular}{|c|c|c|c|c|c|c|c|c|c|c|c|}
\hline Seq & HE & C & Seq & HE & C & Seq & HE & C & Seq & HE & C \\
\hline N99 & * & 4 & N94 & 0.602 & 5 & $\mathrm{~N} 43$ & 0.610 & 5 & N51 & 0.611 & 5 \\
\hline N102 & 0.509 & 6 & N95 & 0.602 & 5 & N45 & 0.610 & 5 & N59 & 0.611 & 5 \\
\hline N80 & 0.510 & 6 & N32 & 0.605 & 5 & N46 & 0.610 & 5 & $\mathrm{~N} 28$ & 0.612 & 5 \\
\hline N100 & 0.538 & 6 & N36 & 0.605 & 5 & N47 & 0.610 & 5 & N105 & 0.616 & 5 \\
\hline N4 & 0.559 & 7 & N63 & 0.606 & 5 & N48 & 0.610 & 5 & N70 & 0.617 & 3 \\
\hline N104 & 0.561 & 7 & N98 & 0.606 & 5 & N49 & 0.610 & 5 & N6 & 0.622 & 3 \\
\hline N1 & 0.563 & 7 & N58 & 0.607 & 5 & N50 & 0.610 & 5 & N69 & 0.625 & 3 \\
\hline N8 & 0.565 & 7 & N35 & 0.607 & 5 & N52 & 0.610 & 5 & N71 & 0.625 & 3 \\
\hline N103 & 0.569 & 7 & N55 & 0.608 & 5 & N53 & 0.610 & 5 & N72 & 0.625 & 3 \\
\hline N5 & 0.570 & 7 & N61 & 0.608 & 5 & N54 & 0.610 & 5 & N73 & 0.625 & 3 \\
\hline N83 & 0.571 & 7 & N65 & 0.608 & 5 & N56 & 0.610 & 5 & N74 & 0.625 & 3 \\
\hline N84 & 0.571 & 7 & $\mathrm{~N} 2$ & 0.609 & 5 & N57 & 0.610 & 5 & N75 & 0.625 & 3 \\
\hline N85 & 0.571 & 7 & N26 & 0.610 & 5 & N60 & 0.610 & 5 & N76 & 0.625 & 3 \\
\hline N86 & 0.571 & 7 & N14 & 0.610 & 5 & N62 & 0.610 & 5 & N77 & 0.625 & 3 \\
\hline N82 & 0.572 & 7 & N16 & 0.610 & 5 & N64 & 0.610 & 5 & N78 & 0.625 & 3 \\
\hline N96 & 0.586 & 1 & $\mathrm{~N} 21$ & 0.610 & 5 & N66 & 0.610 & 5 & N79 & 0.625 & 3 \\
\hline N97 & 0.586 & 1 & $\mathrm{~N} 22$ & 0.610 & 5 & N67 & 0.610 & 5 & N15 & 0.639 & 10 \\
\hline N9 & 0.589 & 1 & $\mathrm{~N} 23$ & 0.610 & 5 & N44 & 0.610 & 5 & N81 & 0.659 & 9 \\
\hline N10 & 0.589 & 1 & N24 & 0.610 & 5 & N13 & 0.610 & 5 & N3 & 0.689 & 8 \\
\hline N11 & 0.589 & 1 & N30 & 0.610 & 5 & $\mathrm{~N} 12$ & 0.610 & 5 & N68 & 0.736 & 2 \\
\hline N101 & 0.590 & 1 & N31 & 0.610 & 5 & N38 & 0.610 & 5 & N87 & 0.736 & 2 \\
\hline N7 & 0.599 & 5 & N33 & 0.610 & 5 & N17 & 0.611 & 5 & & & \\
\hline N88 & 0.602 & 5 & N34 & 0.610 & 5 & N18 & 0.611 & 5 & & & \\
\hline N89 & 0.602 & 5 & N37 & 0.610 & 5 & N19 & 0.611 & 5 & & & \\
\hline N90 & 0.602 & 5 & N39 & 0.610 & 5 & $\mathrm{~N} 20$ & 0.611 & 5 & & & \\
\hline N91 & 0.602 & 5 & N40 & 0.610 & 5 & N25 & 0.611 & 5 & & & \\
\hline N92 & 0.602 & 5 & N41 & 0.610 & 5 & $\mathrm{~N} 27$ & 0.611 & 5 & & & \\
\hline N93 & 0.602 & 5 & $\mathrm{~N} 42$ & 0.610 & 5 & N29 & 0.611 & 5 & & & \\
\hline
\end{tabular}

There is one sequence N99 which does not have any the essential amino acid

I. The spatial distribution of the amino acid I over the the protein sequence 
N102 is truly random since the HE is turned out to be 0.509 whereas the other 104 sequences are trending by having HEs greater than 0.5. The largest cluster 5 contains 71 protein sequences whose spatial distribution of the essential amino acid I are positively autocorrelated (trending) with HE 0.61 (approx.). There are other sequences which belong to different clusters, having same HEs greater than 0.5 .

3.7. Hurst Exponent of $B_{7_{j}}$ for $j=1,2, \ldots 105$ and Classification

For the amino acid $A_{7}(L)$ the $\mathrm{HE}$ for the 105 binary sequences $B_{7_{j}}$ for $j=1,2, \ldots 105$ have been determined. The plot of the HE for the binary sequences has been plotted and corresponding histogram is also given in the Fig 7. The HE of the binary representations of ordering of the amino acid $A_{7}$ over all the primary protein sequences would reveal the autocorrelation of the amino acid.
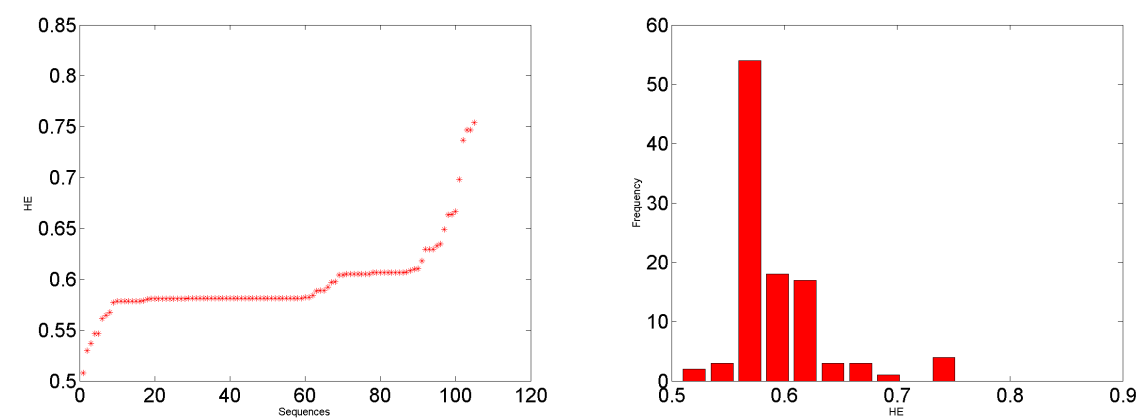

Figure 7: Plot of the HEs and corresponding histogram of all the binary sequences $B_{7_{j}}$ for $j=1,2, \ldots 105$ corresponding to the amino acid $A_{7}(L)$.

Here the $\mathrm{HE}$ of the 105 binary representation of the amino acid $A_{7}$ is ranging from 0.508 to 0.754 with standard deviation 0.0395. Based on the HEs of the binary sequences all these 105 primary protein sequences of SARS-CoV2, ten clustered (C) are formed as presented in the Table 8.

The binary representations $B_{7_{2}}, B_{7_{68}}$ and $B_{7_{15}}$ of the spatial arrangement of the amino acid L over the protein sequences N2, N68 and N15 are random 
as the HEs of these sequences is 0.5 (approx.). There are 54 sequences in the cluster 5 are having the HE 0.58. The spatial arrangements of the amino acid L over these proteins are not random but not either too trending as the $\mathrm{HE}$ is greater than 0.5 but less than 0.6. There are as usual other clusters having sequences with positive autocorrelation (trending) as given in the Table 8 .

Table 8: HE of $105 B_{7_{j}}$ for $j=1,2, \ldots 105$ corresponding to the amino acid $A_{7}(L)$.

\begin{tabular}{|c|c|c|c|c|c|c|c|c|c|c|c|}
\hline Seq & HE & C & Seq & HE & C & Seq & HE & C & Seq & HE & C \\
\hline N2 & 0.508 & 3 & N16 & 0.581 & 5 & $\mathrm{~N} 24$ & 0.582 & 5 & N105 & 0.618 & 7 \\
\hline N68 & 0.530 & 3 & N17 & 0.581 & 5 & N30 & 0.584 & 5 & N82 & 0.629 & 8 \\
\hline N15 & 0.537 & 3 & N18 & 0.581 & 5 & N101 & 0.589 & 5 & N85 & 0.629 & 8 \\
\hline N5 & 0.546 & 6 & N19 & 0.581 & 5 & N32 & 0.589 & 5 & N86 & 0.629 & 8 \\
\hline N3 & 0.547 & 6 & N21 & 0.581 & 5 & N58 & 0.589 & 5 & N6 & 0.633 & 8 \\
\hline N104 & 0.561 & 6 & $\mathrm{~N} 22$ & 0.581 & 5 & N36 & 0.592 & 5 & N102 & 0.635 & 8 \\
\hline N1 & 0.565 & 6 & N28 & 0.581 & 5 & N83 & 0.597 & 1 & N7 & 0.649 & 8 \\
\hline N4 & 0.568 & 6 & N29 & 0.581 & 5 & N98 & 0.597 & 1 & N96 & 0.663 & 4 \\
\hline N100 & 0.577 & 5 & N31 & 0.581 & 5 & N84 & 0.604 & 1 & N99 & 0.664 & 4 \\
\hline $\mathrm{N} 20$ & 0.579 & 5 & N35 & 0.581 & 5 & N87 & 0.604 & 1 & N81 & 0.667 & 4 \\
\hline $\mathrm{N} 27$ & 0.579 & 5 & N38 & 0.581 & 5 & N89 & 0.605 & 1 & N97 & 0.698 & 10 \\
\hline N33 & 0.579 & 5 & N39 & 0.581 & 5 & N90 & 0.605 & 1 & N80 & 0.737 & 9 \\
\hline N34 & 0.579 & 5 & N43 & 0.581 & 5 & N91 & 0.605 & 1 & N10 & 0.747 & 2 \\
\hline $\mathrm{N} 47$ & 0.579 & 5 & $\mathrm{~N} 45$ & 0.581 & 5 & N92 & 0.605 & 1 & N11 & 0.747 & 2 \\
\hline N59 & 0.579 & 5 & $\mathrm{~N} 46$ & 0.581 & 5 & N93 & 0.605 & 1 & N9 & 0.754 & 2 \\
\hline $\mathrm{N} 62$ & 0.579 & 5 & $\mathrm{~N} 48$ & 0.581 & 5 & N94 & 0.605 & 1 & & & \\
\hline N103 & 0.579 & 5 & N49 & 0.581 & 5 & N95 & 0.605 & 1 & & & \\
\hline N42 & 0.580 & 5 & N50 & 0.581 & 5 & N69 & 0.607 & 1 & & & \\
\hline $\mathrm{N} 25$ & 0.581 & 5 & N51 & 0.581 & 5 & N71 & 0.607 & 1 & & & \\
\hline N37 & 0.581 & 5 & N52 & 0.581 & 5 & N72 & 0.607 & 1 & & & \\
\hline N40 & 0.581 & 5 & N53 & 0.581 & 5 & N73 & 0.607 & 1 & & & \\
\hline N41 & 0.581 & 5 & N54 & 0.581 & 5 & N74 & 0.607 & 1 & & & \\
\hline N60 & 0.581 & 5 & N55 & 0.581 & 5 & N75 & 0.607 & 1 & & & \\
\hline $\mathrm{N} 63$ & 0.581 & 5 & N56 & 0.581 & 5 & N76 & 0.607 & 1 & & & \\
\hline $\mathrm{N} 23$ & 0.581 & 5 & N57 & 0.581 & 5 & N77 & 0.607 & 1 & & & \\
\hline N66 & 0.581 & 5 & N61 & 0.581 & 5 & N79 & 0.607 & 1 & & & \\
\hline N26 & 0.581 & 5 & N64 & 0.581 & 5 & N70 & 0.607 & 1 & & & \\
\hline $\mathrm{N} 12$ & 0.581 & 5 & N65 & 0.581 & 5 & N8 & 0.609 & 7 & & & \\
\hline N13 & 0.581 & 5 & N67 & 0.581 & 5 & N78 & 0.610 & 7 & & & \\
\hline N14 & 0.581 & 5 & N44 & 0.582 & 5 & N88 & 0.610 & 7 & & & \\
\hline
\end{tabular}

\subsection{Hurst Exponent of $B_{8_{j}}$ for $j=1,2, \ldots 105$ and Classification}

For the amino acid $A_{8}(M)$ the $\mathrm{HE}$ for the 105 binary sequences $B_{8_{j}}$ for ${ }_{285} j=1,2, \ldots 105$ have been determined. The plot of the HE for the binary sequences has been plotted and corresponding histogram is also given in the Fig 8. The HE of the binary representations of ordering of the amino acid $A_{8}$ over all the primary protein sequences would reveal the autocorrelation of the amino 
acid.
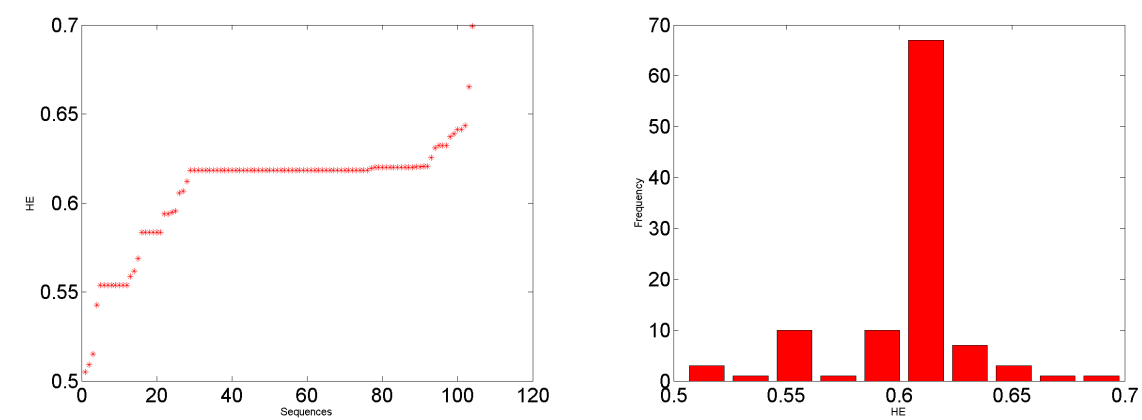

Figure 8: Plot of the HEs and corresponding histogram of all the binary sequences $B_{8_{j}}$ for $j=1,2, \ldots 105$ corresponding to the amino acid $A_{8}(M)$.

Here the $\mathrm{HE}$ of the 105 binary representation of the amino acid $A_{8}$ is ranging from 0.505 to 0.699 with standard deviation 0.0665. Based on the HEs of the binary sequences all these 105 primary protein sequences of SARS-CoV2, five clustered (C) are formed as presented in the Table 9.

Here the cluster 3 contains most of the sequences (80 in number) for which the spatial distributions of the amino acid $\mathrm{M}$ over the protein sequences are having the HE 0.61 (approx) which indicates the trending behaviour. Clearly, the spatial organizations of the amino acid M over the protein sequences N102, N80 and N81 are random. Rest all as usual having the trending trend as seen before. 
Table 9: HE of $105 B_{8_{j}}$ for $j=1,2, \ldots 105$ corresponding to the amino acid $A_{8}(M)$.

\begin{tabular}{|c|c|c|c|c|c|c|c|c|c|c|c|}
\hline Seq & $\mathrm{HE}$ & C & Seq & HE & C & Seq & HE & C & Seq & HE & C \\
\hline N99 & * & 4 & N18 & 0.618 & 3 & N49 & 0.618 & 3 & $\mathrm{~N} 13$ & 0.620 & 3 \\
\hline N102 & 0.505 & 5 & N14 & 0.618 & 3 & N50 & 0.618 & 3 & N52 & 0.620 & 3 \\
\hline N80 & 0.509 & 5 & N16 & 0.618 & 3 & N51 & 0.618 & 3 & N59 & 0.620 & 3 \\
\hline N81 & 0.515 & 5 & N17 & 0.618 & 3 & N53 & 0.618 & 3 & N8 & 0.626 & 3 \\
\hline $\mathrm{N} 2$ & 0.543 & 5 & N19 & 0.618 & 3 & N54 & 0.618 & 3 & N68 & 0.631 & 3 \\
\hline N88 & 0.554 & 5 & N20 & 0.618 & 3 & N55 & 0.618 & 3 & N9 & 0.632 & 3 \\
\hline N89 & 0.554 & 5 & N21 & 0.618 & 3 & N56 & 0.618 & 3 & N10 & 0.632 & 3 \\
\hline N90 & 0.554 & 5 & $\mathrm{~N} 22$ & 0.618 & 3 & N57 & 0.618 & 3 & N11 & 0.632 & 3 \\
\hline N91 & 0.554 & 5 & N23 & 0.618 & 3 & N60 & 0.618 & 3 & N100 & 0.637 & 3 \\
\hline N92 & 0.554 & 5 & N24 & 0.618 & 3 & N61 & 0.618 & 3 & N103 & 0.639 & 3 \\
\hline N93 & 0.554 & 5 & $\mathrm{~N} 25$ & 0.618 & 3 & N62 & 0.618 & 3 & N32 & 0.641 & 3 \\
\hline N94 & 0.554 & 5 & N27 & 0.618 & 3 & N63 & 0.618 & 3 & N36 & 0.641 & 3 \\
\hline N95 & 0.554 & 5 & N28 & 0.618 & 3 & N64 & 0.618 & 3 & N58 & 0.643 & 3 \\
\hline N5 & 0.559 & 5 & N29 & 0.618 & 3 & N65 & 0.618 & 3 & N101 & 0.665 & 2 \\
\hline $\mathrm{N} 4$ & 0.562 & 5 & N30 & 0.618 & 3 & N66 & 0.618 & 3 & N3 & 0.699 & 2 \\
\hline N104 & 0.569 & 1 & N31 & 0.618 & 3 & N67 & 0.618 & 3 & & & \\
\hline N82 & 0.583 & 1 & N33 & 0.618 & 3 & $\mathrm{~N} 26$ & 0.619 & 3 & & & \\
\hline N83 & 0.583 & 1 & N34 & 0.618 & 3 & N105 & 0.619 & 3 & & & \\
\hline N84 & 0.583 & 1 & N35 & 0.618 & 3 & N69 & 0.620 & 3 & & & \\
\hline N85 & 0.583 & 1 & N37 & 0.618 & 3 & N71 & 0.620 & 3 & & & \\
\hline N86 & 0.583 & 1 & N38 & 0.618 & 3 & N72 & 0.620 & 3 & & & \\
\hline N87 & 0.583 & 1 & N39 & 0.618 & 3 & N73 & 0.620 & 3 & & & \\
\hline N96 & 0.594 & 1 & N40 & 0.618 & 3 & N74 & 0.620 & 3 & & & \\
\hline N97 & 0.594 & 1 & N41 & 0.618 & 3 & N75 & 0.620 & 3 & & & \\
\hline N7 & 0.595 & 1 & N42 & 0.618 & 3 & N 76 & 0.620 & 3 & & & \\
\hline N15 & 0.596 & 1 & N43 & 0.618 & 3 & N 77 & 0.620 & 3 & & & \\
\hline N1 & 0.606 & 3 & N45 & 0.618 & 3 & N78 & 0.620 & 3 & & & \\
\hline N6 & 0.607 & 3 & N46 & 0.618 & 3 & N79 & 0.620 & 3 & & & \\
\hline N98 & 0.612 & 3 & N47 & 0.618 & 3 & N70 & 0.620 & 3 & & & \\
\hline N44 & 0.618 & 3 & N48 & 0.618 & 3 & $\mathrm{~N} 12$ & 0.620 & 3 & & & \\
\hline
\end{tabular}

300

3.9. Hurst Exponent of $B_{9_{j}}$ for $j=1,2, \ldots 105$ and Classification

For the amino acid $A_{9}(N)$ the HE for the 105 binary sequences $B_{9_{j}}$ for $j=1,2, \ldots 105$ have been determined. The plot of the HE for the binary sequences has been plotted and corresponding histogram is also given in the Fig 9. The HE of the binary representations of ordering of the amino acid $A_{9}$ over all the primary protein sequences would reveal the autocorrelation of the amino acid.

Here the $\mathrm{HE}$ of the 105 binary representation of the amino acid $A_{9}$ is ranging from 0.505 to 0.699 with standard deviation 0.0665. Based on the HEs of the binary sequences all these 105 primary protein sequences of SARS-CoV2, five clustered $(\mathrm{C})$ are formed as presented in the Table 10. 

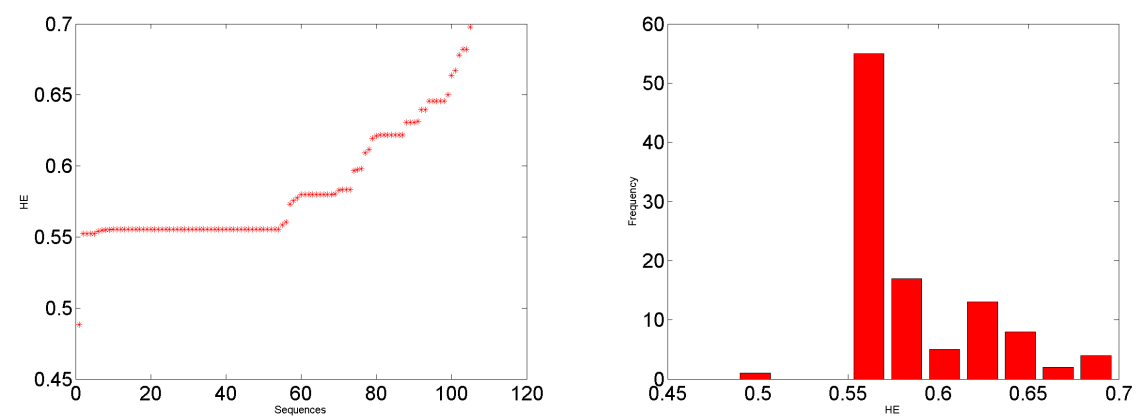

Figure 9: Plot of the HEs and corresponding histogram of all the binary sequences $B_{9_{j}}$ for $j=1,2, \ldots 105$ corresponding to the amino acid $A_{9}(N)$.

Table 10: HE of $105 B_{9_{j}}$ for $j=1,2, \ldots 105$ corresponding to the amino acid $A_{9}(N)$.

\begin{tabular}{|c|c|c|c|c|c|c|c|c|c|c|c|}
\hline Seq & HE & C & Seq & HE & C & Seq & HE & C & Seq & HE & C \\
\hline $\mathrm{N} 2$ & 0.488 & 1 & $\mathrm{~N} 40$ & 0.555 & 1 & N72 & 0.580 & 4 & N89 & 0.631 & 5 \\
\hline N51 & 0.552 & 1 & $\mathrm{~N} 41$ & 0.555 & 1 & N73 & 0.580 & 4 & N96 & 0.640 & 3 \\
\hline $\mathrm{N} 16$ & 0.552 & 1 & $\mathrm{~N} 42$ & 0.555 & 1 & N74 & 0.580 & 4 & N97 & 0.640 & 3 \\
\hline N46 & 0.552 & 1 & $\mathrm{~N} 43$ & 0.555 & 1 & N75 & 0.580 & 4 & N82 & 0.646 & 3 \\
\hline N57 & 0.552 & 1 & $\mathrm{~N} 45$ & 0.555 & 1 & N76 & 0.580 & 4 & N83 & 0.646 & 3 \\
\hline N12 & 0.554 & 1 & N47 & 0.555 & 1 & N77 & 0.580 & 4 & N84 & 0.646 & 3 \\
\hline $\mathrm{N} 13$ & 0.555 & 1 & $\mathrm{~N} 48$ & 0.555 & 1 & N78 & 0.580 & 4 & N85 & 0.646 & 3 \\
\hline N5 & 0.555 & 1 & N49 & 0.555 & 1 & N79 & 0.580 & 4 & N86 & 0.646 & 3 \\
\hline $\mathrm{N} 44$ & 0.555 & 1 & N50 & 0.555 & 1 & N70 & 0.580 & 4 & N87 & 0.650 & 3 \\
\hline N14 & 0.555 & 1 & N52 & 0.555 & 1 & N103 & 0.583 & 4 & N99 & 0.664 & 3 \\
\hline N17 & 0.555 & 1 & N53 & 0.555 & 1 & N32 & 0.583 & 4 & N3 & 0.667 & 2 \\
\hline N18 & 0.555 & 1 & N54 & 0.555 & 1 & N36 & 0.583 & 4 & N104 & 0.678 & 2 \\
\hline N19 & 0.555 & 1 & N55 & 0.555 & 1 & N58 & 0.583 & 4 & N98 & 0.682 & 2 \\
\hline $\mathrm{N} 20$ & 0.555 & 1 & N56 & 0.555 & 1 & N101 & 0.597 & 4 & N15 & 0.682 & 2 \\
\hline $\mathrm{N} 21$ & 0.555 & 1 & N59 & 0.555 & 1 & N102 & 0.597 & 4 & N68 & 0.698 & 2 \\
\hline $\mathrm{N} 22$ & 0.555 & 1 & N60 & 0.555 & 1 & $\mathrm{~N} 4$ & 0.598 & 4 & & & \\
\hline $\mathrm{N} 23$ & 0.555 & 1 & N61 & 0.555 & 1 & N81 & 0.609 & 5 & & & \\
\hline $\mathrm{N} 24$ & 0.555 & 1 & N62 & 0.555 & 1 & N6 & 0.612 & 5 & & & \\
\hline N25 & 0.555 & 1 & N63 & 0.555 & 1 & N8 & 0.619 & 5 & & & \\
\hline $\mathrm{N} 27$ & 0.555 & 1 & N64 & 0.555 & 1 & N80 & 0.621 & 5 & & & \\
\hline $\mathrm{N} 28$ & 0.555 & 1 & N65 & 0.555 & 1 & N88 & 0.622 & 5 & & & \\
\hline $\mathrm{N} 29$ & 0.555 & 1 & N66 & 0.555 & 1 & N90 & 0.622 & 5 & & & \\
\hline N30 & 0.555 & 1 & N67 & 0.555 & 1 & N91 & 0.622 & 5 & & & \\
\hline N31 & 0.555 & 1 & $\mathrm{~N} 26$ & 0.555 & 1 & N92 & 0.622 & 5 & & & \\
\hline N33 & 0.555 & 1 & N7 & 0.558 & 1 & N93 & 0.622 & 5 & & & \\
\hline $\mathrm{N} 34$ & 0.555 & 1 & N105 & 0.561 & 1 & N94 & 0.622 & 5 & & & \\
\hline N35 & 0.555 & 1 & N69 & 0.573 & 4 & N95 & 0.622 & 5 & & & \\
\hline N37 & 0.555 & 1 & N1 & 0.576 & 4 & N9 & 0.631 & 5 & & & \\
\hline N38 & 0.555 & 1 & N100 & 0.577 & 4 & N10 & 0.631 & 5 & & & \\
\hline N39 & 0.555 & 1 & N71 & 0.580 & 4 & N11 & 0.631 & 5 & & & \\
\hline
\end{tabular}

Here the spatial distribution of the amino acid N (a non-essential amino acid) 
over the protein sequence N2 is reverse trending (negatively autocorrelated, HE: 0.488) as observed. In the cluster 1 there are 54 sequences having a slow positive trend (HE: 0.55$)$ whereas the clusters 3,4 and 5 contain all the positive trendy spatial representations of the amino acid $\mathrm{N}$ over the protein sequences.

\subsection{Hurst Exponent of $B_{10_{j}}$ for $j=1,2, \ldots 105$ and Classification}

For the amino acid $A_{10}(P)$ the $\mathrm{HE}$ for the 105 binary sequences $B_{10_{j}}$ for $j=1,2, \ldots 105$ have been determined. The plot of the HE for the binary sequences has been plotted and corresponding histogram is also given in the Fig 10. The HE of the binary representations of ordering of the amino acid $A_{10}$ over all the primary protein sequences would reveal the autocorrelation of the amino acid.

Here the $\mathrm{HE}$ of the 105 binary representation of the amino acid $A_{10}$ is ranging from 0.505 to 0.699 with standard deviation 0.0665. Based on the HEs of the binary sequences all these 105 primary protein sequences of SARS-CoV2, five clustered (C) are formed as presented in the Table 11.
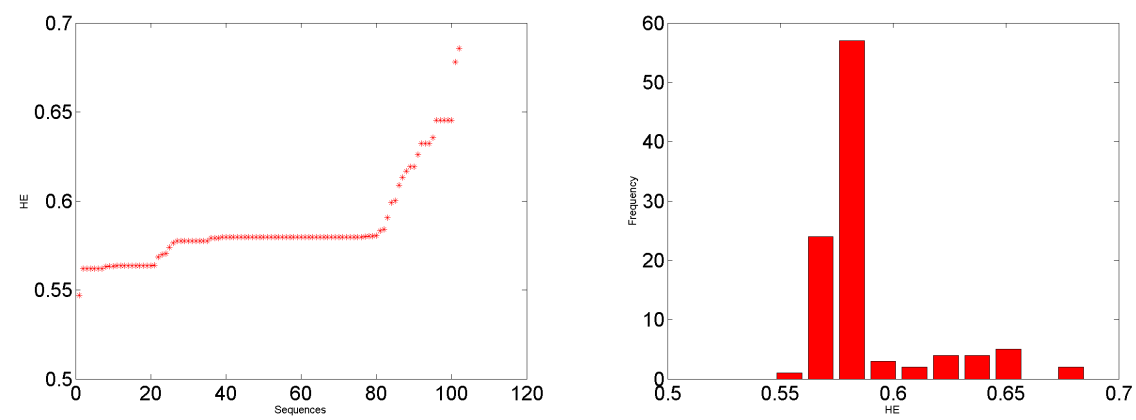

Figure 10: Plot of the HEs and corresponding histogram of all the binary sequences $B_{10_{j}}$ for $j=1,2, \ldots 105$ corresponding to the amino acid $A_{10}(P)$.

One of the conditionally essential amino acids $\mathrm{P}$ does not arise in the protein sequences N81, N99 and N103 of SARS-CoV2. The cluster 1 contains $84 B_{10_{j}}$ for 74 different protein sequences where the amino acid $\mathrm{P}$ is distributed spatially in a positive trendy manner since the HE is approximately 0.56. As usual there 
are other clusters containing positive trendy sequence of spatial distribution of the amino acid $\mathrm{P}$.

Table 11: HE of $105 B_{10_{j}}$ for $j=1,2, \ldots 105$ corresponding to the amino acid $A_{10}(P)$.

\begin{tabular}{|c|c|c|c|c|c|c|c|c|c|c|c|}
\hline Seq & HE & C & Seq & $\mathrm{HE}$ & C & Seq & HE & C & Seq & HE & C \\
\hline N81 & * & 2 & N25 & 0.578 & 1 & $\mathrm{~N} 43$ & 0.580 & 1 & N87 & 0.617 & 4 \\
\hline N99 & $*$ & 2 & N40 & 0.578 & 1 & N45 & 0.580 & 1 & N96 & 0.619 & 4 \\
\hline N103 & $*$ & 2 & N41 & 0.578 & 1 & N46 & 0.580 & 1 & N97 & 0.619 & 4 \\
\hline N94 & 0.547 & 1 & $\mathrm{~N} 42$ & 0.578 & 1 & $\mathrm{~N} 47$ & 0.580 & 1 & N8 & 0.626 & 4 \\
\hline N88 & 0.562 & 1 & N56 & 0.578 & 1 & N48 & 0.580 & 1 & N9 & 0.632 & 5 \\
\hline N89 & 0.562 & 1 & $\mathrm{~N} 23$ & 0.578 & 1 & N49 & 0.580 & 1 & N10 & 0.632 & 5 \\
\hline N90 & 0.562 & 1 & N66 & 0.578 & 1 & N50 & 0.580 & 1 & N11 & 0.632 & 5 \\
\hline N92 & 0.562 & 1 & N67 & 0.578 & 1 & N51 & 0.580 & 1 & N3 & 0.636 & 5 \\
\hline N93 & 0.562 & 1 & N32 & 0.579 & 1 & $\mathrm{~N} 52$ & 0.580 & 1 & N82 & 0.645 & 5 \\
\hline N95 & 0.562 & 1 & N36 & 0.579 & 1 & N53 & 0.580 & 1 & N83 & 0.645 & 5 \\
\hline N102 & 0.563 & 1 & N58 & 0.579 & 1 & N54 & 0.580 & 1 & N84 & 0.645 & 5 \\
\hline N5 & 0.563 & 1 & N14 & 0.580 & 1 & N55 & 0.580 & 1 & N85 & 0.645 & 5 \\
\hline N15 & 0.563 & 1 & N16 & 0.580 & 1 & N57 & 0.580 & 1 & N86 & 0.645 & 5 \\
\hline N69 & 0.564 & 1 & $\mathrm{~N} 17$ & 0.580 & 1 & N59 & 0.580 & 1 & N6 & 0.678 & 3 \\
\hline N71 & 0.564 & 1 & N18 & 0.580 & 1 & N60 & 0.580 & 1 & N98 & 0.686 & 3 \\
\hline N72 & 0.564 & 1 & N19 & 0.580 & 1 & N62 & 0.580 & 1 & & & \\
\hline N73 & 0.564 & 1 & N20 & 0.580 & 1 & N64 & 0.580 & 1 & & & \\
\hline N74 & 0.564 & 1 & N21 & 0.580 & 1 & N65 & 0.580 & 1 & & & \\
\hline N75 & 0.564 & 1 & $\mathrm{~N} 22$ & 0.580 & 1 & N63 & 0.580 & 1 & & & \\
\hline N76 & 0.564 & 1 & N24 & 0.580 & 1 & N44 & 0.580 & 1 & & & \\
\hline N77 & 0.564 & 1 & $\mathrm{~N} 27$ & 0.580 & 1 & N61 & 0.580 & 1 & & & \\
\hline N78 & 0.564 & 1 & N28 & 0.580 & 1 & N13 & 0.580 & 1 & & & \\
\hline N79 & 0.564 & 1 & N29 & 0.580 & 1 & $\mathrm{~N} 12$ & 0.581 & 1 & & & \\
\hline N70 & 0.564 & 1 & N30 & 0.580 & 1 & N37 & 0.583 & 1 & & & \\
\hline N104 & 0.568 & 1 & N31 & 0.580 & 1 & N91 & 0.584 & 1 & & & \\
\hline N7 & 0.570 & 1 & N33 & 0.580 & 1 & $\mathrm{~N} 4$ & 0.591 & 1 & & & \\
\hline $\mathrm{N} 2$ & 0.571 & 1 & N34 & 0.580 & 1 & N68 & 0.599 & 4 & & & \\
\hline N105 & 0.574 & 1 & N35 & 0.580 & 1 & N1 & 0.600 & 4 & & & \\
\hline N100 & 0.577 & 1 & N38 & 0.580 & 1 & N101 & 0.609 & 4 & & & \\
\hline $\mathrm{N} 26$ & 0.578 & 1 & N39 & 0.580 & 1 & N80 & 0.613 & 4 & & & \\
\hline
\end{tabular}

\subsection{Hurst Exponent of $B_{11_{j}}$ for $j=1,2, \ldots 105$ and Classification}

For the amino acid $A_{11}(Q)$ the HE for the 105 binary sequences $B_{11_{j}}$ for $335 j=1,2, \ldots 105$ have been determined. The plot of the HE for the binary sequences has been plotted and corresponding histogram is also given in the Fig 11. The HE of the binary representations of ordering of the amino acid $A_{11}$ over all the primary protein sequences would reveal the autocorrelation of the amino acid.

Here the HE of the 105 binary representation of the amino acid $A_{11}$ is ranging from 0.495 to 0.671 with standard deviation 0.0903. Based on the HEs of the 
binary sequences all these 105 primary protein sequences of SARS-CoV2, five clustered (C) are formed as presented in the Table 12.
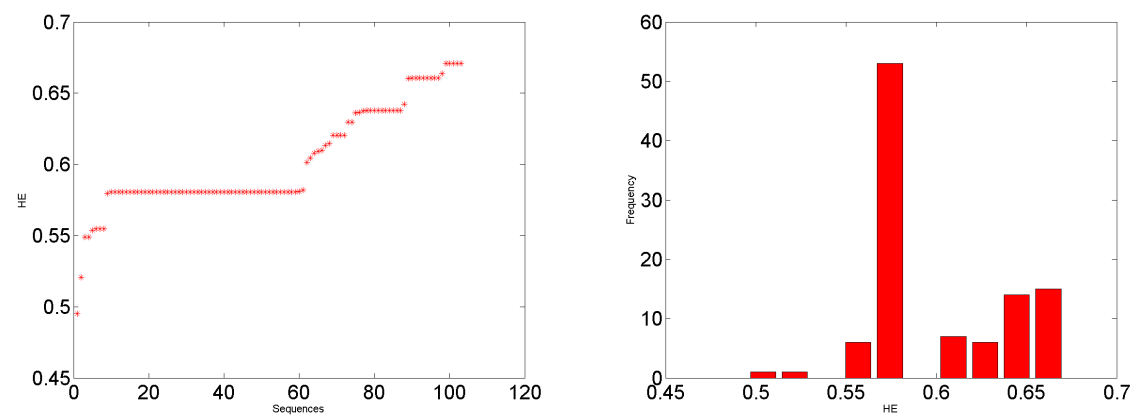

Figure 11: Plot of the HEs and corresponding histogram of all the binary sequences $B_{11_{j}}$ for $j=1,2, \ldots 105$ corresponding to the amino acid $A_{11}(Q)$. 
Table 12: HE of $105 B_{11_{j}}$ for $j=1,2, \ldots 105$ corresponding to the amino acid $A_{11}(Q)$.

\begin{tabular}{|c|c|c|c|c|c|c|c|c|c|c|c|}
\hline Seq & HE & C & Seq & HE & C & Seq & HE & C & Seq & HE & C \\
\hline N96 & * & 3 & N37 & 0.581 & 2 & N13 & 0.581 & 2 & N68 & 0.660 & 4 \\
\hline N97 & $*$ & 3 & N38 & 0.581 & 2 & $\mathrm{~N} 12$ & 0.581 & 2 & N88 & 0.661 & 4 \\
\hline N100 & 0.495 & 5 & N39 & 0.581 & 2 & N5 & 0.582 & 2 & N89 & 0.661 & 4 \\
\hline $\mathrm{N} 2$ & 0.521 & 5 & N40 & 0.581 & 2 & N105 & 0.601 & 2 & N90 & 0.661 & 4 \\
\hline N102 & 0.549 & 5 & N41 & 0.581 & 2 & N7 & 0.604 & 2 & N91 & 0.661 & 4 \\
\hline N1 & 0.549 & 5 & $\mathrm{~N} 42$ & 0.581 & 2 & N15 & 0.608 & 1 & N92 & 0.661 & 4 \\
\hline N6 & 0.554 & 5 & N43 & 0.581 & 2 & N81 & 0.609 & 1 & N93 & 0.661 & 4 \\
\hline N9 & 0.555 & 5 & N45 & 0.581 & 2 & N3 & 0.610 & 1 & N94 & 0.661 & 4 \\
\hline N10 & 0.555 & 5 & N46 & 0.581 & 2 & N80 & 0.613 & 1 & N95 & 0.661 & 4 \\
\hline N11 & 0.555 & 5 & N47 & 0.581 & 2 & N101 & 0.615 & 1 & N99 & 0.664 & 4 \\
\hline $\mathrm{N} 21$ & 0.580 & 2 & N48 & 0.581 & 2 & N98 & 0.620 & 1 & N82 & 0.671 & 4 \\
\hline $\mathrm{N} 26$ & 0.581 & 2 & N49 & 0.581 & 2 & N32 & 0.621 & 1 & N83 & 0.671 & 4 \\
\hline $\mathrm{N} 14$ & 0.581 & 2 & N50 & 0.581 & 2 & N36 & 0.621 & 1 & N84 & 0.671 & 4 \\
\hline N16 & 0.581 & 2 & N51 & 0.581 & 2 & N58 & 0.621 & 1 & N85 & 0.671 & 4 \\
\hline N17 & 0.581 & 2 & N52 & 0.581 & 2 & N87 & 0.630 & 1 & N86 & 0.671 & 4 \\
\hline N18 & 0.581 & 2 & N53 & 0.581 & 2 & $\mathrm{~N} 4$ & 0.630 & 1 & & & \\
\hline N19 & 0.581 & 2 & N54 & 0.581 & 2 & N103 & 0.636 & 1 & & & \\
\hline $\mathrm{N} 20$ & 0.581 & 2 & N55 & 0.581 & 2 & N8 & 0.637 & 1 & & & \\
\hline $\mathrm{N} 22$ & 0.581 & 2 & N56 & 0.581 & 2 & N70 & 0.637 & 1 & & & \\
\hline $\mathrm{N} 23$ & 0.581 & 2 & N57 & 0.581 & 2 & N69 & 0.638 & 1 & & & \\
\hline $\mathrm{N} 24$ & 0.581 & 2 & N59 & 0.581 & 2 & N71 & 0.638 & 1 & & & \\
\hline $\mathrm{N} 25$ & 0.581 & 2 & N60 & 0.581 & 2 & $\mathrm{~N} 72$ & 0.638 & 1 & & & \\
\hline $\mathrm{N} 27$ & 0.581 & 2 & N61 & 0.581 & 2 & N73 & 0.638 & 1 & & & \\
\hline $\mathrm{N} 28$ & 0.581 & 2 & N62 & 0.581 & 2 & N74 & 0.638 & 1 & & & \\
\hline $\mathrm{N} 29$ & 0.581 & 2 & N63 & 0.581 & 2 & N75 & 0.638 & 1 & & & \\
\hline N30 & 0.581 & 2 & N64 & 0.581 & 2 & N76 & 0.638 & 1 & & & \\
\hline N31 & 0.581 & 2 & N65 & 0.581 & 2 & N77 & 0.638 & 1 & & & \\
\hline N33 & 0.581 & 2 & N66 & 0.581 & 2 & N78 & 0.638 & 1 & & & \\
\hline N34 & 0.581 & 2 & N67 & 0.581 & 2 & N79 & 0.638 & 1 & & & \\
\hline N35 & 0.581 & 2 & N44 & 0.581 & 2 & N104 & 0.642 & 1 & & & \\
\hline
\end{tabular}

In the cluster 1, there are two protein sequences N96 and N97 which are absolutely free from the amino acid Q. The cluster 2 contains 45 sequences having HE 0.58 and so the spatial organization of the amino acid Q is positively trending. As usual there are other three clusters 1,4 and 5 which contain positive autocorrelated sequences of the spatial distribution of the amino acid $\mathrm{Q}$ over the protein sequences. There is only one binary representation $B_{11_{100}}$ of

\subsection{Hurst Exponent of $B_{12_{j}}$ for $j=1,2, \ldots 105$ and Classification}

For the amino acid $A_{12}(S)$ the HE for the 105 binary sequences $B_{12}$ for $j=1,2, \ldots 105$ have been determined. The plot of the HE for the binary sequences has been plotted and corresponding histogram is also given in the Fig 
12. The HE of the binary representations of ordering of the amino acid $A_{12}$ over all the primary protein sequences would reveal the autocorrelation of the amino acid.

Here the $\mathrm{HE}$ of the 105 binary representation of the amino acid $A_{12}$ is ranging from 0.486 to 0.694 with standard deviation 0.04. Based on the HEs of the binary sequences all these 105 primary protein sequences of SARS-CoV2, eight clustered (C) are formed as presented in the Table 13.
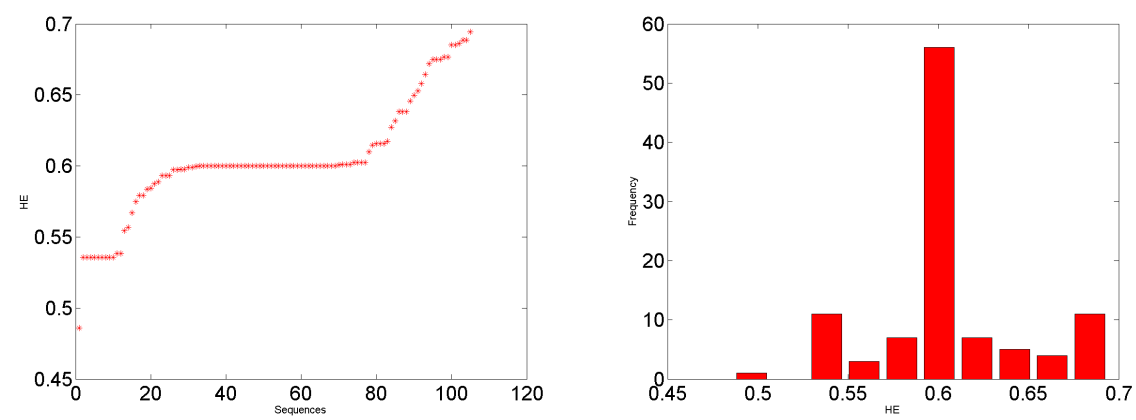

Figure 12: Plot of the HEs and corresponding histogram of all the binary sequences $B_{12}$ for $j=1,2, \ldots 105$ corresponding to the amino acid $A_{12}(S)$. 
Table 13: HE of $105 B_{12}$ for $j=1,2, \ldots 105$ corresponding to the amino acid $A_{12}(S)$.

\begin{tabular}{|c|c|c|c|c|c|c|c|c|c|c|c|}
\hline Seq & $\mathrm{HE}$ & C & Seq & $\mathrm{HE}$ & C & Seq & HE & C & Seq & HE & C \\
\hline N7 & 0.486 & 6 & N56 & 0.599 & 2 & N53 & 0.600 & 2 & N80 & 0.653 & 5 \\
\hline N70 & 0.536 & 1 & $\mathrm{~N} 13$ & 0.600 & 2 & N55 & 0.600 & 2 & N68 & 0.658 & 5 \\
\hline N69 & 0.536 & 1 & N44 & 0.600 & 2 & N57 & 0.600 & 2 & $\mathrm{~N} 103$ & 0.664 & 5 \\
\hline N72 & 0.536 & 1 & N17 & 0.600 & 2 & N59 & 0.600 & 2 & N3 & 0.672 & 3 \\
\hline N73 & 0.536 & 1 & N18 & 0.600 & 2 & N63 & 0.600 & 2 & N88 & 0.675 & 3 \\
\hline N74 & 0.536 & 1 & N19 & 0.600 & 2 & N64 & 0.600 & 2 & N89 & 0.675 & 3 \\
\hline N75 & 0.536 & 1 & N21 & 0.600 & 2 & N65 & 0.600 & 2 & N93 & 0.675 & 3 \\
\hline N 77 & 0.536 & 1 & $\mathrm{~N} 22$ & 0.600 & 2 & N66 & 0.600 & 2 & N96 & 0.677 & 3 \\
\hline N78 & 0.536 & 1 & N23 & 0.600 & 2 & N67 & 0.600 & 2 & N97 & 0.677 & 3 \\
\hline N79 & 0.536 & 1 & $\mathrm{~N} 24$ & 0.600 & 2 & $\mathrm{~N} 12$ & 0.601 & 2 & N91 & 0.685 & 4 \\
\hline N71 & 0.538 & 1 & N25 & 0.600 & 2 & $\mathrm{~N} 40$ & 0.601 & 2 & N94 & 0.685 & 4 \\
\hline N76 & 0.538 & 1 & N27 & 0.600 & 2 & N16 & 0.601 & 2 & N8 & 0.686 & 4 \\
\hline N5 & 0.554 & 1 & N29 & 0.600 & 2 & $\mathrm{~N} 62$ & 0.601 & 2 & N90 & 0.689 & 4 \\
\hline N81 & 0.557 & 1 & N31 & 0.600 & 2 & $\mathrm{~N} 26$ & 0.602 & 2 & N92 & 0.689 & 4 \\
\hline N98 & 0.567 & 1 & N33 & 0.600 & 2 & N51 & 0.603 & 2 & N95 & 0.694 & 4 \\
\hline N101 & 0.575 & 2 & N34 & 0.600 & 2 & N54 & 0.603 & 2 & & & \\
\hline N84 & 0.579 & 2 & N35 & 0.600 & 2 & N61 & 0.603 & 2 & & & \\
\hline $\mathrm{N} 86$ & 0.579 & 2 & N37 & 0.600 & 2 & N100 & 0.610 & 8 & & & \\
\hline $\mathrm{N} 2$ & 0.584 & 2 & N38 & 0.600 & 2 & N6 & 0.615 & 8 & & & \\
\hline N99 & 0.584 & 2 & N39 & 0.600 & 2 & N32 & 0.616 & 8 & & & \\
\hline N15 & 0.588 & 2 & N41 & 0.600 & 2 & N36 & 0.616 & 8 & & & \\
\hline $\mathrm{N} 1$ & 0.589 & 2 & $\mathrm{~N} 42$ & 0.600 & 2 & N58 & 0.616 & 8 & & & \\
\hline N82 & 0.593 & 2 & N43 & 0.600 & 2 & $\mathrm{~N} 102$ & 0.617 & 8 & & & \\
\hline N83 & 0.593 & 2 & $\mathrm{~N} 45$ & 0.600 & 2 & N104 & 0.627 & 8 & & & \\
\hline N85 & 0.593 & 2 & $\mathrm{~N} 46$ & 0.600 & 2 & N105 & 0.632 & 7 & & & \\
\hline $\mathrm{N} 20$ & 0.597 & 2 & N47 & 0.600 & 2 & N9 & 0.638 & 7 & & & \\
\hline N30 & 0.597 & 2 & $\mathrm{~N} 48$ & 0.600 & 2 & N10 & 0.638 & 7 & & & \\
\hline $\mathrm{N} 14$ & 0.598 & 2 & N49 & 0.600 & 2 & $\mathrm{~N} 11$ & 0.638 & 7 & & & \\
\hline $\mathrm{N} 28$ & 0.598 & 2 & N50 & 0.600 & 2 & $\mathrm{~N} 4$ & 0.646 & 7 & & & \\
\hline N60 & 0.599 & 2 & N52 & 0.600 & 2 & N87 & 0.650 & 5 & & & \\
\hline
\end{tabular}

The binary representation $B_{127}$ of spatial organization of the non essential amino acid $\mathrm{S}$ over the protein sequence N7 is negatively autocorrelated whereas the other 104 binary representations corresponding to the protein sequences are positively trending $\left(\mathrm{HE}_{i} 0.5\right)$. The largest cluster 2 contains 62 sequences which are positively trending. It noteworthy that the spatial representations of the amino acid S over the protein sequences N56, N13, N44, .., N67 (belonging to the cluster 2) are having HEs 0.6 exactly, implying the positive autocorrelation.

\subsection{Hurst Exponent of $B_{13_{j}}$ for $j=1,2, \ldots 105$ and Classification}

For the amino acid $A_{13}(T)$ the HE for the 105 binary sequences $B_{13_{j}}$ for $j=1,2, \ldots 105$ have been determined. The plot of the HE for the binary sequences has been plotted and corresponding histogram is also given in the Fig 
13. The HE of the binary representations of ordering of the amino acid $A_{13}$ over all the primary protein sequences would reveal the autocorrelation of the amino acid.

Here the $\mathrm{HE}$ of the 105 binary representation of the amino acid $A_{13}$ is ranging from 0.523 to 0.685 with standard deviation 0.0665. Based on the HEs of the binary sequences all these 105 primary protein sequences of SARS-CoV2, five clustered (C) are formed as presented in the Table 14.

The spatial representation $B_{13_{99}}$ of the essential amino acid $\mathrm{T}$ is a null sequences having only zeros which imply the absence of the amino acid over the protein sequence N99. The spatial distributions of the amino acid T over the 76 protein sequences (belong to cluster 1) are positively trending.
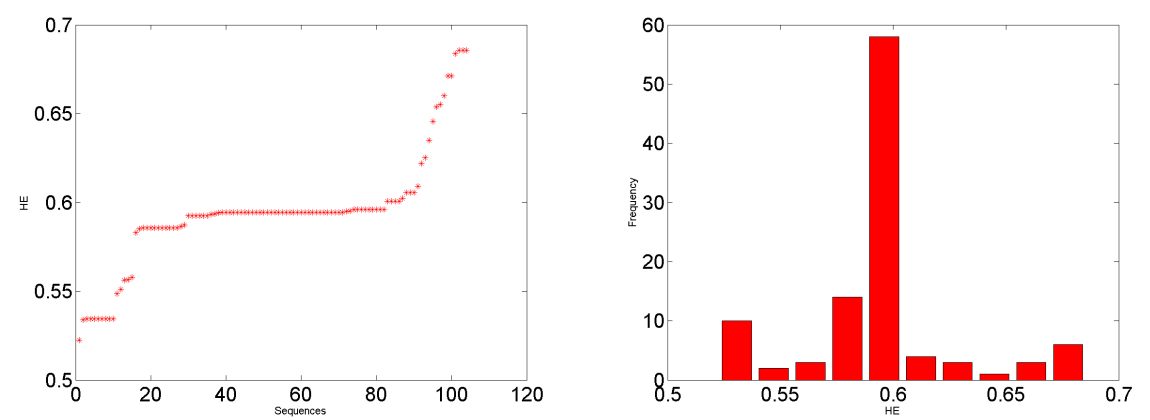

Figure 13: Plot of the HEs and corresponding histogram of all the binary sequences $B_{13_{j}}$ for $j=1,2, \ldots 105$ corresponding to the amino acid $A_{13}(T)$. 
Table 14: HE of $105 B_{13_{j}}$ for $j=1,2, \ldots 105$ corresponding to the amino acid $A_{13}(T)$.

\begin{tabular}{|c|c|c|c|c|c|c|c|c|c|c|c|}
\hline Seq & HE & C & Seq & HE & C & Seq & $\mathrm{HE}$ & C & Seq & HE & C \\
\hline N99 & * & 3 & $\mathrm{~N} 25$ & 0.592 & 1 & N52 & 0.594 & 1 & N58 & 0.606 & 1 \\
\hline N7 & 0.523 & 2 & $\mathrm{~N} 27$ & 0.592 & 1 & N53 & 0.594 & 1 & N81 & 0.609 & 1 \\
\hline N8 & 0.534 & 2 & $\mathrm{~N} 29$ & 0.592 & 1 & N54 & 0.594 & 1 & $\mathrm{~N} 102$ & 0.622 & 5 \\
\hline N88 & 0.534 & 2 & N34 & 0.592 & 1 & N56 & 0.594 & 1 & N2 & 0.625 & 5 \\
\hline N89 & 0.534 & 2 & N35 & 0.592 & 1 & N57 & 0.594 & 1 & N4 & 0.635 & 5 \\
\hline N90 & 0.534 & 2 & N65 & 0.593 & 1 & N59 & 0.594 & 1 & N1 & 0.646 & 5 \\
\hline N91 & 0.534 & 2 & $\mathrm{~N} 12$ & 0.593 & 1 & N60 & 0.594 & 1 & N105 & 0.654 & 5 \\
\hline N92 & 0.534 & 2 & $\mathrm{~N} 13$ & 0.594 & 1 & N62 & 0.594 & 1 & N87 & 0.655 & 5 \\
\hline N93 & 0.534 & 2 & N44 & 0.594 & 1 & N64 & 0.594 & 1 & N98 & 0.660 & 5 \\
\hline N94 & 0.534 & 2 & N16 & 0.594 & 1 & N66 & 0.594 & 1 & N96 & 0.671 & 4 \\
\hline N95 & 0.534 & 2 & N21 & 0.594 & 1 & N67 & 0.594 & 1 & N97 & 0.671 & 4 \\
\hline N68 & 0.549 & 2 & $\mathrm{~N} 22$ & 0.594 & 1 & N26 & 0.594 & 1 & N3 & 0.684 & 4 \\
\hline N101 & 0.551 & 2 & $\mathrm{~N} 23$ & 0.594 & 1 & N6 & 0.595 & 1 & N9 & 0.686 & 4 \\
\hline N82 & 0.556 & 2 & N24 & 0.594 & 1 & N61 & 0.595 & 1 & N10 & 0.686 & 4 \\
\hline $\mathrm{N} 15$ & 0.557 & 2 & N30 & 0.594 & 1 & N17 & 0.596 & 1 & N11 & 0.686 & 4 \\
\hline N100 & 0.558 & 2 & N31 & 0.594 & 1 & N18 & 0.596 & 1 & & & \\
\hline N5 & 0.583 & 1 & N33 & 0.594 & 1 & N19 & 0.596 & 1 & & & \\
\hline N70 & 0.585 & 1 & N37 & 0.594 & 1 & $\mathrm{~N} 20$ & 0.596 & 1 & & & \\
\hline N69 & 0.586 & 1 & N39 & 0.594 & 1 & N28 & 0.596 & 1 & & & \\
\hline N71 & 0.586 & 1 & N40 & 0.594 & 1 & N38 & 0.596 & 1 & & & \\
\hline N72 & 0.586 & 1 & N41 & 0.594 & 1 & N63 & 0.596 & 1 & & & \\
\hline N73 & 0.586 & 1 & $\mathrm{~N} 42$ & 0.594 & 1 & N14 & 0.596 & 1 & & & \\
\hline N74 & 0.586 & 1 & $\mathrm{~N} 43$ & 0.594 & 1 & N55 & 0.596 & 1 & & & \\
\hline N75 & 0.586 & 1 & N45 & 0.594 & 1 & N83 & 0.601 & 1 & & & \\
\hline N76 & 0.586 & 1 & N46 & 0.594 & 1 & N84 & 0.601 & 1 & & & \\
\hline N77 & 0.586 & 1 & N47 & 0.594 & 1 & N85 & 0.601 & 1 & & & \\
\hline N78 & 0.586 & 1 & N48 & 0.594 & 1 & N86 & 0.601 & 1 & & & \\
\hline N79 & 0.586 & 1 & N49 & 0.594 & 1 & N80 & 0.602 & 1 & & & \\
\hline N103 & 0.586 & 1 & N50 & 0.594 & 1 & N32 & 0.606 & 1 & & & \\
\hline $\mathrm{N} 104$ & 0.587 & 1 & N51 & 0.594 & 1 & N36 & 0.606 & 1 & & & \\
\hline
\end{tabular}

\subsection{Hurst Exponent of $B_{14_{j}}$ for $j=1,2, \ldots 105$ and Classification}

385 $j=1,2, \ldots 105$ have been determined. The plot of the HE for the binary sequences has been plotted and corresponding histogram is also given in the Fig 14. The HE of the binary representations of ordering of the amino acid $A_{14}$ over all the primary protein sequences would reveal the autocorrelation of the amino acid.

Here the $\mathrm{HE}$ of the 105 binary representation of the amino acid $A_{14}$ is ranging from 0.507 to 0.723 with standard deviation 0.0450. Based on the HEs of the binary sequences all these 105 primary protein sequences of SARS-CoV2, five clustered $(\mathrm{C})$ are formed as presented in the Table 15. 

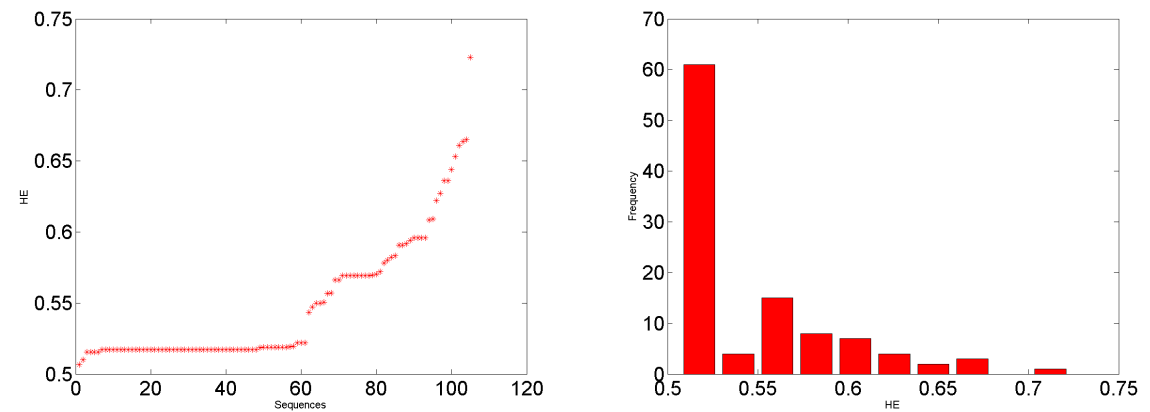

Figure 14: Plot of the HEs and corresponding histogram of all the binary sequences $B_{14_{j}}$ for $j=1,2, \ldots 105$ corresponding to the amino acid $A_{14}(V)$.

Table 15: HE of $105 B_{14}$ for $j=1,2, \ldots 105$ corresponding to the amino acid $A_{14}(V)$.

\begin{tabular}{|c|c|c|c|c|c|c|c|c|c|c|c|}
\hline Seq & $\mathrm{HE}$ & C & Seq & HE & C & Seq & $\mathrm{HE}$ & C & Seq & HE & C \\
\hline N8 & 0.507 & 2 & $\mathrm{~N} 42$ & 0.517 & 2 & N53 & 0.522 & 2 & N84 & 0.596 & 3 \\
\hline N5 & 0.510 & 2 & $\mathrm{~N} 43$ & 0.517 & 2 & N100 & 0.544 & 5 & N85 & 0.596 & 3 \\
\hline N59 & 0.516 & 2 & N45 & 0.517 & 2 & N58 & 0.547 & 5 & N6 & 0.596 & 3 \\
\hline N61 & 0.516 & 2 & N46 & 0.517 & 2 & N32 & 0.550 & 5 & N98 & 0.608 & 8 \\
\hline N63 & 0.516 & 2 & N47 & 0.517 & 2 & N36 & 0.550 & 5 & N81 & 0.609 & 8 \\
\hline N65 & 0.516 & 2 & N49 & 0.517 & 2 & $\mathrm{~N} 1$ & 0.551 & 5 & N103 & 0.622 & 8 \\
\hline N44 & 0.517 & 2 & N51 & 0.517 & 2 & N92 & 0.557 & 5 & N101 & 0.627 & 1 \\
\hline N14 & 0.517 & 2 & N52 & 0.517 & 2 & N74 & 0.557 & 5 & N83 & 0.636 & 1 \\
\hline N16 & 0.517 & 2 & N54 & 0.517 & 2 & N96 & 0.566 & 7 & N86 & 0.636 & 1 \\
\hline N 17 & 0.517 & 2 & N55 & 0.517 & 2 & N97 & 0.566 & 7 & N87 & 0.644 & 1 \\
\hline N18 & 0.517 & 2 & N56 & 0.517 & 2 & N69 & 0.569 & 7 & N68 & 0.653 & 6 \\
\hline N19 & 0.517 & 2 & N57 & 0.517 & 2 & N71 & 0.569 & 7 & N104 & 0.661 & 6 \\
\hline N20 & 0.517 & 2 & N60 & 0.517 & 2 & N72 & 0.569 & 7 & N99 & 0.664 & 6 \\
\hline $\mathrm{N} 21$ & 0.517 & 2 & N62 & 0.517 & 2 & N73 & 0.569 & 7 & N15 & 0.665 & 6 \\
\hline $\mathrm{N} 23$ & 0.517 & 2 & N64 & 0.517 & 2 & N75 & 0.569 & 7 & N80 & 0.723 & 4 \\
\hline $\mathrm{N} 24$ & 0.517 & 2 & N66 & 0.517 & 2 & N76 & 0.569 & 7 & & & \\
\hline $\mathrm{N} 25$ & 0.517 & 2 & N67 & 0.517 & 2 & N78 & 0.569 & 7 & & & \\
\hline $\mathrm{N} 27$ & 0.517 & 2 & N26 & 0.517 & 2 & N79 & 0.569 & 7 & & & \\
\hline N28 & 0.517 & 2 & N22 & 0.519 & 2 & N70 & 0.570 & 7 & & & \\
\hline $\mathrm{N} 29$ & 0.517 & 2 & N88 & 0.519 & 2 & N102 & 0.570 & 7 & & & \\
\hline N30 & 0.517 & 2 & N89 & 0.519 & 2 & N 77 & 0.572 & 7 & & & \\
\hline N31 & 0.517 & 2 & N90 & 0.519 & 2 & N2 & 0.578 & 7 & & & \\
\hline N33 & 0.517 & 2 & N91 & 0.519 & 2 & N10 & 0.580 & 7 & & & \\
\hline N34 & 0.517 & 2 & N93 & 0.519 & 2 & N3 & 0.582 & 3 & & & \\
\hline N35 & 0.517 & 2 & N94 & 0.519 & 2 & N7 & 0.583 & 3 & & & \\
\hline N37 & 0.517 & 2 & N95 & 0.519 & 2 & N9 & 0.591 & 3 & & & \\
\hline N38 & 0.517 & 2 & $\mathrm{~N} 12$ & 0.519 & 2 & N11 & 0.591 & 3 & & & \\
\hline N39 & 0.517 & 2 & N13 & 0.520 & 2 & N4 & 0.592 & 3 & & & \\
\hline N40 & 0.517 & 2 & N48 & 0.522 & 2 & N105 & 0.594 & 3 & & & \\
\hline N41 & 0.517 & 2 & N50 & 0.522 & 2 & N82 & 0.596 & 3 & & & \\
\hline
\end{tabular}


tial distribution of the amino acid $\mathrm{V}$ over the corresponding protein sequences, which are random as the HE is turned out to be 0.51 (approx.). The binary representation $B_{14_{8}}$ is random as the HE is 0.5 which depicts positive trending behaviour of the binary representation $B_{14_{8}}$ of the amino acid $\mathrm{V}$ over the protein sequence N8.

\subsection{Hurst Exponent of $B_{15_{j}}$ for $j=1,2, \ldots 105$ and Classification}

For the amino acid $A_{15}(W)$ the HE for the 105 binary sequences $B_{15_{j}}$ for $j=1,2, \ldots 105$ have been determined. The plot of the HE for the binary sequences has been plotted and corresponding histogram is also given in the Fig 15. The HE of the binary representations of ordering of the amino acid $A_{15}$ over all the primary protein sequences would reveal the autocorrelation of the amino acid.

Here the HE of the 105 binary representation of the amino acid $A_{15}$ is ranging from 0.535 to 0.672 . Based on the HEs of the binary sequences all these 105 primary protein sequences of SARS-CoV2, five clustered (C) are formed as presented in the Table 16.
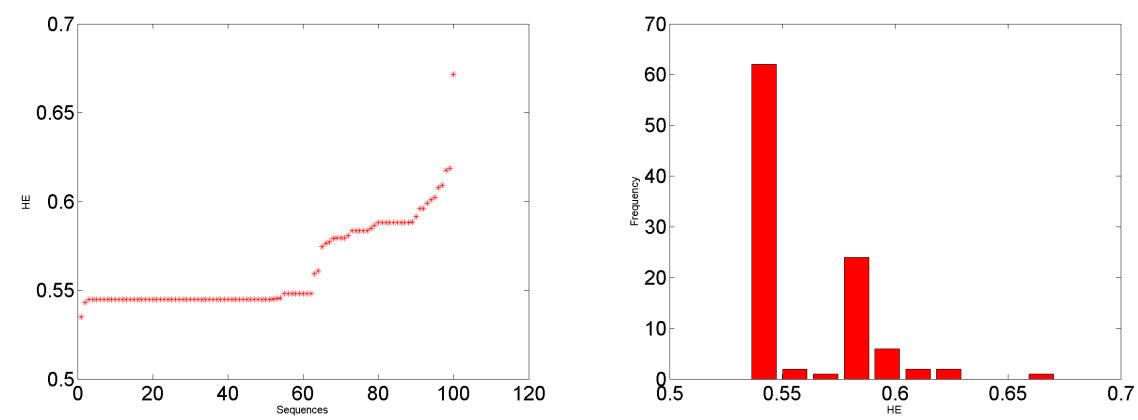

Figure 15: Plot of the HEs and corresponding histogram of all the binary sequences $B_{15_{j}}$ for $j=1,2, \ldots 105$ corresponding to the amino acid $A_{15}(V)$. 
Table 16: HE of $105 B_{15}$ for $j=1,2, \ldots 105$ corresponding to the amino acid $A_{15}(W)$.

\begin{tabular}{|c|c|c|c|c|c|c|c|c|c|c|c|}
\hline Seq & $\mathrm{HE}$ & C & Seq & $\mathbf{H E}$ & C & Seq & $\mathbf{H E}$ & C & Seq & HE & C \\
\hline N80 & * & 2 & N40 & 0.545 & 3 & N89 & 0.548 & 3 & N77 & 0.588 & 1 \\
\hline N87 & $*$ & 2 & N41 & 0.545 & 3 & N90 & 0.548 & 3 & N78 & 0.588 & 1 \\
\hline N96 & * & 2 & N42 & 0.545 & 3 & N91 & 0.548 & 3 & N79 & 0.588 & 1 \\
\hline N97 & * & 2 & N43 & 0.545 & 3 & N92 & 0.548 & 3 & N70 & 0.588 & 1 \\
\hline N99 & * & 2 & N45 & 0.545 & 3 & N93 & 0.548 & 3 & N103 & 0.591 & 1 \\
\hline N1 & 0.535 & 3 & N46 & 0.545 & 3 & N94 & 0.548 & 3 & N10 & 0.596 & 1 \\
\hline N100 & 0.543 & 3 & N 47 & 0.545 & 3 & N95 & 0.548 & 3 & N11 & 0.596 & 1 \\
\hline $\mathrm{N} 26$ & 0.545 & 3 & N48 & 0.545 & 3 & N6 & 0.559 & 3 & N68 & 0.599 & 5 \\
\hline N14 & 0.545 & 3 & N49 & 0.545 & 3 & N5 & 0.561 & 3 & N101 & 0.601 & 5 \\
\hline N16 & 0.545 & 3 & N50 & 0.545 & 3 & N105 & 0.575 & 1 & N76 & 0.602 & 5 \\
\hline N17 & 0.545 & 3 & N51 & 0.545 & 3 & N15 & 0.576 & 1 & N104 & 0.608 & 5 \\
\hline N18 & 0.545 & 3 & N52 & 0.545 & 3 & N9 & 0.577 & 1 & N81 & 0.609 & 5 \\
\hline N19 & 0.545 & 3 & N53 & 0.545 & 3 & N7 & 0.579 & 1 & N3 & 0.617 & 5 \\
\hline N20 & 0.545 & 3 & N54 & 0.545 & 3 & N32 & 0.580 & 1 & N4 & 0.619 & 5 \\
\hline $\mathrm{N} 21$ & 0.545 & 3 & N55 & 0.545 & 3 & N36 & 0.580 & 1 & N8 & 0.672 & 4 \\
\hline $\mathrm{N} 22$ & 0.545 & 3 & N56 & 0.545 & 3 & N58 & 0.580 & 1 & & & \\
\hline $\mathrm{N} 23$ & 0.545 & 3 & N57 & 0.545 & 3 & N2 & 0.581 & 1 & & & \\
\hline N24 & 0.545 & 3 & N59 & 0.545 & 3 & N82 & 0.583 & 1 & & & \\
\hline $\mathrm{N} 25$ & 0.545 & 3 & N60 & 0.545 & 3 & N83 & 0.583 & 1 & & & \\
\hline $\mathrm{N} 27$ & 0.545 & 3 & N61 & 0.545 & 3 & N84 & 0.583 & 1 & & & \\
\hline $\mathrm{N} 28$ & 0.545 & 3 & N62 & 0.545 & 3 & N85 & 0.583 & 1 & & & \\
\hline $\mathrm{N} 29$ & 0.545 & 3 & N63 & 0.545 & 3 & N86 & 0.583 & 1 & & & \\
\hline N30 & 0.545 & 3 & N64 & 0.545 & 3 & N98 & 0.585 & 1 & & & \\
\hline N31 & 0.545 & 3 & N65 & 0.545 & 3 & N102 & 0.586 & 1 & & & \\
\hline N33 & 0.545 & 3 & N66 & 0.545 & 3 & N69 & 0.588 & 1 & & & \\
\hline N34 & 0.545 & 3 & N67 & 0.545 & 3 & N71 & 0.588 & 1 & & & \\
\hline N35 & 0.545 & 3 & N44 & 0.545 & 3 & N72 & 0.588 & 1 & & & \\
\hline N37 & 0.545 & 3 & N13 & 0.545 & 3 & N73 & 0.588 & 1 & & & \\
\hline N38 & 0.545 & 3 & $\mathrm{~N} 12$ & 0.546 & 3 & N74 & 0.588 & 1 & & & \\
\hline N39 & 0.545 & 3 & N88 & 0.548 & 3 & N75 & 0.588 & 1 & & & \\
\hline
\end{tabular}

The essential amino acid $\mathrm{W}$ is absent throughout the protein sequences of N80, N87, N96 and N99 and consequently the binary representations $B_{15_{80}}$, $B_{15_{87}}, B_{15_{96}}$ and $B_{15_{99}}$ contain only zeros and $\mathrm{HE}$ is in-computable as depicted in 415 the Table 16. Rest all the other binary representations of the spatial distribution of the amino acid $\mathrm{V}$ over the protein sequences are positively trending. There are 64 protein sequences (cluster 3 ) where the amino acid $\mathrm{W}$ is spread with positive trend as shown in the Table 16.

\subsection{Hurst Exponent of $B_{16_{j}}$ for $j=1,2, \ldots 105$ and Classification}

For the amino acid $A_{16}(Y)$ the HE for the 105 binary sequences $B_{16}$ for $j=1,2, \ldots 105$ have been determined. The plot of the HE for the binary sequences has been plotted and corresponding histogram is also given in the Fig 
16. The HE of the binary representations of ordering of the amino acid $A_{16}$ over all the primary protein sequences would reveal the autocorrelation of the amino acid.
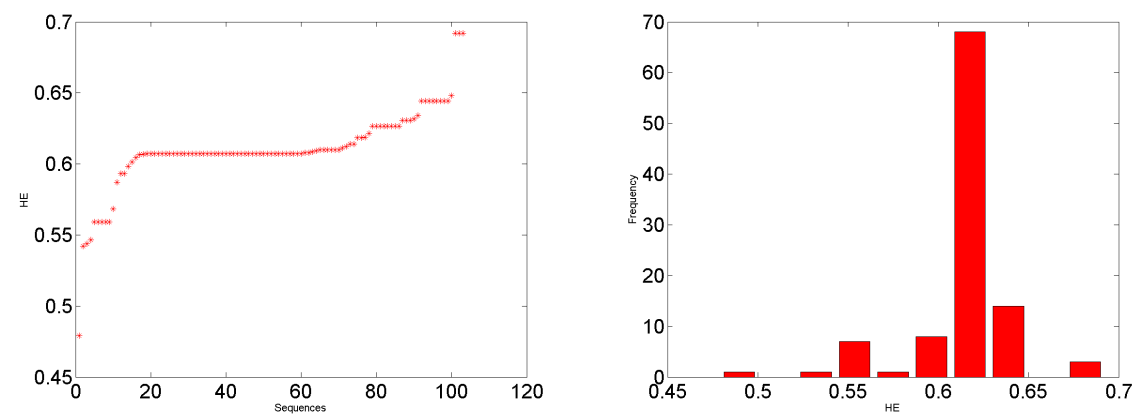

Figure 16: Plot of the HEs and corresponding histogram of all the binary sequences $B_{16_{j}}$ for $j=1,2, \ldots 105$ corresponding to the amino acid $A_{16}(Y)$.

Here the $\mathrm{HE}$ of the 105 binary representation of the amino acid $A_{16}$ is ranging from 0.479 to 0.692 with standard deviation 0.0884. Based on the HEs of the binary sequences all these 105 primary protein sequences of SARS-CoV2, six clustered (C) are formed as presented in the Table 17.

The conditional amino acid Y is absent in the protein sequences N99 and N103. The spatial distribution of the amino acid Y over the only protein N80 belonging to the cluster 6 is not trending as its HE $0.479<0.5$. The largest cluster 1 contains 68 protein sequences where the amino acid Y spatially spread with positive trend. 
Table 17: HE of $105 B_{16}$ for $j=1,2, \ldots 105$ corresponding to the amino acid $A_{16}(Y)$.

\begin{tabular}{|c|c|c|c|c|c|c|c|c|c|c|c|}
\hline Seq & $\mathrm{HE}$ & C & Seq & $\mathbf{H E}$ & C & Seq & $\mathbf{H E}$ & C & Seq & HE & C \\
\hline N99 & $*$ & 4 & N27 & 0.607 & 1 & N66 & 0.607 & 1 & N58 & 0.631 & 5 \\
\hline N103 & $*$ & 4 & N28 & 0.607 & 1 & N67 & 0.607 & 1 & N69 & 0.632 & 5 \\
\hline N80 & 0.479 & 6 & N29 & 0.607 & 1 & $\mathrm{~N} 22$ & 0.608 & 1 & N8 & 0.634 & 5 \\
\hline $\mathrm{N} 2$ & 0.542 & 3 & N30 & 0.607 & 1 & N98 & 0.608 & 1 & N88 & 0.644 & 5 \\
\hline N100 & 0.544 & 3 & N31 & 0.607 & 1 & N49 & 0.609 & 1 & N89 & 0.644 & 5 \\
\hline N105 & 0.546 & 3 & N33 & 0.607 & 1 & N81 & 0.609 & 1 & N90 & 0.644 & 5 \\
\hline N82 & 0.559 & 3 & N34 & 0.607 & 1 & $\mathrm{~N} 102$ & 0.610 & 1 & N91 & 0.644 & 5 \\
\hline N83 & 0.559 & 3 & N35 & 0.607 & 1 & N25 & 0.610 & 1 & N92 & 0.644 & 5 \\
\hline N84 & 0.559 & 3 & N37 & 0.607 & 1 & $\mathrm{~N} 40$ & 0.610 & 1 & N93 & 0.644 & 5 \\
\hline N85 & 0.559 & 3 & N38 & 0.607 & 1 & N41 & 0.610 & 1 & N94 & 0.644 & 5 \\
\hline N86 & 0.559 & 3 & N39 & 0.607 & 1 & $\mathrm{~N} 42$ & 0.610 & 1 & N95 & 0.644 & 5 \\
\hline N87 & 0.568 & 3 & N43 & 0.607 & 1 & N26 & 0.610 & 1 & N101 & 0.648 & 5 \\
\hline N3 & 0.587 & 1 & N45 & 0.607 & 1 & N104 & 0.611 & 1 & N9 & 0.692 & 2 \\
\hline N5 & 0.593 & 1 & N46 & 0.607 & 1 & N15 & 0.612 & 1 & N10 & 0.692 & 2 \\
\hline N6 & 0.593 & 1 & N47 & 0.607 & 1 & N96 & 0.614 & 1 & N11 & 0.692 & 2 \\
\hline N68 & 0.598 & 1 & N48 & 0.607 & 1 & N97 & 0.614 & 1 & & & \\
\hline N1 & 0.602 & 1 & N50 & 0.607 & 1 & N7 & 0.618 & 1 & & & \\
\hline N64 & 0.605 & 1 & N51 & 0.607 & 1 & N70 & 0.619 & 1 & & & \\
\hline $\mathrm{N} 12$ & 0.606 & 1 & N52 & 0.607 & 1 & $\mathrm{~N} 4$ & 0.619 & 1 & & & \\
\hline $\mathrm{N} 13$ & 0.607 & 1 & N53 & 0.607 & 1 & N79 & 0.621 & 1 & & & \\
\hline $\mathrm{N} 44$ & 0.607 & 1 & N54 & 0.607 & 1 & N71 & 0.627 & 5 & & & \\
\hline $\mathrm{N} 14$ & 0.607 & 1 & N55 & 0.607 & 1 & N72 & 0.627 & 5 & & & \\
\hline N16 & 0.607 & 1 & N56 & 0.607 & 1 & N73 & 0.627 & 5 & & & \\
\hline N17 & 0.607 & 1 & N57 & 0.607 & 1 & N74 & 0.627 & 5 & & & \\
\hline N 18 & 0.607 & 1 & N59 & 0.607 & 1 & N75 & 0.627 & 5 & & & \\
\hline N19 & 0.607 & 1 & N60 & 0.607 & 1 & N76 & 0.627 & 5 & & & \\
\hline $\mathrm{N} 20$ & 0.607 & 1 & N61 & 0.607 & 1 & N77 & 0.627 & 5 & & & \\
\hline $\mathrm{N} 21$ & 0.607 & 1 & N62 & 0.607 & 1 & N78 & 0.627 & 5 & & & \\
\hline $\mathrm{N} 23$ & 0.607 & 1 & N63 & 0.607 & 1 & N32 & 0.631 & 5 & & & \\
\hline $\mathrm{N} 24$ & 0.607 & 1 & N65 & 0.607 & 1 & N36 & 0.631 & 5 & & & \\
\hline
\end{tabular}

\subsection{Hurst Exponent of $B_{17}$ for $j=1,2, \ldots 105$ and Classification}

For the amino acid $A_{17}(D)$ the HE for the 105 binary sequences $B_{17_{j}}$ for $j=1,2, \ldots 105$ have been determined. The plot of the HE for the binary sequences has been plotted and corresponding histogram is also given in the Fig 17. The HE of the binary representations of ordering of the amino acid $A_{17}$ over all the primary protein sequences would reveal the autocorrelation of the amino acid.

Here the $\mathrm{HE}$ of the 105 binary representation of the amino acid $A_{17}$ is ranging from 0.501 to 0.6918 with standard deviation 0.0434. Based on the HEs of the binary sequences all these 105 primary protein sequences of SARS-CoV2, six clustered $(\mathrm{C})$ are formed as presented in the Table 18. 

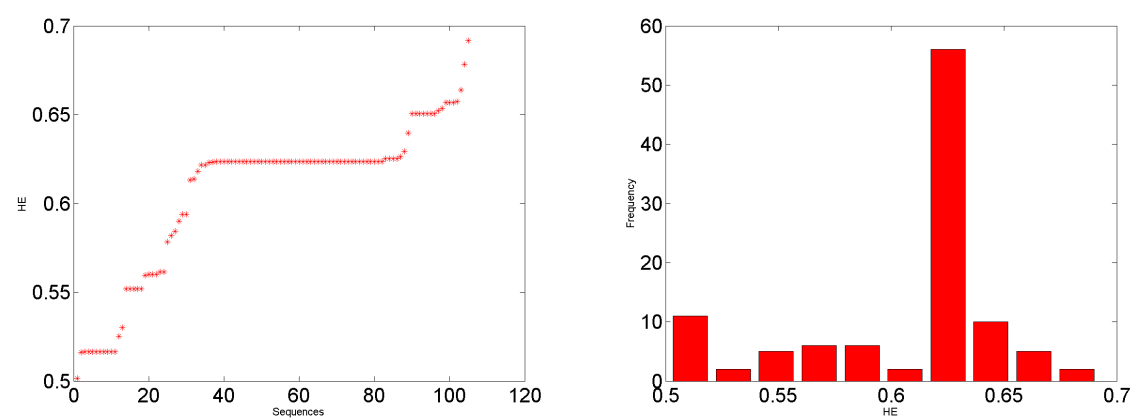

Figure 17: Plot of the HEs and corresponding histogram of all the binary sequences $B_{17_{j}}$ for $j=1,2, \ldots 105$ corresponding to the amino acid $A_{17}(D)$.

Table 18: HE of $105 B_{17_{j}}$ for $j=1,2, \ldots 105$ corresponding to the amino acid $A_{17}(D)$.

\begin{tabular}{|c|c|c|c|c|c|c|c|c|c|c|c|}
\hline Seq & HE & C & Seq & $\mathrm{HE}$ & C & Seq & $\mathrm{HE}$ & C & Seq & HE & C \\
\hline $\mathrm{N} 2$ & 0.501 & 5 & N80 & 0.613 & 1 & $\mathrm{~N} 42$ & 0.624 & 1 & N89 & 0.650 & 2 \\
\hline N70 & 0.516 & 5 & N68 & 0.614 & 1 & N45 & 0.624 & 1 & N90 & 0.650 & 2 \\
\hline N69 & 0.516 & 5 & $\mathrm{~N} 4$ & 0.618 & 1 & $\mathrm{~N} 47$ & 0.624 & 1 & N91 & 0.650 & 2 \\
\hline N71 & 0.516 & 5 & N7 & 0.622 & 1 & $\mathrm{~N} 48$ & 0.624 & 1 & N93 & 0.650 & 2 \\
\hline N72 & 0.516 & 5 & $\mathrm{~N} 43$ & 0.622 & 1 & N49 & 0.624 & 1 & N94 & 0.650 & 2 \\
\hline N73 & 0.516 & 5 & $\mathrm{~N} 12$ & 0.623 & 1 & N50 & 0.624 & 1 & N95 & 0.650 & 2 \\
\hline N74 & 0.516 & 5 & N13 & 0.623 & 1 & N51 & 0.624 & 1 & N15 & 0.652 & 2 \\
\hline N76 & 0.516 & 5 & N14 & 0.624 & 1 & N52 & 0.624 & 1 & N98 & 0.654 & 2 \\
\hline N77 & 0.516 & 5 & N16 & 0.624 & 1 & N53 & 0.624 & 1 & N9 & 0.657 & 2 \\
\hline N78 & 0.516 & 5 & N17 & 0.624 & 1 & N54 & 0.624 & 1 & N10 & 0.657 & 2 \\
\hline N79 & 0.516 & 5 & N18 & 0.624 & 1 & N55 & 0.624 & 1 & N11 & 0.657 & 2 \\
\hline N75 & 0.525 & 5 & N19 & 0.624 & 1 & N56 & 0.624 & 1 & N101 & 0.657 & 2 \\
\hline N5 & 0.530 & 5 & $\mathrm{~N} 20$ & 0.624 & 1 & N57 & 0.624 & 1 & N99 & 0.664 & 2 \\
\hline N82 & 0.552 & 3 & $\mathrm{~N} 21$ & 0.624 & 1 & N59 & 0.624 & 1 & N105 & 0.678 & 4 \\
\hline N83 & 0.552 & 3 & $\mathrm{~N} 22$ & 0.624 & 1 & N60 & 0.624 & 1 & N8 & 0.692 & 4 \\
\hline N84 & 0.552 & 3 & N23 & 0.624 & 1 & N61 & 0.624 & 1 & & & \\
\hline N85 & 0.552 & 3 & $\mathrm{~N} 24$ & 0.624 & 1 & $\mathrm{~N} 62$ & 0.624 & 1 & & & \\
\hline N86 & 0.552 & 3 & N25 & 0.624 & 1 & N63 & 0.624 & 1 & & & \\
\hline N6 & 0.560 & 3 & $\mathrm{~N} 27$ & 0.624 & 1 & N64 & 0.624 & 1 & & & \\
\hline N32 & 0.560 & 3 & $\mathrm{~N} 28$ & 0.624 & 1 & N65 & 0.624 & 1 & & & \\
\hline N36 & 0.560 & 3 & N30 & 0.624 & 1 & $\mathrm{~N} 26$ & 0.624 & 1 & & & \\
\hline N58 & 0.560 & 3 & N31 & 0.624 & 1 & $\mathrm{~N} 44$ & 0.624 & 1 & & & \\
\hline N1 & 0.561 & 3 & N33 & 0.624 & 1 & N46 & 0.625 & 1 & & & \\
\hline N103 & 0.562 & 3 & N34 & 0.624 & 1 & $\mathrm{~N} 29$ & 0.625 & 1 & & & \\
\hline N104 & 0.578 & 3 & N35 & 0.624 & 1 & N66 & 0.625 & 1 & & & \\
\hline N81 & 0.582 & 3 & N37 & 0.624 & 1 & N67 & 0.625 & 1 & & & \\
\hline N102 & 0.584 & 3 & N38 & 0.624 & 1 & N100 & 0.626 & 1 & & & \\
\hline N3 & 0.590 & 3 & N39 & 0.624 & 1 & N87 & 0.629 & 1 & & & \\
\hline N96 & 0.594 & 1 & $\mathrm{~N} 40$ & 0.624 & 1 & N92 & 0.640 & 2 & & & \\
\hline N97 & 0.594 & 1 & N41 & 0.624 & 1 & N88 & 0.650 & 2 & & & \\
\hline
\end{tabular}

The spatial distribution $B_{17_{2}}$ of the amino acid D over the protein sequence 
$\mathrm{N} 2$ is random since the $\mathrm{HE}$ of $B_{17_{2}}$ is turned out to be 0.501 . The largest cluster 1 contains 60 protein sequences where the amino acid $\mathrm{D}$ is spread with positive trend as shown in the Table 18.

\subsection{Hurst Exponent of $B_{18_{j}}$ for $j=1,2, \ldots 105$ and Classification}

For the amino acid $A_{18}(E)$ the HE for the 105 binary sequences $B_{18_{j}}$ for $j=1,2, \ldots 105$ have been determined. The plot of the HE for the binary sequences has been plotted and corresponding histogram is also given in the Fig 18. The HE of the binary representations of ordering of the amino acid $A_{18}$ over all the primary protein sequences would reveal the autocorrelation of the amino acid.

Here the HE of the 105 binary representation of the amino acid $A_{18}$ is ranging from 0.525 to 0.724. Based on the HEs of the binary sequences all these 105 primary protein sequences of SARS-CoV2, eight clustered (C) are formed as presented in the Table 19.
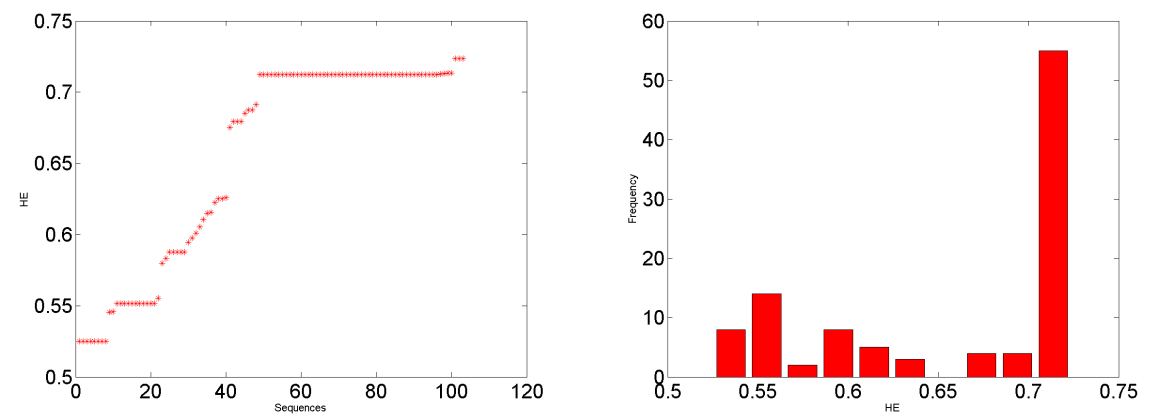

Figure 18: Plot of the HEs and corresponding histogram of all the binary sequences $B_{18_{j}}$ for $j=1,2, \ldots 105$ corresponding to the amino acid $A_{18}(E)$.

There are 48 sequences in the cluster 1 where corresponding spatial distributions $B_{18_{j}}$ of are positively trending with HE 0.712 exactly. Such a organized trend is certainly noteworthy. it is noted that, the non-essential amino acid $\mathrm{E}$ does not appear in the protein sequences N80 and N99. 
Table 19: HE of $105 B_{18_{j}}$ for $j=1,2, \ldots 105$ corresponding to the amino acid $A_{18}(E)$.

\begin{tabular}{|c|c|c|c|c|c|c|c|c|c|c|c|}
\hline Seq & HE & C & Seq & $\mathrm{HE}$ & C & Seq & HE & C & Seq & HE & C \\
\hline N80 & * & 3 & N86 & 0.588 & 8 & N25 & 0.712 & 1 & N60 & 0.712 & 1 \\
\hline N99 & $*$ & 3 & N105 & 0.595 & 8 & $\mathrm{~N} 27$ & 0.712 & 1 & N61 & 0.712 & 1 \\
\hline N88 & 0.525 & 4 & $\mathrm{~N} 102$ & 0.597 & 8 & $\mathrm{~N} 28$ & 0.712 & 1 & N62 & 0.712 & 1 \\
\hline N89 & 0.525 & 4 & $\mathrm{~N} 6$ & 0.601 & 2 & $\mathrm{~N} 29$ & 0.712 & 1 & N63 & 0.712 & 1 \\
\hline N90 & 0.525 & 4 & N8 & 0.606 & 2 & N30 & 0.712 & 1 & N64 & 0.712 & 1 \\
\hline N91 & 0.525 & 4 & N103 & 0.610 & 2 & N31 & 0.712 & 1 & N65 & 0.712 & 1 \\
\hline N92 & 0.525 & 4 & N98 & 0.615 & 2 & N33 & 0.712 & 1 & N67 & 0.712 & 1 \\
\hline N93 & 0.525 & 4 & N104 & 0.616 & 2 & N34 & 0.712 & 1 & N26 & 0.712 & 1 \\
\hline N94 & 0.525 & 4 & N7 & 0.622 & 6 & N35 & 0.712 & 1 & $\mathrm{~N} 13$ & 0.713 & 1 \\
\hline N95 & 0.525 & 4 & N5 & 0.625 & 6 & N37 & 0.712 & 1 & $\mathrm{~N} 12$ & 0.713 & 1 \\
\hline N1 & 0.545 & 7 & N3 & 0.625 & 6 & N38 & 0.712 & 1 & N14 & 0.713 & 1 \\
\hline N15 & 0.546 & 7 & N87 & 0.626 & 6 & N39 & 0.712 & 1 & N66 & 0.713 & 1 \\
\hline N70 & 0.551 & 7 & N81 & 0.675 & 5 & $\mathrm{~N} 40$ & 0.712 & 1 & N32 & 0.724 & 1 \\
\hline N69 & 0.552 & 7 & N9 & 0.679 & 5 & $\mathrm{~N} 41$ & 0.712 & 1 & N36 & 0.724 & 1 \\
\hline N71 & 0.552 & 7 & N10 & 0.679 & 5 & $\mathrm{~N} 42$ & 0.712 & 1 & N58 & 0.724 & 1 \\
\hline N72 & 0.552 & 7 & N11 & 0.679 & 5 & $\mathrm{~N} 43$ & 0.712 & 1 & & & \\
\hline N73 & 0.552 & 7 & N68 & 0.685 & 5 & N45 & 0.712 & 1 & & & \\
\hline N74 & 0.552 & 7 & N96 & 0.688 & 5 & $\mathrm{~N} 46$ & 0.712 & 1 & & & \\
\hline N75 & 0.552 & 7 & N97 & 0.688 & 5 & $\mathrm{~N} 47$ & 0.712 & 1 & & & \\
\hline N76 & 0.552 & 7 & $\mathrm{~N} 4$ & 0.691 & 5 & $\mathrm{~N} 48$ & 0.712 & 1 & & & \\
\hline N77 & 0.552 & 7 & N44 & 0.712 & 1 & N49 & 0.712 & 1 & & & \\
\hline N78 & 0.552 & 7 & N16 & 0.712 & 1 & N50 & 0.712 & 1 & & & \\
\hline N79 & 0.552 & 7 & $\mathrm{~N} 17$ & 0.712 & 1 & N51 & 0.712 & 1 & & & \\
\hline N101 & 0.555 & 7 & $\mathrm{~N} 18$ & 0.712 & 1 & N52 & 0.712 & 1 & & & \\
\hline N2 & 0.580 & 8 & N19 & 0.712 & 1 & N53 & 0.712 & 1 & & & \\
\hline N100 & 0.583 & 8 & $\mathrm{~N} 20$ & 0.712 & 1 & N54 & 0.712 & 1 & & & \\
\hline N82 & 0.588 & 8 & $\mathrm{~N} 21$ & 0.712 & 1 & N55 & 0.712 & 1 & & & \\
\hline N83 & 0.588 & 8 & $\mathrm{~N} 22$ & 0.712 & 1 & N56 & 0.712 & 1 & & & \\
\hline N84 & 0.588 & 8 & $\mathrm{~N} 23$ & 0.712 & 1 & N57 & 0.712 & 1 & & & \\
\hline N85 & 0.588 & 8 & $\mathrm{~N} 24$ & 0.712 & 1 & N59 & 0.712 & 1 & & & \\
\hline
\end{tabular}

465

\subsection{Hurst Exponent of $B_{19_{j}}$ for $j=1,2, \ldots 105$ and Classification}

For the amino acid $A_{19}(K)$ the HE for the 105 binary sequences $B_{19_{j}}$ for $j=1,2, \ldots 105$ have been determined. The plot of the HE for the binary sequences has been plotted and corresponding histogram is also given in the Fig 19. The HE of the binary representations of ordering of the amino acid $A_{19}$ over all the primary protein sequences would reveal the autocorrelation of the amino acid.

Here the $\mathrm{HE}$ of the 105 binary representation of the amino acid $A_{19}$ is ranging from 0.483 to 0.695 with standard deviation 0.111. Based on the HEs of the binary sequences all these 105 primary protein sequences of SARS-CoV2, eight 475 clustered (C) are formed as presented in the Table 20. 

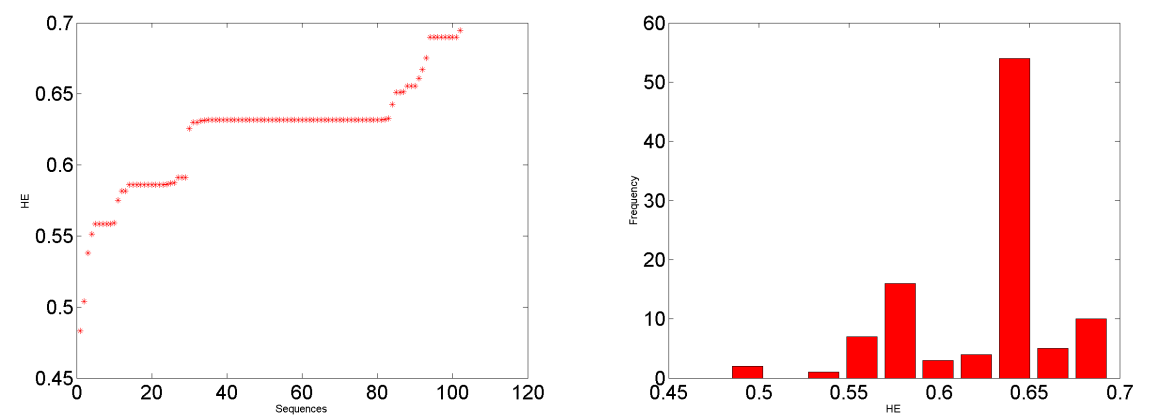

Figure 19: Plot of the HEs and corresponding histogram of all the binary sequences $B_{19_{j}}$ for $j=1,2, \ldots 105$ corresponding to the amino acid $A_{19}(K)$.

Table 20: HE of $105 B_{19_{j}}$ for $j=1,2, \ldots 105$ corresponding to the amino acid $A_{19}(K)$.

\begin{tabular}{|c|c|c|c|c|c|c|c|c|c|c|c|}
\hline Seq & $\mathrm{HE}$ & C & Seq & HE & C & Seq & HE & C & Seq & HE & C \\
\hline N80 & $*$ & 2 & N10 & 0.591 & 8 & N41 & 0.632 & 3 & N32 & 0.655 & 7 \\
\hline N81 & $*$ & 2 & N11 & 0.591 & 8 & $\mathrm{~N} 42$ & 0.632 & 3 & N36 & 0.655 & 7 \\
\hline N99 & $*$ & 2 & $\mathrm{~N} 4$ & 0.626 & 3 & $\mathrm{~N} 43$ & 0.632 & 3 & N58 & 0.655 & 7 \\
\hline N103 & 0.483 & 6 & N54 & 0.630 & 3 & $\mathrm{~N} 45$ & 0.632 & 3 & N98 & 0.661 & 7 \\
\hline N104 & 0.504 & 6 & N57 & 0.630 & 3 & $\mathrm{~N} 46$ & 0.632 & 3 & N101 & 0.667 & 5 \\
\hline N100 & 0.538 & 1 & $\mathrm{~N} 12$ & 0.631 & 3 & N47 & 0.632 & 3 & N7 & 0.675 & 5 \\
\hline N5 & 0.551 & 1 & N26 & 0.631 & 3 & $\mathrm{~N} 48$ & 0.632 & 3 & N88 & 0.690 & 4 \\
\hline N82 & 0.558 & 1 & N14 & 0.632 & 3 & N49 & 0.632 & 3 & N89 & 0.690 & 4 \\
\hline N83 & 0.558 & 1 & N16 & 0.632 & 3 & N50 & 0.632 & 3 & N90 & 0.690 & 4 \\
\hline N84 & 0.558 & 1 & N17 & 0.632 & 3 & N51 & 0.632 & 3 & N91 & 0.690 & 4 \\
\hline N85 & 0.558 & 1 & N18 & 0.632 & 3 & N52 & 0.632 & 3 & N92 & 0.690 & 4 \\
\hline N86 & 0.558 & 1 & N19 & 0.632 & 3 & N53 & 0.632 & 3 & N93 & 0.690 & 4 \\
\hline N6 & 0.559 & 1 & $\mathrm{~N} 20$ & 0.632 & 3 & N55 & 0.632 & 3 & N94 & 0.690 & 4 \\
\hline N15 & 0.575 & 8 & $\mathrm{~N} 21$ & 0.632 & 3 & N56 & 0.632 & 3 & N95 & 0.690 & 4 \\
\hline N105 & 0.582 & 8 & $\mathrm{~N} 22$ & 0.632 & 3 & N59 & 0.632 & 3 & N3 & 0.695 & 4 \\
\hline N1 & 0.582 & 8 & $\mathrm{~N} 23$ & 0.632 & 3 & N60 & 0.632 & 3 & & & \\
\hline N69 & 0.586 & 8 & $\mathrm{~N} 24$ & 0.632 & 3 & N61 & 0.632 & 3 & & & \\
\hline N71 & 0.586 & 8 & $\mathrm{~N} 25$ & 0.632 & 3 & N62 & 0.632 & 3 & & & \\
\hline N72 & 0.586 & 8 & $\mathrm{~N} 27$ & 0.632 & 3 & N63 & 0.632 & 3 & & & \\
\hline N73 & 0.586 & 8 & $\mathrm{~N} 28$ & 0.632 & 3 & N64 & 0.632 & 3 & & & \\
\hline N74 & 0.586 & 8 & N29 & 0.632 & 3 & N65 & 0.632 & 3 & & & \\
\hline N75 & 0.586 & 8 & N30 & 0.632 & 3 & N66 & 0.632 & 3 & & & \\
\hline N76 & 0.586 & 8 & N31 & 0.632 & 3 & N67 & 0.632 & 3 & & & \\
\hline N77 & 0.586 & 8 & N33 & 0.632 & 3 & N44 & 0.632 & 3 & & & \\
\hline N78 & 0.586 & 8 & N34 & 0.632 & 3 & $\mathrm{~N} 13$ & 0.632 & 3 & & & \\
\hline N79 & 0.586 & 8 & N35 & 0.632 & 3 & $\mathrm{~N} 102$ & 0.633 & 3 & & & \\
\hline N70 & 0.586 & 8 & N37 & 0.632 & 3 & N8 & 0.643 & 3 & & & \\
\hline N87 & 0.587 & 8 & N38 & 0.632 & 3 & N96 & 0.651 & 7 & & & \\
\hline $\mathrm{N} 2$ & 0.587 & 8 & N39 & 0.632 & 3 & N97 & 0.651 & 7 & & & \\
\hline N9 & 0.591 & 8 & $\mathrm{~N} 40$ & 0.632 & 3 & N68 & 0.652 & 7 & & & \\
\hline
\end{tabular}

The protein sequences N80, N81 and N99 are free from one of the amino 
acid $\mathrm{K}$. The spatial organization of the amino acid $\mathrm{K}$ over the protein sequence N103 is negatively trending as it's HE $0.483<0.5$. There 58 protein sequences in the cluster 3 where the amino acid $\mathrm{K}$ is spatially distributed with positive trend as shown in the the Table 20. It is noted that the spatial distribution $B_{19_{104}}$ is random as the HE of N104 is turned out to be 0.5 .

\subsection{Hurst Exponent of $B_{20_{j}}$ for $j=1,2, \ldots 105$ and Classification}

For the amino acid $A_{19}(R)$ the HE for the 105 binary sequences $B_{20_{j}}$ for $j=1,2, \ldots 105$ have been determined. The plot of the HE for the binary sequences has been plotted and corresponding histogram is also given in the Fig 20. The HE of the binary representations of ordering of the amino acid $A_{20}$ over all the primary protein sequences would reveal the autocorrelation of the amino acid.

Here the $\mathrm{HE}$ of the 105 binary representation of the amino acid $A_{20}$ is ranging from 0.498 to 0.697 with standard deviation 0.0904. Based on the HEs of the binary sequences all these 105 primary protein sequences of SARS-CoV2, eight clustered (C) are formed as presented in the Table 21.
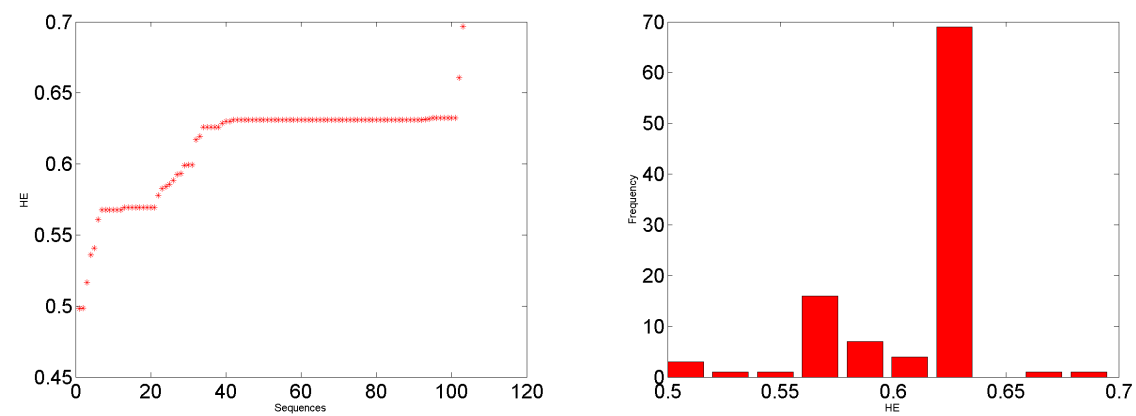

Figure 20: Plot of the HEs and corresponding histogram of all the binary sequences $B_{20_{j}}$ for $j=1,2, \ldots 105$ corresponding to the amino acid $A_{20}(R)$. 
Table 21: HE of $105 B_{20_{j}}$ for $j=1,2, \ldots 105$ corresponding to the amino acid $A_{20}(R)$.

\begin{tabular}{|c|c|c|c|c|c|c|c|c|c|c|c|}
\hline Seq & HE & C & Seq & $\mathrm{HE}$ & C & Seq & $\mathrm{HE}$ & C & Seq & $\mathrm{HE}$ & C \\
\hline N81 & $*$ & 3 & N68 & 0.599 & 7 & N34 & 0.631 & 1 & N32 & 0.631 & 1 \\
\hline N99 & $*$ & 3 & N96 & 0.599 & 7 & N35 & 0.631 & 1 & N36 & 0.631 & 1 \\
\hline N98 & 0.498 & 4 & N97 & 0.599 & 7 & N37 & 0.631 & 1 & N58 & 0.631 & 1 \\
\hline N102 & 0.498 & 4 & N87 & 0.617 & 1 & N38 & 0.631 & 1 & $\mathrm{~N} 13$ & 0.631 & 1 \\
\hline N100 & 0.517 & 4 & N104 & 0.620 & 1 & $\mathrm{~N} 40$ & 0.631 & 1 & N12 & 0.631 & 1 \\
\hline N15 & 0.536 & 2 & N105 & 0.626 & 1 & $\mathrm{~N} 41$ & 0.631 & 1 & N54 & 0.632 & 1 \\
\hline $\mathrm{N} 2$ & 0.541 & 2 & N9 & 0.626 & 1 & $\mathrm{~N} 42$ & 0.631 & 1 & N88 & 0.632 & 1 \\
\hline N70 & 0.561 & 2 & N10 & 0.626 & 1 & $\mathrm{~N} 43$ & 0.631 & 1 & N89 & 0.632 & 1 \\
\hline N82 & 0.568 & 2 & $\mathrm{~N} 11$ & 0.626 & 1 & N45 & 0.631 & 1 & N90 & 0.632 & 1 \\
\hline N83 & 0.568 & 2 & N95 & 0.626 & 1 & $\mathrm{~N} 46$ & 0.631 & 1 & N91 & 0.632 & 1 \\
\hline N84 & 0.568 & 2 & N8 & 0.629 & 1 & $\mathrm{~N} 47$ & 0.631 & 1 & N92 & 0.632 & 1 \\
\hline N85 & 0.568 & 2 & N31 & 0.630 & 1 & $\mathrm{~N} 48$ & 0.631 & 1 & N93 & 0.632 & 1 \\
\hline N86 & 0.568 & 2 & N39 & 0.630 & 1 & $\mathrm{~N} 49$ & 0.631 & 1 & N94 & 0.632 & 1 \\
\hline N6 & 0.568 & 2 & N26 & 0.631 & 1 & N50 & 0.631 & 1 & N3 & 0.661 & 6 \\
\hline N69 & 0.570 & 2 & N14 & 0.631 & 1 & N51 & 0.631 & 1 & N80 & 0.697 & 5 \\
\hline N72 & 0.570 & 2 & N16 & 0.631 & 1 & N52 & 0.631 & 1 & & & \\
\hline N73 & 0.570 & 2 & $\mathrm{~N} 17$ & 0.631 & 1 & N53 & 0.631 & 1 & & & \\
\hline N74 & 0.570 & 2 & N18 & 0.631 & 1 & N55 & 0.631 & 1 & & & \\
\hline N75 & 0.570 & 2 & N19 & 0.631 & 1 & N56 & 0.631 & 1 & & & \\
\hline N76 & 0.570 & 2 & N20 & 0.631 & 1 & N57 & 0.631 & 1 & & & \\
\hline N77 & 0.570 & 2 & N21 & 0.631 & 1 & N59 & 0.631 & 1 & & & \\
\hline N78 & 0.570 & 2 & $\mathrm{~N} 22$ & 0.631 & 1 & N60 & 0.631 & 1 & & & \\
\hline N79 & 0.570 & 2 & $\mathrm{~N} 23$ & 0.631 & 1 & N61 & 0.631 & 1 & & & \\
\hline N71 & 0.578 & 8 & $\mathrm{~N} 24$ & 0.631 & 1 & N62 & 0.631 & 1 & & & \\
\hline N101 & 0.583 & 8 & $\mathrm{~N} 25$ & 0.631 & 1 & N63 & 0.631 & 1 & & & \\
\hline N4 & 0.584 & 8 & $\mathrm{~N} 27$ & 0.631 & 1 & N64 & 0.631 & 1 & & & \\
\hline N1 & 0.586 & 8 & N28 & 0.631 & 1 & N65 & 0.631 & 1 & & & \\
\hline N103 & 0.588 & 8 & N29 & 0.631 & 1 & N66 & 0.631 & 1 & & & \\
\hline N7 & 0.592 & 7 & N30 & 0.631 & 1 & N67 & 0.631 & 1 & & & \\
\hline N5 & 0.593 & 7 & N33 & 0.631 & 1 & $\mathrm{~N} 44$ & 0.631 & 1 & & & \\
\hline
\end{tabular}

The conditionally essential amino acid $\mathrm{R}$ is not at all present in the protein sequences N81 and N99 and consequently the HE is not enumerable. There are two sequences N98 and N102 having positive trending spatial representation of the amino acid $\mathrm{R}$. The cluster 1 contains 70 protein sequences where the amino acid $\mathrm{R}$ is positively trended, spatially.As usual there other clusters containing positive autocorrelated spatial representations of the amino acid $R$.

\subsection{A Collective Views of the HEs}

Following we have listed the protein sequences of different lengths ranging from 13 to 419, which does not contain some amino acid(s) as listed in the following Table 22 . 
Table 22: Absence of amino acids on various SARS-CoV2 proteins

\begin{tabular}{ccc}
\hline Amino Acids: Absent & Types & Sequences \\
\hline C & Hydroxyl, Conditionally Essential & N68, N88, N89, N90,... N95, N99 \\
G & Aliphatic, Conditionally Essential & N68, N81 \\
H & Basic, Essential & N3, N80, N97, N98, N99 \\
I & Aliphatic, Essential & N99 \\
M & Hydroxyl, Essential & N99 \\
P & Cyclic, Conditionally Essential & N81, N99, N103 \\
Q & Acidic, Conditionally Essential & N96, N97 \\
T & Hydroxyl, Essential & N99 \\
W & Aromatic, Essential & N80, N87, N96, N97, N99 \\
Y & Aromatic, Conditionally Essential & N99, N103 \\
E & Aromatic, Non Essential & N80, N99 \\
K & Basic, Essential & $\mathrm{N} 80, \mathrm{~N} 81, \mathrm{~N} 99$ \\
R & Basic, Conditionally Essential & $\mathrm{N} 81, \mathrm{~N} 99$ \\
\hline
\end{tabular}

The protein sequence N99 of length 13 does not contains the amino acids C, H, M, P, T, W, Y, E, K and R which are of different types of essential, conditionally essential as well as non essential. The largest sequences N88, N89, N90, N91, N92, N93, N94, N95 of length 419 do not contain the amino acid C. It is noted that the amino acid M is present over all the proteins except N99 which of the smallest length 13. Also it is observed that the essential amino acids $\mathrm{L}, \mathrm{M}, \mathrm{F}$ and $\mathrm{V}$ are present in all the proteins of SARS-CoV2. The non essential amino acids $\mathrm{A}, \mathrm{D}, \mathrm{N}$ and $\mathrm{S}$ is also present in all the protein sequences. It is noted that all the six conditionally essential amino acids are not found essential for all the proteins of SARS-CoV2. Proteins that are of greater than 419 contains all the twenty amino acids. It is reported that the presence of the amino acid I, G including $\mathrm{V}$ is of primordial importance through in this study we found N99 which does not contain I, N68, N81 do not contain G.

It is found that the amino acid $\mathrm{H}$ is randomly spatially distributed over the proteins N5, N15, N88, N89, N90, N91, N92, N93, N94 and N95 as observed in the previous subsections. The essential, hydroxyl amino acid $\mathrm{M}$ is randomly arranged over the protein N80 and N102. Also the amino acid L is distributed over the protein N102 randomly. The only amino acid K which is randomly spread over the protein N104. There are other sequences N98 and N102 where the amino acid $\mathrm{R}$ is spread with negatively trend $(H E<0.5)$. Also the amino 
acid $\mathrm{K}, \mathrm{Y}, \mathrm{S}, \mathrm{Q}, \mathrm{N}$ and $\mathrm{F}$ are negatively trending over the protein sequences N103, N80, N7, N100, N2 and N5 respectively. Therefore the amino acid C, G, $\mathrm{P}, \mathrm{T}, \mathrm{W}$ and $\mathrm{E}$ is spread over all the 105 proteins with positive autocorrelation (positively trending).

Here we explore the correlation (of trending behaviours) of the distribution of the amino acids over 105 proteins of SARS-CoV2. Following is the correlation matrix of ten amino acids A, C, F, G, H, I, L, M, N and P versus another ten amino acids Q, S, T, V, W, Y, D, E, K and R.

Table 23: Correlation matrix of HEs

\begin{tabular}{|c|c|c|c|c|c|c|c|c|c|c|}
\hline & $\mathbf{Q}$ & $\mathbf{S}$ & $\mathbf{T}$ & $\mathbf{V}$ & $\mathbf{W}$ & $\mathbf{Y}$ & $\mathbf{D}$ & $\mathbf{E}$ & $\mathbf{K}$ & $\mathbf{R}$ \\
\hline $\mathbf{A}$ & 0.280 & -0.342 & 0.271 & 0.667 & 0.599 & 0.306 & -0.513 & -0.711 & -0.607 & -0.625 \\
\hline $\mathbf{C}$ & -0.434 & 0.067 & 0.385 & -0.239 & -0.101 & 0.657 & 0.062 & 0.223 & 0.308 & 0.246 \\
\hline $\mathbf{F}$ & 0.538 & 0.061 & -0.273 & 0.051 & 0.265 & -0.104 & 0.107 & 0.032 & 0.230 & 0.122 \\
\hline $\mathbf{G}$ & -0.376 & 0.407 & -0.126 & -0.453 & -0.439 & 0.130 & 0.598 & 0.780 & 0.660 & 0.702 \\
\hline $\mathbf{H}$ & 0.282 & -0.201 & -0.134 & -0.095 & 0.112 & 0.052 & -0.241 & -0.140 & 0.025 & 0.006 \\
\hline $\mathbf{I}$ & 0.027 & -0.374 & -0.142 & -0.278 & -0.292 & 0.218 & -0.066 & 0.155 & 0.279 & 0.339 \\
\hline $\mathbf{L}$ & 0.103 & 0.064 & 0.491 & 0.355 & 0.400 & 0.546 & 0.038 & -0.193 & -0.200 & -0.107 \\
\hline $\mathbf{M}$ & -0.096 & 0.034 & -0.053 & -0.333 & -0.204 & 0.443 & 0.300 & 0.281 & 0.389 & 0.504 \\
\hline $\mathbf{N}$ & 0.548 & 0.102 & 0.082 & 0.806 & 0.636 & 0.116 & -0.165 & -0.509 & -0.613 & -0.452 \\
\hline $\mathbf{P}$ & 0.163 & 0.385 & 0.262 & 0.376 & 0.240 & -0.091 & 0.103 & -0.097 & -0.296 & -0.088 \\
\hline
\end{tabular}

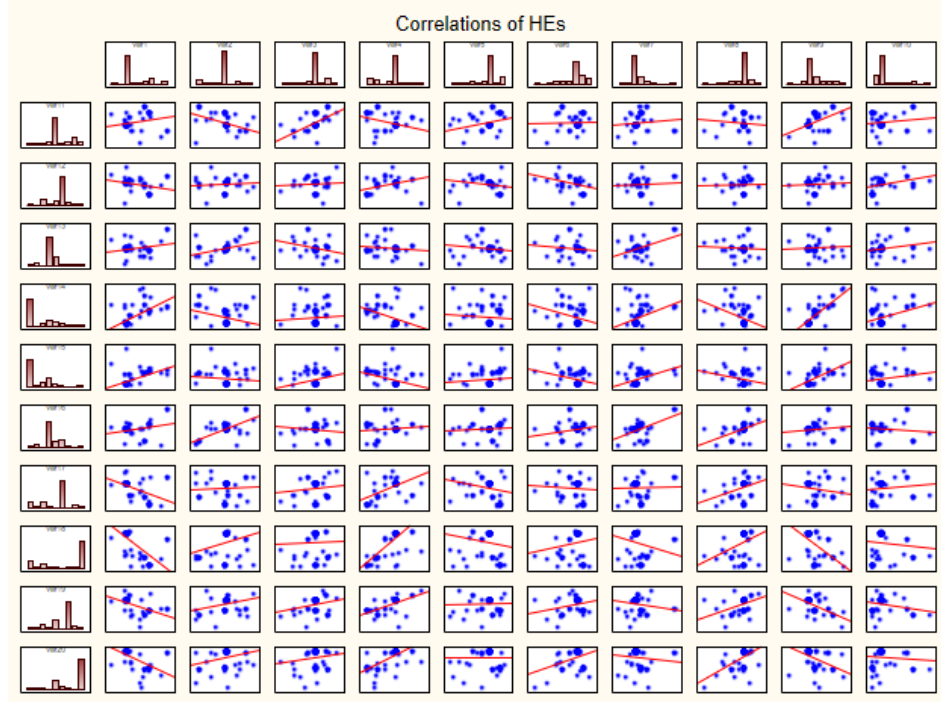

Figure 21: Plot of the correlation of the HEs of the amino acids distribution distinct pairwise. 
The spatial distribution of the amino acid A with the same of the amino acids Q, T, V, W, and Y are turned out to be positively correlated based on HEs as shown in the Table 23. Likewise, the the HEs of the spatial distribution of the amino acid $\mathrm{C}$ is positively correlated with the $\mathrm{S}, \mathrm{T}, \mathrm{Y}, \mathrm{D}, \mathrm{E}, \mathrm{K}$ and $\mathrm{R}$. Similarly, the positive correlations of the spatial distributions of the amino acids F, G, H, I, L, M, N and P with the spatial distribution of the other amino acids are established in the correlation matrix, Table 23. The correlation based on HEs of the spatial distribution is also shown through graphs in the Fig 21. It is worthy mentioning that in the correlation matrix in the Table 23, the negative correlations of the spatial distribution of the proteins are also shown.

As an example of the correlation (the correlation coefficient r: 0.443) of the spatial distribution (autocorrelation) of the amino acid $M$ with the spatial distribution of the amino acid $\mathrm{Y}$ is given below in the Fig. 22.

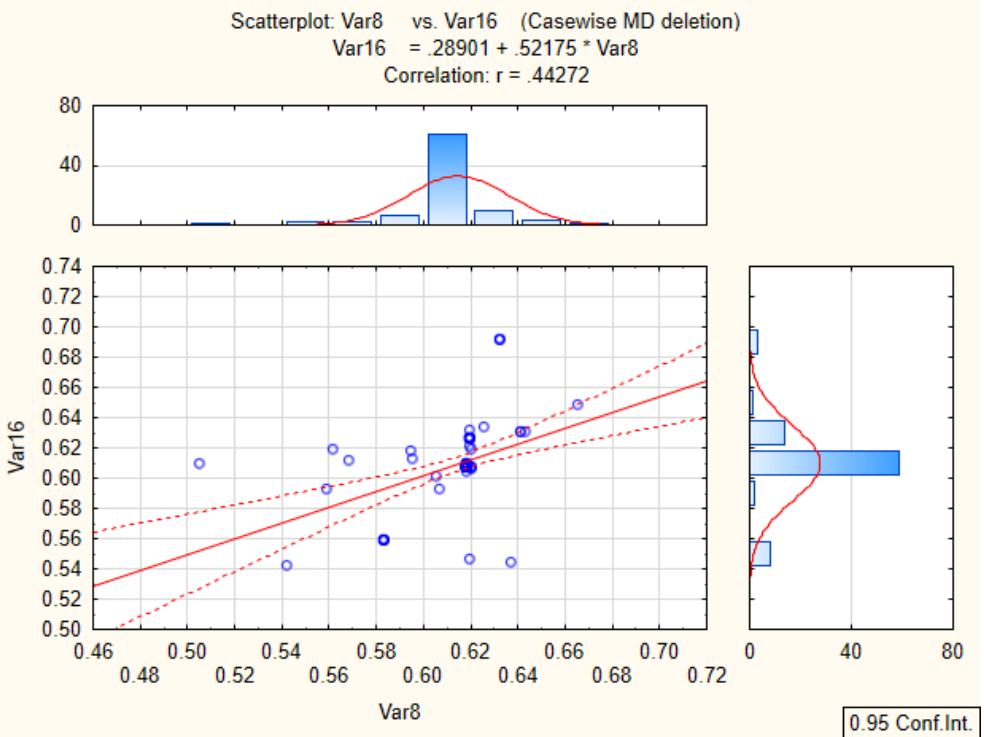

Figure 22: Plot of the correlation of the HEs of the amino acid M with that of $\mathrm{L}$.

Now we move on the amount of uncertainty/certainty of presence of amino acids over the protein sequences in the following subsections. 


\subsection{Shannon Entropy of $B_{1_{j}}$ for $j=1,2, \ldots 105$ and Classification}

For the amino acid $A_{1}(A)$ the Shannon Entropy (SE) for the 105 binary sequences $B_{1_{j}}$ for $j=1,2, \ldots 105$ have been determined. The plot of the SE for the binary sequences has been plotted and corresponding histogram is also given in the Fig 23. The SE of the binary representations of ordering of the amino acid $A_{1}$ over all the primary protein sequences would reveal the amount of uncertainty of the amino acid.
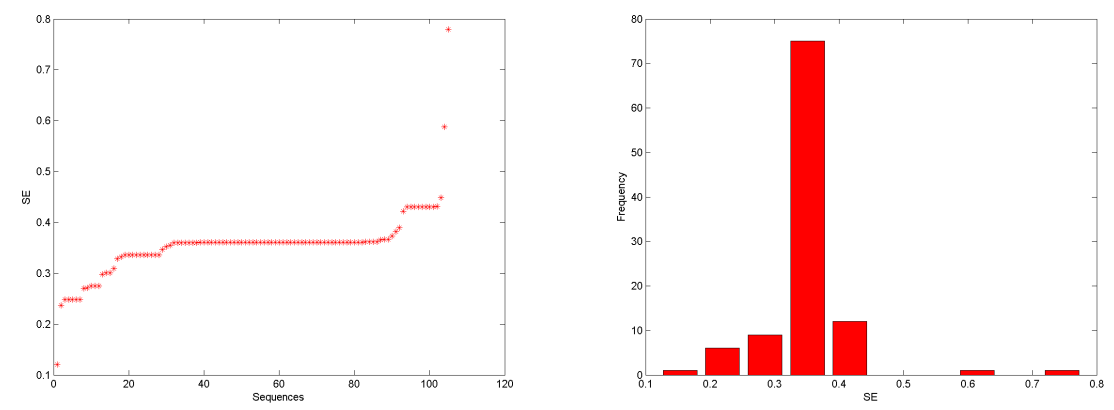

Figure 23: Plot of the SEs and corresponding histogram of all the binary sequences $B_{1_{j}}$ for $j=1,2, \ldots 105$ corresponding to the amino acid $A_{1}(A)$.

Here the SE of the 105 binary representation of the amino acid $A_{1}$ is ranging from 0.121 to 0.779 with standard deviation 0.0679. Based on the SEs of the binary sequences all these 105 primary protein sequences of SARS-CoV2, five clustered (C) are formed as presented in the Table 24.

It is found that the SE of the spatial distribution of amino acid $A_{1}$ in the protein sequence N68 is 0.121 which indicates the amount of uncertainly is lowest as compare to the others. The cluster 4 as well the the cluster 1 contains almost all the protein sequences where the SEs are less than 0.5 which says that the presence and absence over the protein sequences are mostly certain. Also amount of uncertainly is high for the proteins N3 and N99 of length 198 and 13 respectively. 
Table 24: SE of $105 B_{1_{j}}$ for $j=1,2, \ldots 105$ corresponding to the amino acid $A_{1}(A)$.

\begin{tabular}{|c|c|c|c|c|c|c|c|c|c|c|c|}
\hline Seq & $\mathrm{SE}$ & C & Seq & $\mathrm{SE}$ & C & Seq & $\mathrm{SE}$ & C & Seq & $\mathrm{SE}$ & C \\
\hline N68 & 0.121 & 3 & N105 & 0.355 & 1 & $\mathrm{~N} 42$ & 0.361 & 1 & N87 & 0.382 & 1 \\
\hline N15 & 0.237 & 4 & N20 & 0.360 & 1 & N45 & 0.361 & 1 & N5 & 0.390 & 1 \\
\hline $\mathrm{N} 82$ & 0.248 & 4 & $\mathrm{~N} 22$ & 0.360 & 1 & $\mathrm{~N} 46$ & 0.361 & 1 & N8 & 0.422 & 1 \\
\hline N 83 & 0.248 & 4 & $\mathrm{~N} 48$ & 0.360 & 1 & $\mathrm{~N} 47$ & 0.361 & 1 & N88 & 0.431 & 1 \\
\hline N84 & 0.248 & 4 & N50 & 0.360 & 1 & N49 & 0.361 & 1 & N89 & 0.431 & 1 \\
\hline N85 & 0.248 & 4 & N59 & 0.360 & 1 & N51 & 0.361 & 1 & N90 & 0.431 & 1 \\
\hline N 86 & 0.248 & 4 & $\mathrm{~N} 61$ & 0.360 & 1 & $\mathrm{~N} 52$ & 0.361 & 1 & N91 & 0.431 & 1 \\
\hline N104 & 0.270 & 4 & N65 & 0.360 & 1 & N53 & 0.361 & 1 & N92 & 0.431 & 1 \\
\hline N81 & 0.271 & 4 & $\mathrm{~N} 26$ & 0.361 & 1 & N54 & 0.361 & 1 & N93 & 0.431 & 1 \\
\hline N9 & 0.275 & 4 & N14 & 0.361 & 1 & N55 & 0.361 & 1 & N94 & 0.431 & 1 \\
\hline N10 & 0.275 & 4 & N16 & 0.361 & 1 & N56 & 0.361 & 1 & N95 & 0.431 & 1 \\
\hline N11 & 0.275 & 4 & N17 & 0.361 & 1 & N57 & 0.361 & 1 & N98 & 0.431 & 1 \\
\hline N80 & 0.297 & 4 & N18 & 0.361 & 1 & N60 & 0.361 & 1 & N2 & 0.448 & 1 \\
\hline N96 & 0.300 & 4 & N19 & 0.361 & 1 & $\mathrm{~N} 62$ & 0.361 & 1 & N3 & 0.588 & 5 \\
\hline N97 & 0.300 & 4 & $\mathrm{~N} 21$ & 0.361 & 1 & N63 & 0.361 & 1 & N99 & 0.779 & 2 \\
\hline N102 & 0.310 & 4 & $\mathrm{~N} 23$ & 0.361 & 1 & N64 & 0.361 & 1 & & & \\
\hline N103 & 0.328 & 1 & $\mathrm{~N} 24$ & 0.361 & 1 & N66 & 0.361 & 1 & & & \\
\hline N74 & 0.332 & 1 & $\mathrm{~N} 25$ & 0.361 & 1 & N67 & 0.361 & 1 & & & \\
\hline N69 & 0.336 & 1 & $\mathrm{~N} 27$ & 0.361 & 1 & N44 & 0.361 & 1 & & & \\
\hline N71 & 0.336 & 1 & N28 & 0.361 & 1 & N100 & 0.361 & 1 & & & \\
\hline N72 & 0.336 & 1 & N30 & 0.361 & 1 & N13 & 0.361 & 1 & & & \\
\hline N73 & 0.336 & 1 & N31 & 0.361 & 1 & N12 & 0.361 & 1 & & & \\
\hline N75 & 0.336 & 1 & N33 & 0.361 & 1 & N29 & 0.361 & 1 & & & \\
\hline N76 & 0.336 & 1 & N34 & 0.361 & 1 & N43 & 0.361 & 1 & & & \\
\hline N77 & 0.336 & 1 & N35 & 0.361 & 1 & N6 & 0.362 & 1 & & & \\
\hline N78 & 0.336 & 1 & N37 & 0.361 & 1 & N101 & 0.362 & 1 & & & \\
\hline N79 & 0.336 & 1 & N38 & 0.361 & 1 & N58 & 0.366 & 1 & & & \\
\hline N70 & 0.336 & 1 & N39 & 0.361 & 1 & N32 & 0.366 & 1 & & & \\
\hline N4 & 0.346 & 1 & N40 & 0.361 & 1 & N36 & 0.366 & 1 & & & \\
\hline N1 & 0.352 & 1 & N41 & 0.361 & 1 & N7 & 0.373 & 1 & & & \\
\hline
\end{tabular}

\subsection{Shannon Entropy of $B_{2_{j}}$ for $j=1,2, \ldots 105$ and Classification}

565 $j=1,2, \ldots 105$ have been determined. The plot of the SE for the binary sequences has been plotted and corresponding histogram is also given in the Fig 24. The SE of the binary representations of ordering of the amino acid $A_{2}$ over all the primary protein sequences would reveal the amount of uncertainty of the presence or absence of the amino acid. 

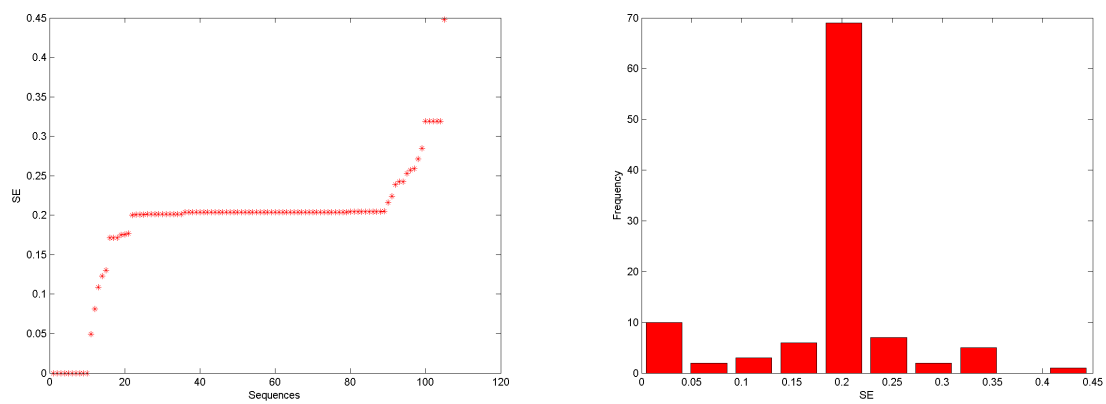

Figure 24: Plot of the SEs and corresponding histogram of all the binary sequences $B_{2}$ for $j=1,2, \ldots 105$ corresponding to the amino acid $A_{2}(C)$.

Here the SE of the 105 binary representation of the amino acid $A_{2}$ is ranging from 0 to 0.448 with standard deviation 0.0765. Based on the SEs of the binary sequences all these 105 primary protein sequences of SARS-CoV2, seven clusters (C) are formed as presented in the Table 25.

It is found that the $\mathrm{SE}$ of the spatial distribution of amino acid $A_{2}$ in the protein sequence N68, N88, N89, N90, N91, N92, N93, N94, N95 and N99 is zero which indicates the amount of uncertainly is zero i.e. the absolutely absence of the amino acid $A_{2}(C)$ over these proteins. The other clusters contains rest all protein sequences where the spatial presence of the amino acid over the protein sequences are having low uncertainly (high certainty) as shown in the Table 25. 
Table 25: SE of $105 B_{2_{j}}$ for $j=1,2, \ldots 105$ corresponding to the amino acid $A_{2}(C)$.

\begin{tabular}{|c|c|c|c|c|c|c|c|c|c|c|c|}
\hline Seq & $\mathrm{SE}$ & C & Seq & $\mathrm{SE}$ & C & Seq & $\mathrm{SE}$ & C & Seq & $\mathrm{SE}$ & C \\
\hline N68 & 0.000 & 1 & N76 & 0.201 & 4 & N51 & 0.204 & 4 & $\mathrm{~N} 103$ & 0.224 & 5 \\
\hline N88 & 0.000 & 1 & N77 & 0.201 & 4 & N52 & 0.204 & 4 & $\mathrm{~N} 102$ & 0.239 & 5 \\
\hline N89 & 0.000 & 1 & N78 & 0.201 & 4 & N53 & 0.204 & 4 & N96 & 0.242 & 5 \\
\hline N90 & 0.000 & 1 & N79 & 0.201 & 4 & N54 & 0.204 & 4 & N97 & 0.242 & 5 \\
\hline N91 & 0.000 & 1 & N70 & 0.202 & 4 & N55 & 0.204 & 4 & N6 & 0.253 & 5 \\
\hline N92 & 0.000 & 1 & $\mathrm{~N} 14$ & 0.204 & 4 & N56 & 0.204 & 4 & N5 & 0.257 & 5 \\
\hline N93 & 0.000 & 1 & N16 & 0.204 & 4 & N57 & 0.204 & 4 & N1 & 0.259 & 5 \\
\hline N94 & 0.000 & 1 & N17 & 0.204 & 4 & N59 & 0.204 & 4 & N81 & 0.271 & 5 \\
\hline N95 & 0.000 & 1 & N18 & 0.204 & 4 & N60 & 0.204 & 4 & N87 & 0.285 & 5 \\
\hline N99 & 0.000 & 1 & N19 & 0.204 & 4 & N61 & 0.204 & 4 & N82 & 0.319 & 6 \\
\hline N15 & 0.050 & 2 & $\mathrm{~N} 20$ & 0.204 & 4 & N62 & 0.204 & 4 & N83 & 0.319 & 6 \\
\hline N3 & 0.081 & 2 & N21 & 0.204 & 4 & N63 & 0.204 & 4 & N84 & 0.319 & 6 \\
\hline N104 & 0.109 & 3 & $\mathrm{~N} 23$ & 0.204 & 4 & N64 & 0.204 & 4 & N85 & 0.319 & 6 \\
\hline N105 & 0.123 & 3 & $\mathrm{~N} 24$ & 0.204 & 4 & N65 & 0.204 & 4 & N86 & 0.319 & 6 \\
\hline N8 & 0.130 & 3 & $\mathrm{~N} 27$ & 0.204 & 4 & N66 & 0.204 & 4 & $\mathrm{~N} 2$ & 0.448 & 7 \\
\hline N9 & 0.171 & 3 & $\mathrm{~N} 28$ & 0.204 & 4 & N67 & 0.204 & 4 & & & \\
\hline N10 & 0.171 & 3 & $\mathrm{~N} 29$ & 0.204 & 4 & $\mathrm{~N} 44$ & 0.204 & 4 & & & \\
\hline N11 & 0.171 & 3 & N30 & 0.204 & 4 & $\mathrm{~N} 13$ & 0.204 & 4 & & & \\
\hline N4 & 0.175 & 3 & N33 & 0.204 & 4 & N12 & 0.204 & 4 & & & \\
\hline N80 & 0.176 & 3 & N34 & 0.204 & 4 & $\mathrm{~N} 26$ & 0.204 & 4 & & & \\
\hline N98 & 0.177 & 3 & N35 & 0.204 & 4 & $\mathrm{~N} 22$ & 0.204 & 4 & & & \\
\hline N100 & 0.200 & 4 & N37 & 0.204 & 4 & $\mathrm{~N} 25$ & 0.204 & 4 & & & \\
\hline N32 & 0.201 & 4 & N38 & 0.204 & 4 & N31 & 0.204 & 4 & & & \\
\hline N36 & 0.201 & 4 & $\mathrm{~N} 43$ & 0.204 & 4 & N39 & 0.204 & 4 & & & \\
\hline N58 & 0.201 & 4 & N45 & 0.204 & 4 & N40 & 0.204 & 4 & & & \\
\hline N69 & 0.201 & 4 & $\mathrm{~N} 46$ & 0.204 & 4 & $\mathrm{~N} 41$ & 0.204 & 4 & & & \\
\hline N71 & 0.201 & 4 & $\mathrm{~N} 47$ & 0.204 & 4 & $\mathrm{~N} 42$ & 0.204 & 4 & & & \\
\hline N73 & 0.201 & 4 & N48 & 0.204 & 4 & N7 & 0.204 & 4 & & & \\
\hline N74 & 0.201 & 4 & N49 & 0.204 & 4 & N72 & 0.205 & 4 & & & \\
\hline N75 & 0.201 & 4 & N50 & 0.204 & 4 & N101 & 0.216 & 5 & & & \\
\hline
\end{tabular}

\subsection{Shannon Entropy of $B_{3_{j}}$ for $j=1,2, \ldots 105$ and Classification}

For the amino acid $A_{3}(F)$ the SE for the 105 binary sequences $B_{3_{j}}$ for $j=1,2, \ldots 105$ have been determined. The plot of the SE for the binary sequences has been plotted and corresponding histogram is also given in the Fig 25. The SE of the binary representations of ordering of the amino acid $A_{3}$ over all the primary protein sequences would reveal the amount of uncertainty of the presence or absence of the amino acid. 

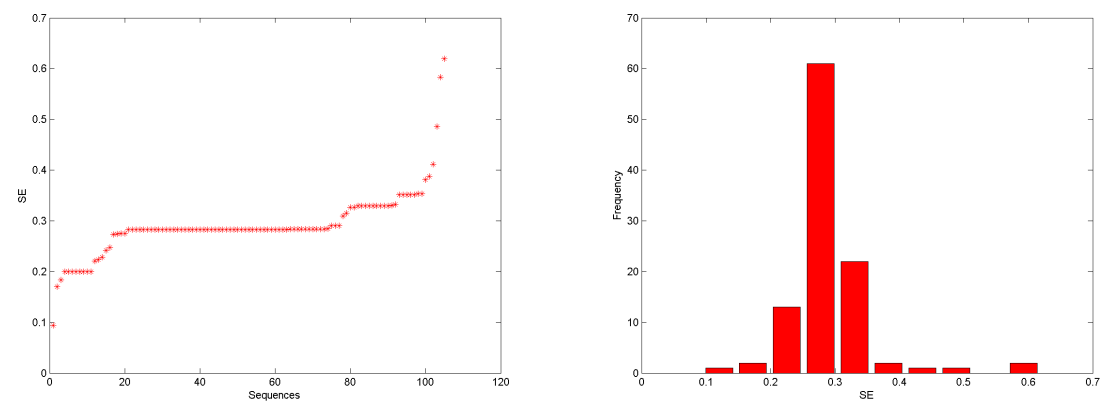

Figure 25: Plot of the SEs and corresponding histogram of all the binary sequences $B_{3_{j}}$ for $j=1,2, \ldots 105$ corresponding to the amino acid $A_{3}(F)$.

Table 26: SE of $105 B_{3}$ for $j=1,2, \ldots 105$ corresponding to the amino acid $A_{3}(F)$.

\begin{tabular}{|c|c|c|c|c|c|c|c|c|c|c|c|}
\hline Seq & $\mathrm{SE}$ & C & Seq & $\mathrm{SE}$ & C & Seq & $\mathrm{SE}$ & C & Seq & $\mathrm{SE}$ & C \\
\hline N103 & 0.094 & 4 & $\mathrm{~N} 21$ & 0.283 & 2 & N67 & 0.283 & 2 & N104 & 0.330 & 7 \\
\hline N3 & 0.170 & 5 & $\mathrm{~N} 23$ & 0.283 & 2 & $\mathrm{~N} 44$ & 0.283 & 2 & $\mathrm{~N} 100$ & 0.332 & 7 \\
\hline N15 & 0.183 & 5 & $\mathrm{~N} 25$ & 0.283 & 2 & $\mathrm{~N} 13$ & 0.283 & 2 & N82 & 0.351 & 7 \\
\hline N88 & 0.200 & 5 & $\mathrm{~N} 28$ & 0.283 & 2 & $\mathrm{~N} 20$ & 0.284 & 2 & N83 & 0.351 & 7 \\
\hline N89 & 0.200 & 5 & $\mathrm{~N} 29$ & 0.283 & 2 & $\mathrm{~N} 22$ & 0.284 & 2 & $\mathrm{~N} 84$ & 0.351 & 7 \\
\hline N90 & 0.200 & 5 & N30 & 0.283 & 2 & $\mathrm{~N} 24$ & 0.284 & 2 & N85 & 0.351 & 7 \\
\hline N91 & 0.200 & 5 & N31 & 0.283 & 2 & $\mathrm{~N} 27$ & 0.284 & 2 & N86 & 0.351 & 7 \\
\hline N92 & 0.200 & 5 & N35 & 0.283 & 2 & N33 & 0.284 & 2 & N96 & 0.353 & 7 \\
\hline N93 & 0.200 & 5 & N37 & 0.283 & 2 & N34 & 0.284 & 2 & N97 & 0.353 & 7 \\
\hline N94 & 0.200 & 5 & N38 & 0.283 & 2 & $\mathrm{~N} 40$ & 0.284 & 2 & N7 & 0.381 & 1 \\
\hline N95 & 0.200 & 5 & N39 & 0.283 & 2 & N59 & 0.284 & 2 & N101 & 0.387 & 1 \\
\hline N98 & 0.221 & 5 & N41 & 0.283 & 2 & $\mathrm{~N} 62$ & 0.284 & 2 & N87 & 0.411 & 1 \\
\hline N2 & 0.224 & 5 & N43 & 0.283 & 2 & $\mathrm{~N} 26$ & 0.284 & 2 & N80 & 0.485 & 6 \\
\hline N105 & 0.228 & 5 & N45 & 0.283 & 2 & N8 & 0.284 & 2 & N81 & 0.583 & 8 \\
\hline N5 & 0.242 & 5 & N46 & 0.283 & 2 & N9 & 0.290 & 2 & N99 & 0.619 & 3 \\
\hline $\mathrm{N} 4$ & 0.247 & 2 & $\mathrm{~N} 47$ & 0.283 & 2 & N10 & 0.290 & 2 & & & \\
\hline N6 & 0.274 & 2 & $\mathrm{~N} 48$ & 0.283 & 2 & N11 & 0.290 & 2 & & & \\
\hline N36 & 0.274 & 2 & N49 & 0.283 & 2 & $\mathrm{~N} 102$ & 0.310 & 7 & & & \\
\hline N32 & 0.275 & 2 & N50 & 0.283 & 2 & N1 & 0.315 & 7 & & & \\
\hline N58 & 0.275 & 2 & N52 & 0.283 & 2 & N72 & 0.326 & 7 & & & \\
\hline N42 & 0.282 & 2 & N53 & 0.283 & 2 & N78 & 0.326 & 7 & & & \\
\hline N51 & 0.282 & 2 & N54 & 0.283 & 2 & N69 & 0.329 & 7 & & & \\
\hline N60 & 0.282 & 2 & N55 & 0.283 & 2 & N71 & 0.329 & 7 & & & \\
\hline $\mathrm{N} 12$ & 0.283 & 2 & N56 & 0.283 & 2 & N73 & 0.329 & 7 & & & \\
\hline N68 & 0.283 & 2 & N57 & 0.283 & 2 & N74 & 0.329 & 7 & & & \\
\hline N 14 & 0.283 & 2 & N61 & 0.283 & 2 & N75 & 0.329 & 7 & & & \\
\hline N16 & 0.283 & 2 & N63 & 0.283 & 2 & N76 & 0.329 & 7 & & & \\
\hline N17 & 0.283 & 2 & N64 & 0.283 & 2 & N 77 & 0.329 & 7 & & & \\
\hline N18 & 0.283 & 2 & N65 & 0.283 & 2 & N79 & 0.329 & 7 & & & \\
\hline N19 & 0.283 & 2 & N66 & 0.283 & 2 & N70 & 0.330 & 7 & & & \\
\hline
\end{tabular}

Here the SE of the 105 binary representation of the amino acid $A_{3}$ is ranging 
from 0.094 to 0.619 with standard deviation 0.0667. Based on the SEs of the binary sequences all these 105 primary protein sequences of SARS-CoV2, seven clusters $(\mathrm{C})$ are formed as presented in the Table 26.

The $\mathrm{SE}$ is greater than 0.5 for the binary representations of the protein $A_{3}$ over the proteins N81 and N99 and consequently the amount of uncertainty is lowering. It is noted that these two sequences are very small in length. Other clusters as usual contains rest all protein sequences where the spatial presence of the amino acid $A_{3}$ over the protein sequences are having low uncertainly (high certainty) as shown in the Table 26.

\subsection{Shannon Entropy of $B_{4_{j}}$ for $j=1,2, \ldots 105$ and Classification}

For the amino acid $A_{4}(G)$ the SE for the 105 binary sequences $B_{4_{j}}$ for $j=1,2, \ldots 105$ have been determined. The plot of the SE for the binary sequences has been plotted and corresponding histogram is also given in the Fig 26. The SE of the binary representations of ordering of the amino acid $A_{4}$ over all the primary protein sequences would reveal the amount of uncertainty of the presence or absence of the amino acid.
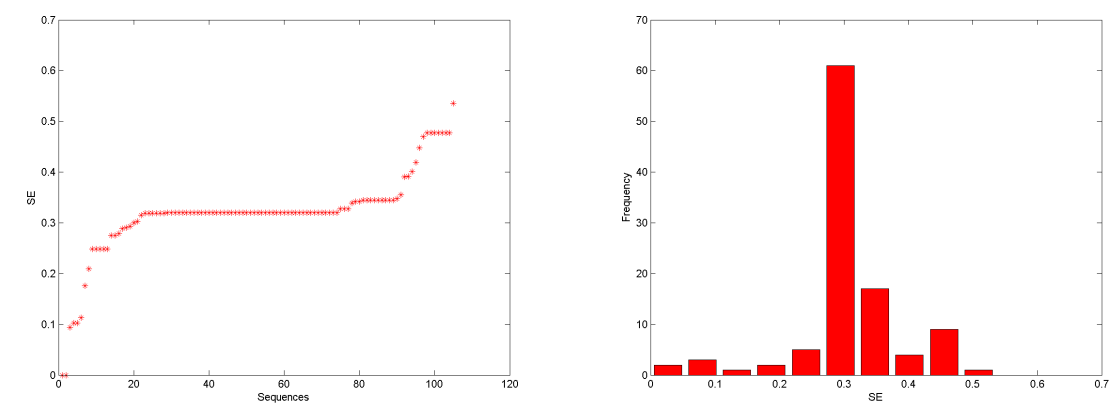

Figure 26: Plot of the SEs and corresponding histogram of all the binary sequences $B_{4_{j}}$ for $j=1,2, \ldots 105$ corresponding to the amino acid $A_{4}(G)$.

Here the SE of the 105 binary representation of the amino acid $A_{4}$ is ranging from 0 to 0.536 with standard deviation 0.0852. Based on the SEs of the binary 
sequences all these 105 primary protein sequences of SARS-CoV2, six clusters (C) are formed as presented in the Table 27.

Table 27: SE of $105 B_{4_{j}}$ for $j=1,2, \ldots 105$ corresponding to the amino acid $A_{4}(G)$.

\begin{tabular}{|c|c|c|c|c|c|c|c|c|c|c|c|}
\hline Seq & $\mathrm{SE}$ & C & Seq & $\mathrm{SE}$ & C & Seq & $\mathrm{SE}$ & C & Seq & $\mathrm{SE}$ & C \\
\hline N68 & 0.000 & 4 & N18 & 0.320 & 1 & N52 & 0.320 & 1 & N105 & 0.355 & 6 \\
\hline N81 & 0.000 & 4 & N19 & 0.320 & 1 & N55 & 0.320 & 1 & N6 & 0.391 & 5 \\
\hline $\mathrm{N} 103$ & 0.094 & 4 & $\mathrm{~N} 20$ & 0.320 & 1 & N56 & 0.320 & 1 & N99 & 0.391 & 5 \\
\hline N96 & 0.102 & 4 & N21 & 0.320 & 1 & N57 & 0.320 & 1 & N98 & 0.401 & 5 \\
\hline N97 & 0.102 & 4 & N22 & 0.320 & 1 & N59 & 0.320 & 1 & N102 & 0.419 & 5 \\
\hline N3 & 0.113 & 4 & N23 & 0.320 & 1 & N61 & 0.320 & 1 & N2 & 0.448 & 3 \\
\hline N80 & 0.176 & 4 & N24 & 0.320 & 1 & N62 & 0.320 & 1 & N95 & 0.470 & 3 \\
\hline N87 & 0.210 & 1 & N25 & 0.320 & 1 & N63 & 0.320 & 1 & N88 & 0.477 & 3 \\
\hline $\mathrm{N} 82$ & 0.248 & 1 & N27 & 0.320 & 1 & N64 & 0.320 & 1 & N89 & 0.477 & 3 \\
\hline N83 & 0.248 & 1 & N28 & 0.320 & 1 & N65 & 0.320 & 1 & N90 & 0.477 & 3 \\
\hline N84 & 0.248 & 1 & N29 & 0.320 & 1 & N66 & 0.320 & 1 & N91 & 0.477 & 3 \\
\hline N85 & 0.248 & 1 & N30 & 0.320 & 1 & N67 & 0.320 & 1 & N92 & 0.477 & 3 \\
\hline N86 & 0.248 & 1 & N31 & 0.320 & 1 & $\mathrm{~N} 44$ & 0.320 & 1 & N93 & 0.477 & 3 \\
\hline N9 & 0.275 & 1 & N33 & 0.320 & 1 & $\mathrm{~N} 26$ & 0.320 & 1 & N94 & 0.477 & 3 \\
\hline N11 & 0.275 & 1 & N34 & 0.320 & 1 & N32 & 0.327 & 6 & N15 & 0.536 & 2 \\
\hline N100 & 0.279 & 1 & N35 & 0.320 & 1 & N36 & 0.327 & 6 & & & \\
\hline N4 & 0.288 & 1 & N37 & 0.320 & 1 & N58 & 0.327 & 6 & & & \\
\hline N10 & 0.290 & 1 & N38 & 0.320 & 1 & N8 & 0.339 & 6 & & & \\
\hline N101 & 0.294 & 1 & N39 & 0.320 & 1 & N104 & 0.342 & 6 & & & \\
\hline N5 & 0.300 & 1 & N40 & 0.320 & 1 & N77 & 0.342 & 6 & & & \\
\hline N7 & 0.303 & 1 & N41 & 0.320 & 1 & N69 & 0.345 & 6 & & & \\
\hline N1 & 0.315 & 1 & N42 & 0.320 & 1 & N71 & 0.345 & 6 & & & \\
\hline $\mathrm{N} 14$ & 0.319 & 1 & $\mathrm{~N} 43$ & 0.320 & 1 & N72 & 0.345 & 6 & & & \\
\hline N53 & 0.319 & 1 & N45 & 0.320 & 1 & N73 & 0.345 & 6 & & & \\
\hline N54 & 0.319 & 1 & N46 & 0.320 & 1 & N74 & 0.345 & 6 & & & \\
\hline N60 & 0.319 & 1 & N 47 & 0.320 & 1 & N76 & 0.345 & 6 & & & \\
\hline $\mathrm{N} 13$ & 0.319 & 1 & N48 & 0.320 & 1 & N78 & 0.345 & 6 & & & \\
\hline $\mathrm{N} 12$ & 0.319 & 1 & N49 & 0.320 & 1 & N79 & 0.345 & 6 & & & \\
\hline N16 & 0.320 & 1 & N50 & 0.320 & 1 & N70 & 0.345 & 6 & & & \\
\hline $\mathrm{N} 17$ & 0.320 & 1 & N51 & 0.320 & 1 & N75 & 0.348 & 6 & & & \\
\hline
\end{tabular}

It is noted that the amino acid $A_{4}(G)$ does not present in the primary protein sequences of N68 and N81 and consequently the SE is turned up as zero saying that there is no uncertainty. In the cluster 4 there are other sequences N103, N96, N97, N3 and N80 having 0.0839 as the centre cluster 4 of the SEs and so the amount of uncertainty of presence of the amino acid $A_{4}(G)$ is low. All these sequences are smaller than 198 in length. The largest cluster 1 which contains most of the protein sequences where the the presence of the amino acid over the protein sequences is almost certain with $\mathrm{HE}$ at centre of the cluster 0.3088 . The other clusters also contains similar proteins where the amino acid $A_{3}$ is present 
with almost certainty.

\subsection{Shannon Entropy of $B_{5_{j}}$ for $j=1,2, \ldots 105$ and Classification}

For the amino acid $A_{5}(H)$ the SE for the 105 binary sequences $B_{5_{j}}$ for $j=1,2, \ldots 105$ have been determined. The plot of the SE for the binary sequences has been plotted and corresponding histogram is also given in the Fig 27. The SE of the binary representations of ordering of the amino acid $A_{5}$ over all the primary protein sequences would reveal the amount of uncertainty of the presence or absence of the amino acid.
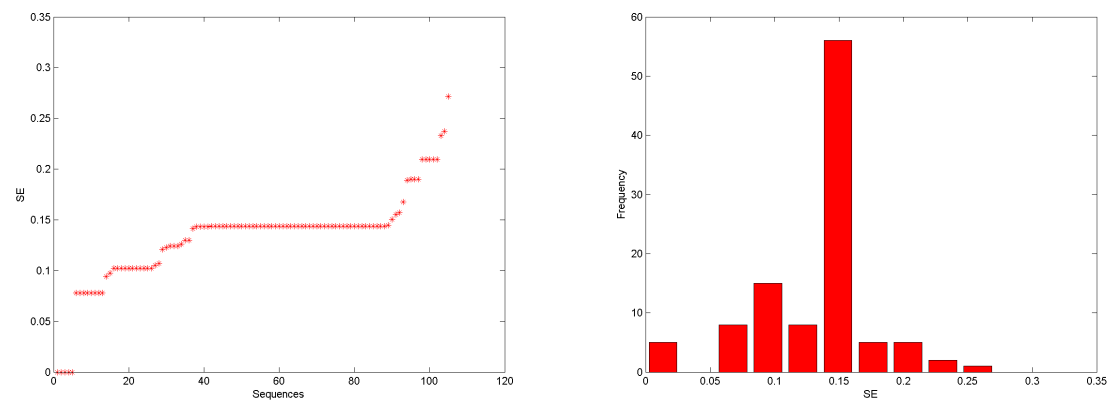

Figure 27: Plot of the SEs and corresponding histogram of all the binary sequences $B_{5_{j}}$ for $j=1,2, \ldots 105$ corresponding to the amino acid $A_{5}(H)$.

Here the SE of the 105 binary representation of the amino acid $A_{5}$ is ranging from 0 to 0.271 with standard deviation 0.0459. Based on the SEs of the binary sequences all these 105 primary protein sequences of SARS-CoV2, eight clusters (C) are formed as presented in the Table 28.

The amino acid $A_{5}(H)$ does not present in the amino acid sequence of the proteins N3, N80, N97, N98 and N99 and so the SE is turned up as zero implying there is no uncertainly at all, naturally. The SE of the spatial representation of the presence and absence of the amino acid $A_{5}$ over the proteins N88, N89, N90, N91, N92, N94 and N95 (belong to cluster 4) of length 419 is 0.078 and hence the spatial distriburion is more certainly/orderly. The largest cluster 1 contains protein sequence of various lengths including highest length where the 
presence of the amino acid is clearly having least of uncertainty (SE: 0.144). It is noted that the protein N81 of length 43 having highest SE 0.271 having having certainty of appearance of the amino acid $A_{5}$.

Table 28: SE of $105 B_{5_{j}}$ for $j=1,2, \ldots 105$ corresponding to the amino acid $A_{5}(H)$.

\begin{tabular}{|c|c|c|c|c|c|c|c|c|c|c|c|}
\hline Seq & SE & C & Seq & SE & C & Seq & SE & C & Seq & $\mathrm{SE}$ & C \\
\hline N3 & 0.000 & 3 & N32 & 0.124 & 8 & N37 & 0.144 & 1 & N8 & 0.155 & 6 \\
\hline N80 & 0.000 & 3 & N36 & 0.124 & 8 & N38 & 0.144 & 1 & $\mathrm{~N} 102$ & 0.157 & 6 \\
\hline N97 & 0.000 & 3 & N58 & 0.124 & 8 & N39 & 0.144 & 1 & N87 & 0.168 & 6 \\
\hline N98 & 0.000 & 3 & N104 & 0.126 & 1 & $\mathrm{~N} 40$ & 0.144 & 1 & N 100 & 0.189 & 2 \\
\hline N99 & 0.000 & 3 & $\mathrm{~N} 4$ & 0.130 & 1 & $\mathrm{~N} 41$ & 0.144 & 1 & N9 & 0.190 & 2 \\
\hline N88 & 0.078 & 4 & N7 & 0.130 & 1 & $\mathrm{~N} 42$ & 0.144 & 1 & N10 & 0.190 & 2 \\
\hline N89 & 0.078 & 4 & N5 & 0.141 & 1 & $\mathrm{~N} 43$ & 0.144 & 1 & N11 & 0.190 & 2 \\
\hline N90 & 0.078 & 4 & N49 & 0.143 & 1 & N45 & 0.144 & 1 & N82 & 0.210 & 2 \\
\hline N91 & 0.078 & 4 & N64 & 0.143 & 1 & $\mathrm{~N} 46$ & 0.144 & 1 & N83 & 0.210 & 2 \\
\hline N92 & 0.078 & 4 & N13 & 0.143 & 1 & $\mathrm{~N} 47$ & 0.144 & 1 & N84 & 0.210 & 2 \\
\hline N93 & 0.078 & 4 & N12 & 0.143 & 1 & $\mathrm{~N} 48$ & 0.144 & 1 & N85 & 0.210 & 2 \\
\hline N94 & 0.078 & 4 & $\mathrm{~N} 26$ & 0.144 & 1 & N50 & 0.144 & 1 & N86 & 0.210 & 2 \\
\hline N95 & 0.078 & 4 & N14 & 0.144 & 1 & N51 & 0.144 & 1 & N1 & 0.233 & 7 \\
\hline N103 & 0.094 & 8 & $\mathrm{~N} 16$ & 0.144 & 1 & N52 & 0.144 & 1 & N15 & 0.237 & 7 \\
\hline N79 & 0.097 & 8 & N17 & 0.144 & 1 & N53 & 0.144 & 1 & N81 & 0.271 & 5 \\
\hline N96 & 0.102 & 8 & $\mathrm{~N} 18$ & 0.144 & 1 & N54 & 0.144 & 1 & & & \\
\hline N69 & 0.102 & 8 & N19 & 0.144 & 1 & N55 & 0.144 & 1 & & & \\
\hline N71 & 0.102 & 8 & $\mathrm{~N} 20$ & 0.144 & 1 & N56 & 0.144 & 1 & & & \\
\hline N72 & 0.102 & 8 & $\mathrm{~N} 22$ & 0.144 & 1 & N57 & 0.144 & 1 & & & \\
\hline N73 & 0.102 & 8 & $\mathrm{~N} 23$ & 0.144 & 1 & N59 & 0.144 & 1 & & & \\
\hline N74 & 0.102 & 8 & $\mathrm{~N} 24$ & 0.144 & 1 & N60 & 0.144 & 1 & & & \\
\hline N75 & 0.102 & 8 & $\mathrm{~N} 25$ & 0.144 & 1 & N61 & 0.144 & 1 & & & \\
\hline N76 & 0.102 & 8 & $\mathrm{~N} 27$ & 0.144 & 1 & $\mathrm{~N} 62$ & 0.144 & 1 & & & \\
\hline N77 & 0.102 & 8 & $\mathrm{~N} 28$ & 0.144 & 1 & N63 & 0.144 & 1 & & & \\
\hline N78 & 0.102 & 8 & N29 & 0.144 & 1 & N65 & 0.144 & 1 & & & \\
\hline N70 & 0.102 & 8 & N30 & 0.144 & 1 & N66 & 0.144 & 1 & & & \\
\hline N101 & 0.105 & 8 & N31 & 0.144 & 1 & $\mathrm{~N} 67$ & 0.144 & 1 & & & \\
\hline N6 & 0.107 & 8 & N33 & 0.144 & 1 & $\mathrm{~N} 44$ & 0.144 & 1 & & & \\
\hline N68 & 0.121 & 8 & N34 & 0.144 & 1 & $\mathrm{~N} 21$ & 0.145 & 1 & & & \\
\hline N105 & 0.123 & 8 & N35 & 0.144 & 1 & $\mathrm{~N} 2$ & 0.150 & 1 & & & \\
\hline
\end{tabular}

\subsection{Shannon Entropy of $B_{6_{j}}$ for $j=1,2, \ldots 105$ and Classification}

For the amino acid $A_{6}(I)$ the SE for the 105 binary sequences $B_{6_{j}}$ for $j=1,2, \ldots 105$ have been determined. The plot of the SE for the binary sequences has been plotted and corresponding histogram is also given in the Fig 28. The SE of the binary representations of ordering of the amino acid $A_{6}$ over all the primary protein sequences would reveal the amount of uncertainty of the presence or absence of the amino acid. 

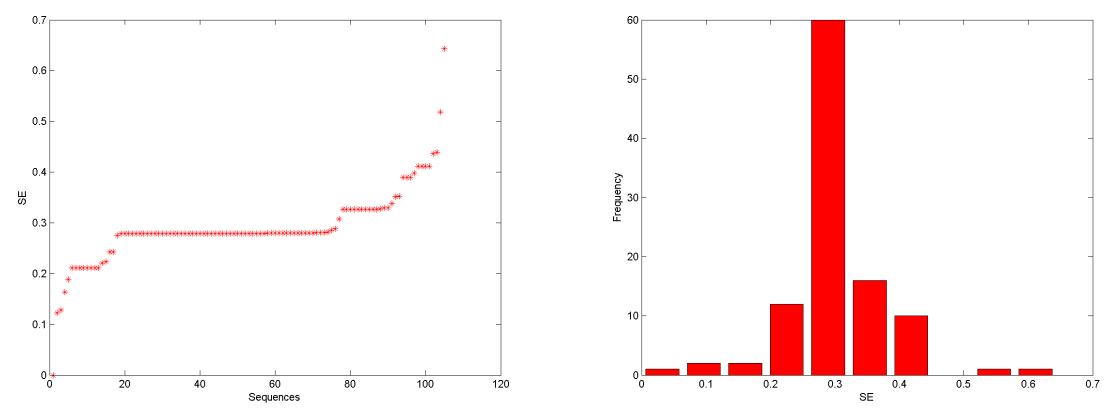

Figure 28: Plot of the SEs and corresponding histogram of all the binary sequences $B_{6_{j}}$ for $j=1,2, \ldots 105$ corresponding to the amino acid $A_{6}(I)$.

Here the SE of the 105 binary representation of the amino acid $A_{6}$ is ranging from 0 to 0.644 with standard deviation 0.0749. Based on the SEs of the binary sequences all these 105 primary protein sequences of SARS-CoV2, eight clusters ${ }_{650}$ (C) are formed as presented in the Table 29.

The amino acid $A_{6}(I)$ does not present in the protein N99 (of smallest length 13) and so the SE is turned up as zero implying there is no uncertainly at all, as usual. The rest all the clusters except 6 contain only those proteins where the amino acid $A_{6}(I)$ is spread spatially with certainty whereas the cluster 6 contains two sequences N81 (of length 43) and N68 (of length 61) where the absence of the amino acid dominate the presence with certainty. 
Table 29: SE of $105 B_{6_{j}}$ for $j=1,2, \ldots 105$ corresponding to the amino acid $A_{6}(I)$.

\begin{tabular}{|c|c|c|c|c|c|c|c|c|c|c|c|}
\hline Seq & SE & C & Seq & $\mathrm{SE}$ & C & Seq & $\mathrm{SE}$ & C & Seq & $\mathrm{SE}$ & C \\
\hline N99 & 0.000 & 1 & N31 & 0.279 & 4 & N18 & 0.280 & 4 & N6 6 & 0.338 & 5 \\
\hline $\mathrm{N} 15$ & 0.122 & 1 & N33 & 0.279 & 4 & N19 & 0.280 & 4 & N87 & 0.351 & 5 \\
\hline N98 & 0.128 & 1 & N34 & 0.279 & 4 & $\mathrm{~N} 20$ & 0.280 & 4 & N104 & 0.353 & 5 \\
\hline N103 & 0.164 & 7 & N37 & 0.279 & 4 & N25 & 0.280 & 4 & N9 & 0.389 & 3 \\
\hline $\mathrm{N} 2$ & 0.188 & 7 & N39 & 0.279 & 4 & N27 & 0.280 & 4 & N10 & 0.389 & 3 \\
\hline N88 & 0.211 & 7 & N40 & 0.279 & 4 & N29 & 0.280 & 4 & N11 & 0.389 & 3 \\
\hline N89 & 0.211 & 7 & N41 & 0.279 & 4 & N35 & 0.280 & 4 & N80 & 0.398 & 3 \\
\hline N90 & 0.211 & 7 & $\mathrm{~N} 42$ & 0.279 & 4 & N38 & 0.280 & 4 & N83 & 0.411 & 6 \\
\hline N91 & 0.211 & 7 & $\mathrm{~N} 43$ & 0.279 & 4 & N51 & 0.280 & 4 & N84 & 0.411 & 6 \\
\hline N92 & 0.211 & 7 & N45 & 0.279 & 4 & N59 & 0.280 & 4 & N85 & 0.411 & 6 \\
\hline N93 & 0.211 & 7 & N46 & 0.279 & 4 & $\mathrm{~N} 28$ & 0.281 & 4 & N86 & 0.411 & 6 \\
\hline N94 & 0.211 & 7 & N47 & 0.279 & 4 & N32 & 0.281 & 4 & N8 & 0.437 & 6 \\
\hline N95 & 0.211 & 7 & N48 & 0.279 & 4 & N36 & 0.281 & 4 & N82 & 0.439 & 6 \\
\hline N100 & 0.221 & 8 & N49 & 0.279 & 4 & N58 & 0.282 & 4 & N81 & 0.519 & 2 \\
\hline $\mathrm{N} 102$ & 0.223 & 8 & N50 & 0.279 & 4 & $\mathrm{~N} 4$ & 0.286 & 4 & N68 & 0.644 & 2 \\
\hline N96 & 0.242 & 8 & N52 & 0.279 & 4 & N3 & 0.289 & 4 & & & \\
\hline N97 & 0.242 & 8 & N53 & 0.279 & 4 & N101 & 0.308 & 5 & & & \\
\hline N1 & 0.275 & 4 & N54 & 0.279 & 4 & N69 & 0.326 & 5 & & & \\
\hline N55 & 0.279 & 4 & N56 & 0.279 & 4 & N71 & 0.326 & 5 & & & \\
\hline $\mathrm{N} 61$ & 0.279 & 4 & N5 7 & 0.279 & 4 & N72 & 0.326 & 5 & & & \\
\hline N65 & 0.279 & 4 & N60 & 0.279 & 4 & N73 & 0.326 & 5 & & & \\
\hline N5 & 0.279 & 4 & N62 & 0.279 & 4 & N74 & 0.326 & 5 & & & \\
\hline N26 & 0.279 & 4 & N63 & 0.279 & 4 & N75 & 0.326 & 5 & & & \\
\hline N14 & 0.279 & 4 & N64 & 0.279 & 4 & N76 & 0.326 & 5 & & & \\
\hline N16 & 0.279 & 4 & N66 & 0.279 & 4 & N 77 & 0.326 & 5 & & & \\
\hline $\mathrm{N} 21$ & 0.279 & 4 & N67 & 0.279 & 4 & N78 & 0.326 & 5 & & & \\
\hline $\mathrm{N} 22$ & 0.279 & 4 & N44 & 0.279 & 4 & N79 & 0.326 & 5 & & & \\
\hline $\mathrm{N} 23$ & 0.279 & 4 & N13 & 0.279 & 4 & N7 & 0.327 & 5 & & & \\
\hline $\mathrm{N} 24$ & 0.279 & 4 & $\mathrm{~N} 12$ & 0.280 & 4 & N105 & 0.329 & 5 & & & \\
\hline N30 & 0.279 & 4 & N17 & 0.280 & 4 & N70 & 0.330 & 5 & & & \\
\hline
\end{tabular}

\subsection{Shannon Entropy of $B_{7_{j}}$ for $j=1,2, \ldots 105$ and Classification}

For the amino acid $A_{7}(L)$ the $\mathrm{SE}$ for the 105 binary sequences $B_{7_{j}}$ for $j=1,2, \ldots 105$ have been determined. The plot of the SE for the binary sequences has been plotted and corresponding histogram is also given in the Fig 29. The SE of the binary representations of ordering of the amino acid $A_{7}$ over all the primary protein sequences would reveal the amount of uncertainty of the presence or absence of the amino acid.

Here the $\mathrm{SE}$ of the 105 binary representation of the amino acid $A_{7}$ is ranging from 0 to 0.644 with standard deviation 0.0749. Based on the SEs of the binary sequences all these 105 primary protein sequences of SARS-CoV2, six clusters (C) are formed as presented in the Table 30. 

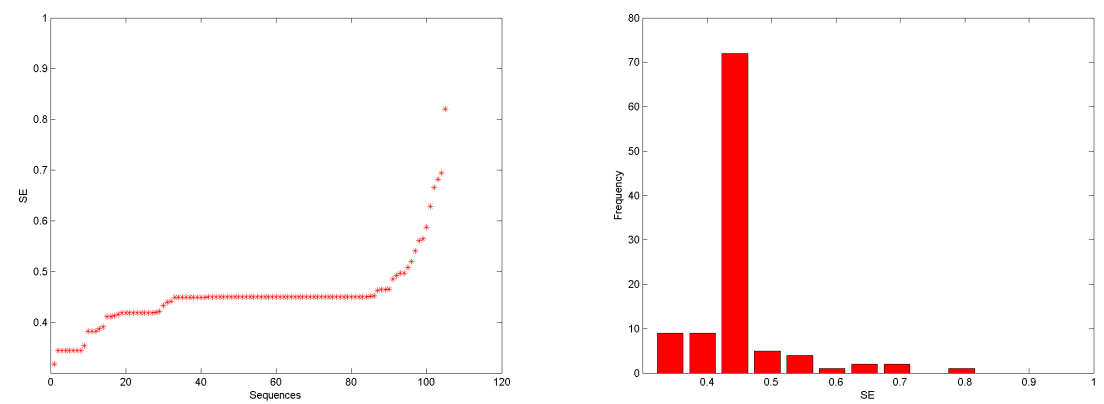

Figure 29: Plot of the SEs and corresponding histogram of all the binary sequences $B_{7_{j}}$ for $j=1,2, \ldots 105$ corresponding to the amino acid $A_{7}(L)$.

Table 30: SE of $105 B_{7_{j}}$ for $j=1,2, \ldots 105$ corresponding to the amino acid $A_{7}(L)$.

\begin{tabular}{|c|c|c|c|c|c|c|c|c|c|c|c|}
\hline Seq & $\mathrm{SE}$ & C & Seq & $\mathrm{SE}$ & C & Seq & $\mathrm{SE}$ & C & Seq & $\mathrm{SE}$ & C \\
\hline N2 & 0.318 & 3 & N3 & 0.439 & 1 & N50 & 0.450 & 1 & $\mathrm{~N} 80$ & 0.485 & 1 \\
\hline N89 & 0.345 & 3 & $\mathrm{~N} 4$ & 0.442 & 1 & N51 & 0.450 & 1 & N105 & 0.492 & 1 \\
\hline N90 & 0.345 & 3 & $\mathrm{~N} 20$ & 0.450 & 1 & N52 & 0.450 & 1 & N10 & 0.497 & 1 \\
\hline N91 & 0.345 & 3 & $\mathrm{~N} 24$ & 0.450 & 1 & N53 & 0.450 & 1 & N11 & 0.497 & 1 \\
\hline N92 & 0.345 & 3 & $\mathrm{~N} 27$ & 0.450 & 1 & N54 & 0.450 & 1 & N9 & 0.508 & 4 \\
\hline N93 & 0.345 & 3 & N33 & 0.450 & 1 & N55 & 0.450 & 1 & N15 & 0.520 & 4 \\
\hline N94 & 0.345 & 3 & N34 & 0.450 & 1 & N56 6 & 0.450 & 1 & N87 & 0.541 & 4 \\
\hline N95 & 0.345 & 3 & N47 & 0.450 & 1 & N57 & 0.450 & 1 & N68 & 0.561 & 4 \\
\hline N88 & 0.354 & 3 & N59 & 0.450 & 1 & N61 & 0.450 & 1 & N98 & 0.565 & 4 \\
\hline N82 & 0.382 & 5 & $\mathrm{~N} 62$ & 0.450 & 1 & N64 & 0.450 & 1 & N101 & 0.588 & 4 \\
\hline N85 & 0.382 & 5 & $\mathrm{~N} 44$ & 0.450 & 1 & N65 & 0.450 & 1 & N8 & 0.629 & 6 \\
\hline N86 & 0.382 & 5 & $\mathrm{~N} 6$ & 0.450 & 1 & N67 & 0.450 & 1 & N96 & 0.665 & 6 \\
\hline N1 & 0.388 & 5 & N14 & 0.450 & 1 & $\mathrm{~N} 13$ & 0.450 & 1 & N103 & 0.682 & 6 \\
\hline N99 & 0.391 & 5 & N16 & 0.450 & 1 & $\mathrm{~N} 12$ & 0.450 & 1 & N97 & 0.694 & 6 \\
\hline N83 & 0.411 & 5 & N17 & 0.450 & 1 & $\mathrm{~N} 26$ & 0.451 & 1 & N81 & 0.820 & 2 \\
\hline N84 & 0.411 & 5 & N18 & 0.450 & 1 & $\mathrm{~N} 23$ & 0.451 & 1 & & & \\
\hline N5 & 0.413 & 5 & N19 & 0.450 & 1 & $\mathrm{~N} 25$ & 0.451 & 1 & & & \\
\hline N104 & 0.415 & 5 & N21 & 0.450 & 1 & N30 & 0.451 & 1 & & & \\
\hline N69 & 0.419 & 5 & $\mathrm{~N} 22$ & 0.450 & 1 & N37 & 0.451 & 1 & & & \\
\hline N71 & 0.419 & 5 & $\mathrm{~N} 28$ & 0.450 & 1 & $\mathrm{~N} 40$ & 0.451 & 1 & & & \\
\hline N72 & 0.419 & 5 & N29 & 0.450 & 1 & N41 & 0.451 & 1 & & & \\
\hline N73 & 0.419 & 5 & N31 & 0.450 & 1 & N60 & 0.451 & 1 & & & \\
\hline N74 & 0.419 & 5 & N35 & 0.450 & 1 & N63 & 0.451 & 1 & & & \\
\hline N75 & 0.419 & 5 & N38 & 0.450 & 1 & N66 & 0.451 & 1 & & & \\
\hline N76 & 0.419 & 5 & N39 & 0.450 & 1 & $\mathrm{~N} 42$ & 0.451 & 1 & & & \\
\hline N77 & 0.419 & 5 & N43 & 0.450 & 1 & N102 & 0.452 & 1 & & & \\
\hline N79 & 0.419 & 5 & N45 & 0.450 & 1 & N7 & 0.463 & 1 & & & \\
\hline N70 & 0.419 & 5 & $\mathrm{~N} 46$ & 0.450 & 1 & N32 & 0.464 & 1 & & & \\
\hline N78 & 0.422 & 5 & $\mathrm{~N} 48$ & 0.450 & 1 & N58 & 0.464 & 1 & & & \\
\hline N100 & 0.433 & 1 & N49 & 0.450 & 1 & N36 & 0.465 & 1 & & & \\
\hline
\end{tabular}

The proteins N2 (of length 138) and N89, N90, N91, N92, N93, N94 and N95 
of length 419 in the cluster 3 , where the amino acid $A_{7}(L)$ is spread spatially with certainty. The clusters 1 and 5 contain majority of the protein sequences where the presence of the amino acid is spread over the proteins with almost certainty whereas the clusters 2 and 6 contain five protein sequences where the absence of the amino acid $A_{7}$ is spread with almost certainty.

\subsection{Shannon Entropy of $B_{8_{j}}$ for $j=1,2, \ldots 105$ and Classification}

For the amino acid $A_{8}(M)$ the SE for the 105 binary sequences $B_{8_{j}}$ for $j=1,2, \ldots 105$ have been determined. The plot of the SE for the binary sequences has been plotted and corresponding histogram is also given in the Fig 30. The SE of the binary representations of ordering of the amino acid $A_{8}$ over all the primary protein sequences would reveal the amount of uncertainty of the presence or absence of the amino acid.
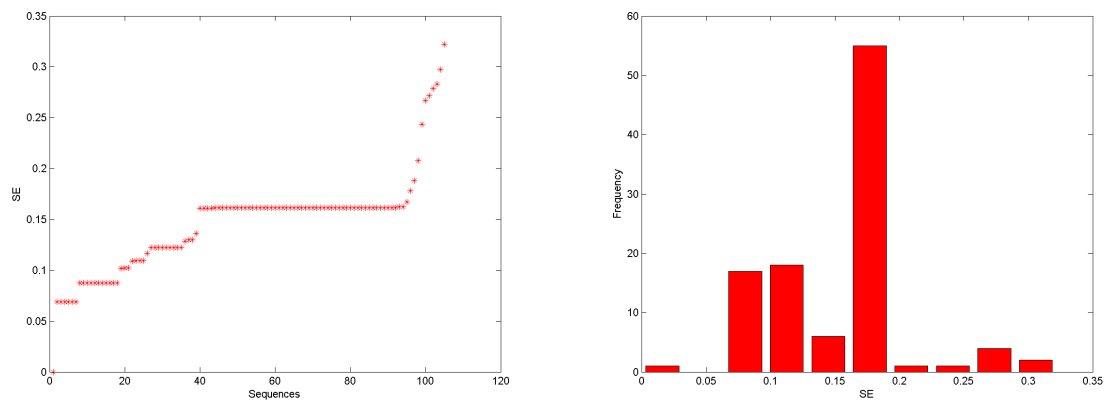

Figure 30: Plot of the SEs and corresponding histogram of all the binary sequences $B_{8_{j}}$ for $j=1,2, \ldots 105$ corresponding to the amino acid $A_{8}(M)$.

Here the SE of the 105 binary representation of the amino acid $A_{8}$ is ranging from 0 to 0.322 with standard deviation 0.0749. Based on the SEs of the binary sequences all these 105 primary protein sequences of SARS-CoV2, six clusters (C) are formed as presented in the Table 31.

685 The amino acid $A_{8}(M)$ does not present in the sequence N99 which is of smallest length and so the amount of uncertaintly is zero as found in the Table 31. The cluster 1 including others contains most of the proteins of SARS-CoV2 
where the amino acid is present all over the proteins of various lengths with almost certainty which is validated by its SE which is 0.162 .

Table 31: SE of $105 B_{8_{j}}$ for $j=1,2, \ldots 105$ corresponding to the amino acid $A_{8}(M)$.

\begin{tabular}{|c|c|c|c|c|c|c|c|c|c|c|c|}
\hline Seq & $\mathrm{SE}$ & C & Seq & SE & C & Seq & $\mathrm{SE}$ & C & Seq & $\mathrm{SE}$ & C \\
\hline N99 & 0.000 & 3 & N91 & 0.123 & 4 & N31 & 0.162 & 1 & N67 & 0.162 & 1 \\
\hline $\mathrm{N} 82$ & 0.069 & 6 & N92 & 0.123 & 4 & N33 & 0.162 & 1 & $\mathrm{~N} 44$ & 0.162 & 1 \\
\hline N83 & 0.069 & 6 & N93 & 0.123 & 4 & N34 & 0.162 & 1 & N32 & 0.162 & 1 \\
\hline N84 & 0.069 & 6 & N94 & 0.123 & 4 & N35 & 0.162 & 1 & N36 & 0.162 & 1 \\
\hline N85 & 0.069 & 6 & N95 & 0.123 & 4 & N37 & 0.162 & 1 & N1 & 0.167 & 1 \\
\hline N86 & 0.069 & 6 & N98 & 0.128 & 4 & N38 & 0.162 & 1 & N100 & 0.178 & 1 \\
\hline N87 & 0.069 & 6 & N7 & 0.130 & 4 & N39 & 0.162 & 1 & $\mathrm{~N} 2$ & 0.188 & 1 \\
\hline N69 & 0.087 & 5 & N8 & 0.130 & 4 & $\mathrm{~N} 40$ & 0.162 & 1 & $\mathrm{~N} 102$ & 0.208 & 1 \\
\hline N71 & 0.087 & 5 & N4 & 0.136 & 4 & $\mathrm{~N} 41$ & 0.162 & 1 & N105 & 0.244 & 2 \\
\hline N72 & 0.087 & 5 & N52 & 0.161 & 1 & $\mathrm{~N} 42$ & 0.162 & 1 & N3 & 0.267 & 2 \\
\hline N73 & 0.087 & 5 & N59 & 0.161 & 1 & $\mathrm{~N} 43$ & 0.162 & 1 & N81 & 0.271 & 2 \\
\hline N74 & 0.087 & 5 & $\mathrm{~N} 13$ & 0.161 & 1 & $\mathrm{~N} 45$ & 0.162 & 1 & N103 & 0.279 & 2 \\
\hline N75 & 0.087 & 5 & $\mathrm{~N} 12$ & 0.161 & 1 & $\mathrm{~N} 46$ & 0.162 & 1 & N68 & 0.283 & 2 \\
\hline N76 & 0.087 & 5 & N58 & 0.161 & 1 & $\mathrm{~N} 47$ & 0.162 & 1 & N80 & 0.297 & 2 \\
\hline N77 & 0.087 & 5 & $\mathrm{~N} 26$ & 0.162 & 1 & $\mathrm{~N} 48$ & 0.162 & 1 & N101 & 0.322 & 2 \\
\hline N78 & 0.087 & 5 & N14 & 0.162 & 1 & $\mathrm{~N} 49$ & 0.162 & 1 & & & \\
\hline N79 & 0.087 & 5 & N16 & 0.162 & 1 & N50 & 0.162 & 1 & & & \\
\hline N70 & 0.087 & 5 & N17 & 0.162 & 1 & N51 & 0.162 & 1 & & & \\
\hline N5 & 0.102 & 5 & N18 & 0.162 & 1 & N53 & 0.162 & 1 & & & \\
\hline N96 & 0.102 & 5 & N19 & 0.162 & 1 & N54 & 0.162 & 1 & & & \\
\hline N97 & 0.102 & 5 & N20 & 0.162 & 1 & N55 & 0.162 & 1 & & & \\
\hline N104 & 0.109 & 4 & N21 & 0.162 & 1 & N56 & 0.162 & 1 & & & \\
\hline N9 & 0.110 & 4 & $\mathrm{~N} 22$ & 0.162 & 1 & N57 & 0.162 & 1 & & & \\
\hline N10 & 0.110 & 4 & $\mathrm{~N} 23$ & 0.162 & 1 & N60 & 0.162 & 1 & & & \\
\hline N11 & 0.110 & 4 & $\mathrm{~N} 24$ & 0.162 & 1 & N61 & 0.162 & 1 & & & \\
\hline N6 & 0.116 & 4 & $\mathrm{~N} 25$ & 0.162 & 1 & $\mathrm{~N} 62$ & 0.162 & 1 & & & \\
\hline N15 & 0.122 & 4 & $\mathrm{~N} 27$ & 0.162 & 1 & N63 & 0.162 & 1 & & & \\
\hline N88 & 0.123 & 4 & N28 & 0.162 & 1 & N64 & 0.162 & 1 & & & \\
\hline N89 & 0.123 & 4 & N29 & 0.162 & 1 & N65 & 0.162 & 1 & & & \\
\hline N90 & 0.123 & 4 & N30 & 0.162 & 1 & N66 & 0.162 & 1 & & & \\
\hline
\end{tabular}

3.30. Shannon Entropy of $B_{9_{j}}$ for $j=1,2, \ldots 105$ and Classification

For the amino acid $A_{9}(N)$ the SE For the 105 binary sequences $B_{9_{j}}$ for $j=1,2, \ldots 105$ have been determined. The plot of the SE for the binary sequences has been plotted and corresponding histogram is also given in the Fig 31. The SE of the binary representations of ordering of the amino acid $A_{9}$ over all the primary protein sequences would reveal the amount of uncertainty of the presence or absence of the amino acid.

Here the $\mathrm{SE}$ of the 105 binary representation of the amino acid $A_{9}$ is ranging from 0.121 to 0.562 . Based on the SEs of the binary sequences all these 
105 primary protein sequences of SARS-CoV2, six clusters (C) are formed as presented in the Table 32 .
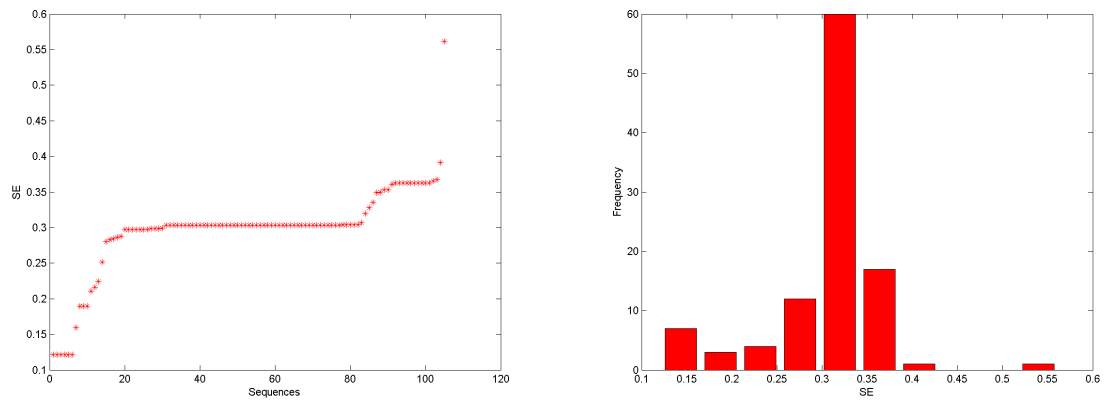

Figure 31: Plot of the SEs and corresponding histogram of all the binary sequences $B_{9_{j}}$ for $j=1,2, \ldots 105$ corresponding to the amino acid $A_{9}(M)$.

The cluster 3 contains one protein N80 where the spatial distribution $B_{980}$ has the SE 0.562 which says the absence of the the amino acid $A_{9}$ over the protein is without uncertainty. It is noted that total number of amino acid $A_{9}$ placed over the 38 length protein N80 is 5 . The other five clusters contains rest 104 proteins where the amino acid $A_{9}$ is spread with certainty as the HE is less than 0.5 . 
Table 32: SE of $105 B_{9_{j}}$ for $j=1,2, \ldots 105$ corresponding to the amino acid $A_{9}(N)$.

\begin{tabular}{|c|c|c|c|c|c|c|c|c|c|c|c|}
\hline Seq & $\mathrm{SE}$ & C & Seq & $\mathrm{SE}$ & C & Seq & $\mathrm{SE}$ & C & Seq & $\mathrm{SE}$ & C \\
\hline N82 & 0.121 & 5 & N51 & 0.303 & 1 & N49 & 0.304 & 1 & $\mathrm{~N} 102$ & 0.361 & 6 \\
\hline N83 & 0.121 & 5 & N26 & 0.304 & 1 & N50 & 0.304 & 1 & N71 & 0.363 & 6 \\
\hline N84 & 0.121 & 5 & N14 & 0.304 & 1 & N52 & 0.304 & 1 & N72 & 0.363 & 6 \\
\hline $\mathrm{N} 85$ & 0.121 & 5 & N17 & 0.304 & 1 & N53 & 0.304 & 1 & N73 & 0.363 & 6 \\
\hline N86 & 0.121 & 5 & N18 & 0.304 & 1 & N54 & 0.304 & 1 & N74 & 0.363 & 6 \\
\hline N87 & 0.121 & 5 & N19 & 0.304 & 1 & N55 & 0.304 & 1 & N75 & 0.363 & 6 \\
\hline $\mathrm{N} 81$ & 0.159 & 2 & N20 & 0.304 & 1 & N56 & 0.304 & 1 & N76 & 0.363 & 6 \\
\hline N9 & 0.190 & 2 & N21 & 0.304 & 1 & N59 & 0.304 & 1 & N77 & 0.363 & 6 \\
\hline $\mathrm{N} 10$ & 0.190 & 2 & $\mathrm{~N} 22$ & 0.304 & 1 & N60 & 0.304 & 1 & N78 & 0.363 & 6 \\
\hline $\mathrm{N} 11$ & 0.190 & 2 & $\mathrm{~N} 23$ & 0.304 & 1 & $\mathrm{~N} 61$ & 0.304 & 1 & N79 & 0.363 & 6 \\
\hline $\mathrm{N} 15$ & 0.211 & 2 & N24 & 0.304 & 1 & $\mathrm{~N} 62$ & 0.304 & 1 & N70 & 0.363 & 6 \\
\hline N101 & 0.216 & 2 & N25 & 0.304 & 1 & N63 & 0.304 & 1 & N69 & 0.366 & 6 \\
\hline N103 & 0.224 & 2 & N27 & 0.304 & 1 & N64 & 0.304 & 1 & N105 & 0.368 & 6 \\
\hline N7 & 0.251 & 1 & N28 & 0.304 & 1 & N65 & 0.304 & 1 & N99 & 0.391 & 4 \\
\hline N6 & 0.280 & 1 & N29 & 0.304 & 1 & N66 & 0.304 & 1 & N80 & 0.562 & 3 \\
\hline N104 & 0.283 & 1 & N30 & 0.304 & 1 & N67 & 0.304 & 1 & & & \\
\hline N8 & 0.284 & 1 & N31 & 0.304 & 1 & $\mathrm{~N} 44$ & 0.304 & 1 & & & \\
\hline N5 & 0.286 & 1 & N33 & 0.304 & 1 & $\mathrm{~N} 13$ & 0.304 & 1 & & & \\
\hline $\mathrm{N} 2$ & 0.288 & 1 & N34 & 0.304 & 1 & $\mathrm{~N} 12$ & 0.304 & 1 & & & \\
\hline N88 & 0.297 & 1 & N35 & 0.304 & 1 & N16 & 0.304 & 1 & & & \\
\hline N90 & 0.297 & 1 & N37 & 0.304 & 1 & $\mathrm{~N} 46$ & 0.304 & 1 & & & \\
\hline N91 & 0.297 & 1 & N38 & 0.304 & 1 & N57 & 0.304 & 1 & & & \\
\hline N92 & 0.297 & 1 & N39 & 0.304 & 1 & N89 & 0.307 & 1 & & & \\
\hline N93 & 0.297 & 1 & $\mathrm{~N} 40$ & 0.304 & 1 & $\mathrm{~N} 4$ & 0.320 & 1 & & & \\
\hline N94 & 0.297 & 1 & $\mathrm{~N} 41$ & 0.304 & 1 & N100 & 0.328 & 1 & & & \\
\hline N95 & 0.297 & 1 & $\mathrm{~N} 42$ & 0.304 & 1 & N98 & 0.335 & 6 & & & \\
\hline N32 & 0.299 & 1 & $\mathrm{~N} 43$ & 0.304 & 1 & N68 & 0.349 & 6 & & & \\
\hline N36 & 0.299 & 1 & N45 & 0.304 & 1 & N3 & 0.350 & 6 & & & \\
\hline N58 & 0.299 & 1 & $\mathrm{~N} 47$ & 0.304 & 1 & N96 & 0.353 & 6 & & & \\
\hline N1 & 0.300 & 1 & N48 & 0.304 & 1 & N97 & 0.353 & 6 & & & \\
\hline
\end{tabular}

\subsection{Shannon Entropy of $B_{10_{j}}$ for $j=1,2, \ldots 105$ and Classification}

For the amino acid $A_{10}(P)$ the SE for the 105 binary sequences $B_{10_{j}}$ for $j=$ $1,2, \ldots 105$ have been determined. The plot of the SE for the binary sequences has been plotted and corresponding histogram is also given in the Fig 32 . The SE of the binary representations of ordering of the amino acid $A_{10}$ over all the primary protein sequences would reveal the amount of uncertainty of the presence or absence of the amino acid.

Here the $\mathrm{SE}$ of the 105 binary representation of the amino acid $A_{10}$ is ranging 715 from 0 to 0.644 with standard deviation 0.0749. Based on the SEs of the binary sequences all these 105 primary protein sequences of SARS-CoV2, six clusters (C) are formed as presented in the Table 33. 

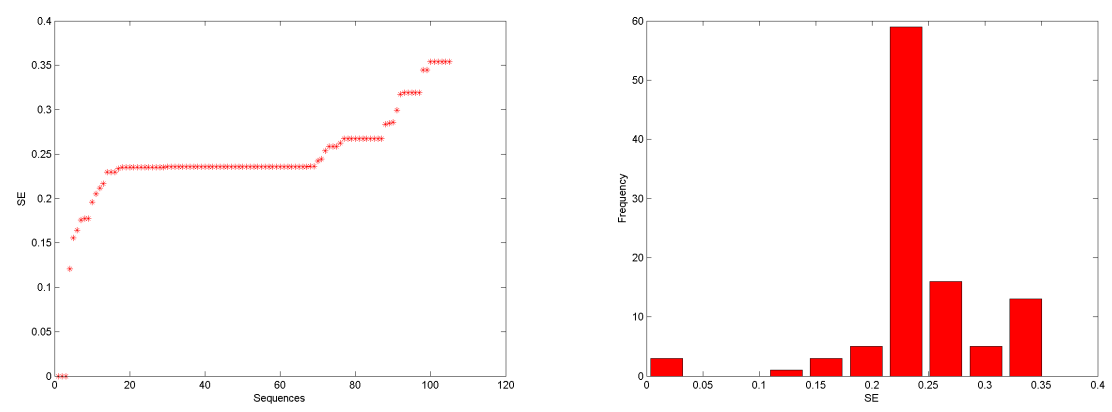

Figure 32: Plot of the SEs and corresponding histogram of all the binary sequences $B_{10_{j}}$ for $j=1,2, \ldots 105$ corresponding to the amino acid $A_{10}(P)$.

Table 33: SE of $105 B_{10_{j}}$ for $j=1,2, \ldots 105$ corresponding to the amino acid $A_{10}(P)$.

\begin{tabular}{|c|c|c|c|c|c|c|c|c|c|c|c|}
\hline Seq & $\mathrm{SE}$ & C & Seq & $\mathrm{SE}$ & C & Seq & $\mathrm{SE}$ & C & Seq & $\mathrm{SE}$ & C \\
\hline N81 & 0.000 & 4 & N16 & 0.236 & 2 & N57 & 0.236 & 2 & N98 & 0.299 & 6 \\
\hline N99 & 0.000 & 4 & N 17 & 0.236 & 2 & N59 & 0.236 & 2 & $\mathrm{~N} 2$ & 0.318 & 6 \\
\hline N103 & 0.000 & 4 & N18 & 0.236 & 2 & N60 & 0.236 & 2 & N82 & 0.319 & 6 \\
\hline N68 & 0.121 & 3 & N19 & 0.236 & 2 & N62 & 0.236 & 2 & N83 & 0.319 & 6 \\
\hline N8 & 0.155 & 3 & $\mathrm{~N} 20$ & 0.236 & 2 & N64 & 0.236 & 2 & N84 & 0.319 & 6 \\
\hline N101 & 0.164 & 3 & N21 & 0.236 & 2 & N65 & 0.236 & 2 & N85 & 0.319 & 6 \\
\hline N80 & 0.176 & 3 & $\mathrm{~N} 22$ & 0.236 & 2 & N44 & 0.236 & 2 & N86 & 0.319 & 6 \\
\hline N96 & 0.177 & 3 & N24 & 0.236 & 2 & N13 & 0.236 & 2 & N91 & 0.345 & 1 \\
\hline N97 & 0.177 & 3 & $\mathrm{~N} 27$ & 0.236 & 2 & $\mathrm{~N} 12$ & 0.236 & 2 & N94 & 0.345 & 1 \\
\hline N3 & 0.196 & 3 & $\mathrm{~N} 28$ & 0.236 & 2 & N7 & 0.242 & 2 & N88 & 0.354 & 1 \\
\hline N100 & 0.205 & 2 & $\mathrm{~N} 29$ & 0.236 & 2 & N104 & 0.244 & 2 & N89 & 0.354 & 1 \\
\hline N105 & 0.212 & 2 & N30 & 0.236 & 2 & N102 & 0.254 & 5 & N90 & 0.354 & 1 \\
\hline N6 & 0.216 & 2 & N31 & 0.236 & 2 & N9 & 0.259 & 5 & N92 & 0.354 & 1 \\
\hline N32 & 0.229 & 2 & N33 & 0.236 & 2 & N10 & 0.259 & 5 & N93 & 0.354 & 1 \\
\hline N36 & 0.229 & 2 & N34 & 0.236 & 2 & N11 & 0.259 & 5 & N95 & 0.354 & 1 \\
\hline N58 & 0.229 & 2 & N35 & 0.236 & 2 & N15 & 0.262 & 5 & & & \\
\hline $\mathrm{N} 4$ & 0.233 & 2 & N38 & 0.236 & 2 & N69 & 0.267 & 5 & & & \\
\hline $\mathrm{N} 26$ & 0.235 & 2 & N39 & 0.236 & 2 & N71 & 0.267 & 5 & & & \\
\hline $\mathrm{N} 23$ & 0.235 & 2 & N43 & 0.236 & 2 & N72 & 0.267 & 5 & & & \\
\hline $\mathrm{N} 25$ & 0.235 & 2 & N45 & 0.236 & 2 & N73 & 0.267 & 5 & & & \\
\hline N37 & 0.235 & 2 & N46 & 0.236 & 2 & N74 & 0.267 & 5 & & & \\
\hline $\mathrm{N} 40$ & 0.235 & 2 & N47 & 0.236 & 2 & N75 & 0.267 & 5 & & & \\
\hline N41 & 0.235 & 2 & N48 & 0.236 & 2 & N76 & 0.267 & 5 & & & \\
\hline $\mathrm{N} 42$ & 0.235 & 2 & N49 & 0.236 & 2 & N77 & 0.267 & 5 & & & \\
\hline N56 & 0.235 & 2 & N50 & 0.236 & 2 & N78 & 0.267 & 5 & & & \\
\hline N61 & 0.235 & 2 & N51 & 0.236 & 2 & N79 & 0.267 & 5 & & & \\
\hline N63 & 0.235 & 2 & N52 & 0.236 & 2 & N70 & 0.267 & 5 & & & \\
\hline N66 & 0.235 & 2 & N53 & 0.236 & 2 & N1 & 0.284 & 5 & & & \\
\hline N67 & 0.235 & 2 & N54 & 0.236 & 2 & N87 & 0.285 & 5 & & & \\
\hline N14 & 0.236 & 2 & N55 & 0.236 & 2 & N5 & 0.286 & 5 & & & \\
\hline
\end{tabular}

The cluster 3 contains the proteins N81, N99 and N103 where the HE is 
turned out to be zero for the binary representations $B_{10_{j}}$ for $j=81,99$ and 103 from 0 to 0.415 with standard deviation 0.0749. Based on the SEs of the binary sequences all these 105 primary protein sequences of SARS-CoV2, six clusters (C) are formed as presented in the Table 34 .

The cluster 4 contains the proteins N96 and N97 of length where the HE is 735 turned out to be zero for the binary representations $B_{10_{j}}$ for $j=96$ and 97 of the amino acid $A_{11}$. It is noted that these two proteins naturally absolutely free 
from the amino acid $A_{11}$. All the rest clusters contain all the protein sequences where the amino acid $A_{10}$ is present over the proteins with almost certainty.

Table 34: SE of $105 B_{11_{j}}$ for $j=1,2, \ldots 105$ corresponding to the amino acid $A_{11}(Q)$.

\begin{tabular}{|c|c|c|c|c|c|c|c|c|c|c|c|}
\hline Seq & SE & C & Seq & $\mathrm{SE}$ & C & Seq & $\mathrm{SE}$ & C & Seq & $\mathrm{SE}$ & C \\
\hline N96 & 0.000 & 4 & N31 & 0.213 & 3 & N65 & 0.213 & 3 & N83 & 0.285 & 1 \\
\hline N97 & 0.000 & 4 & N33 & 0.213 & 3 & N66 & 0.213 & 3 & N84 & 0.285 & 1 \\
\hline N7 & 0.130 & 3 & N34 & 0.213 & 3 & N67 & 0.213 & 3 & N85 & 0.285 & 1 \\
\hline N8 & 0.130 & 3 & N35 & 0.213 & 3 & $\mathrm{~N} 44$ & 0.213 & 3 & N86 & 0.285 & 1 \\
\hline N81 & 0.159 & 3 & N37 & 0.213 & 3 & $\mathrm{~N} 13$ & 0.213 & 3 & N3 & 0.310 & 1 \\
\hline N101 & 0.164 & 3 & N38 & 0.213 & 3 & N12 & 0.213 & 3 & $\mathrm{~N} 103$ & 0.374 & 6 \\
\hline N80 & 0.176 & 3 & N39 & 0.213 & 3 & N32 & 0.215 & 3 & N99 & 0.391 & 6 \\
\hline N6 & 0.185 & 3 & N40 & 0.213 & 3 & N36 & 0.215 & 3 & N88 & 0.415 & 2 \\
\hline N5 & 0.194 & 3 & N41 & 0.213 & 3 & N58 & 0.215 & 3 & N89 & 0.415 & 2 \\
\hline N100 & 0.195 & 3 & $\mathrm{~N} 42$ & 0.213 & 3 & N4 & 0.219 & 3 & N90 & 0.415 & 2 \\
\hline N1 & 0.196 & 3 & N43 & 0.213 & 3 & N98 & 0.221 & 3 & N91 & 0.415 & 2 \\
\hline N9 & 0.208 & 3 & N45 & 0.213 & 3 & $\mathrm{~N} 15$ & 0.237 & 5 & N92 & 0.415 & 2 \\
\hline N10 & 0.208 & 3 & N46 & 0.213 & 3 & N105 & 0.244 & 5 & N93 & 0.415 & 2 \\
\hline N11 & 0.208 & 3 & N47 & 0.213 & 3 & N87 & 0.248 & 5 & N94 & 0.415 & 2 \\
\hline $\mathrm{N} 21$ & 0.212 & 3 & N48 & 0.213 & 3 & N2 & 0.257 & 5 & N95 & 0.415 & 2 \\
\hline N26 & 0.213 & 3 & N49 & 0.213 & 3 & N104 & 0.257 & 5 & & & \\
\hline N14 & 0.213 & 3 & N50 & 0.213 & 3 & $\mathrm{~N} 102$ & 0.268 & 1 & & & \\
\hline N16 & 0.213 & 3 & N51 & 0.213 & 3 & N69 & 0.281 & 1 & & & \\
\hline N17 & 0.213 & 3 & N52 & 0.213 & 3 & N71 & 0.281 & 1 & & & \\
\hline N18 & 0.213 & 3 & N53 & 0.213 & 3 & N72 & 0.281 & 1 & & & \\
\hline N19 & 0.213 & 3 & N54 & 0.213 & 3 & N73 & 0.281 & 1 & & & \\
\hline N20 & 0.213 & 3 & N55 & 0.213 & 3 & N74 & 0.281 & 1 & & & \\
\hline $\mathrm{N} 22$ & 0.213 & 3 & N56 & 0.213 & 3 & N75 & 0.281 & 1 & & & \\
\hline N23 & 0.213 & 3 & N57 & 0.213 & 3 & N76 & 0.281 & 1 & & & \\
\hline $\mathrm{N} 24$ & 0.213 & 3 & N59 & 0.213 & 3 & N77 & 0.281 & 1 & & & \\
\hline $\mathrm{N} 25$ & 0.213 & 3 & N60 & 0.213 & 3 & N78 & 0.281 & 1 & & & \\
\hline N27 & 0.213 & 3 & N61 & 0.213 & 3 & N79 & 0.281 & 1 & & & \\
\hline $\mathrm{N} 28$ & 0.213 & 3 & N62 & 0.213 & 3 & N70 & 0.281 & 1 & & & \\
\hline $\mathrm{N} 29$ & 0.213 & 3 & N63 & 0.213 & 3 & N68 & 0.283 & 1 & & & \\
\hline N30 & 0.213 & 3 & N64 & 0.213 & 3 & N82 & 0.285 & 1 & & & \\
\hline
\end{tabular}

\subsection{Shannon Entropy of $B_{12_{j}}$ for $j=1,2, \ldots 105$ and Classification}

For the amino acid $A_{12}(S)$ the SE for the 105 binary sequences $B_{12_{j}}$ for $j=$ $1,2, \ldots 105$ have been determined. The plot of the SE for the binary sequences has been plotted and corresponding histogram is also given in the Fig 34. The SE of the binary representations of ordering of the amino acid $A_{12}$ over all the primary protein sequences would reveal the amount of uncertainty of the 745 presence or absence of the amino acid. 

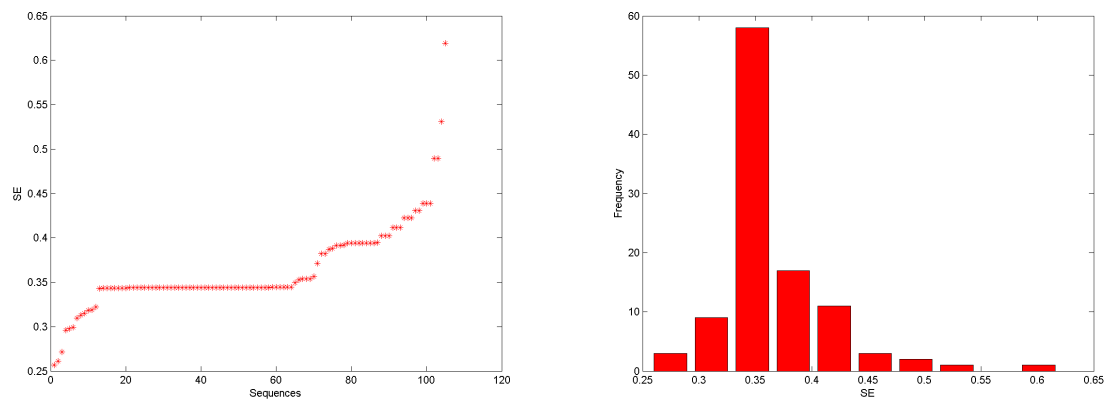

Figure 34: Plot of the SEs and corresponding histogram of all the binary sequences $B_{12}$ for $j=1,2, \ldots 105$ corresponding to the amino acid $A_{12}(S)$.

Table 35: SE of $105 B_{12}$ for $j=1,2, \ldots 105$ corresponding to the amino acid $A_{12}(S)$.

\begin{tabular}{|c|c|c|c|c|c|c|c|c|c|c|c|}
\hline Seq & $\mathrm{SE}$ & C & Seq & $\mathrm{SE}$ & C & Seq & $\mathrm{SE}$ & C & Seq & $\mathrm{SE}$ & C \\
\hline $\mathrm{N} 2$ & 0.257 & 3 & N29 & 0.344 & 5 & N54 & 0.345 & 5 & $\mathrm{~N} 82$ & 0.411 & 1 \\
\hline N98 & 0.261 & 3 & N31 & 0.344 & 5 & N56 & 0.345 & 5 & N83 & 0.411 & 1 \\
\hline N81 & 0.271 & 3 & N33 & 0.344 & 5 & N60 & 0.345 & 5 & N85 & 0.411 & 1 \\
\hline N102 & 0.296 & 3 & N34 & 0.344 & 5 & N61 & 0.345 & 5 & N88 & 0.423 & 1 \\
\hline N80 & 0.297 & 3 & N35 & 0.344 & 5 & N68 & 0.349 & 5 & N89 & 0.423 & 1 \\
\hline N1 & 0.300 & 3 & N37 & 0.344 & 5 & N5 & 0.353 & 5 & N93 & 0.423 & 1 \\
\hline $\mathrm{N} 15$ & 0.310 & 3 & N38 & 0.344 & 5 & N32 & 0.354 & 5 & N90 & 0.431 & 1 \\
\hline N6 & 0.313 & 3 & N39 & 0.344 & 5 & N36 & 0.354 & 5 & N92 & 0.431 & 1 \\
\hline N100 & 0.315 & 3 & N41 & 0.344 & 5 & N58 & 0.354 & 5 & N91 & 0.439 & 1 \\
\hline N104 & 0.319 & 5 & $\mathrm{~N} 42$ & 0.344 & 5 & N8 & 0.357 & 5 & N94 & 0.439 & 1 \\
\hline N87 & 0.319 & 5 & $\mathrm{~N} 43$ & 0.344 & 5 & $\mathrm{~N} 4$ & 0.371 & 5 & N95 & 0.439 & 1 \\
\hline N101 & 0.322 & 5 & $\mathrm{~N} 45$ & 0.344 & 5 & N84 & 0.382 & 1 & N96 & 0.490 & 4 \\
\hline $\mathrm{N} 26$ & 0.343 & 5 & N46 & 0.344 & 5 & N86 & 0.382 & 1 & N97 & 0.490 & 4 \\
\hline N14 & 0.344 & 5 & $\mathrm{~N} 47$ & 0.344 & 5 & N3 & 0.387 & 1 & N103 & 0.531 & 4 \\
\hline N16 & 0.344 & 5 & $\mathrm{~N} 48$ & 0.344 & 5 & N7 & 0.388 & 1 & N99 & 0.619 & 2 \\
\hline $\mathrm{N} 20$ & 0.344 & 5 & N49 & 0.344 & 5 & N71 & 0.391 & 1 & & & \\
\hline $\mathrm{N} 28$ & 0.344 & 5 & N50 & 0.344 & 5 & N76 & 0.391 & 1 & & & \\
\hline N30 & 0.344 & 5 & N52 & 0.344 & 5 & N105 & 0.392 & 1 & & & \\
\hline $\mathrm{N} 40$ & 0.344 & 5 & N53 & 0.344 & 5 & N69 & 0.394 & 1 & & & \\
\hline N62 & 0.344 & 5 & N55 & 0.344 & 5 & N72 & 0.394 & 1 & & & \\
\hline $\mathrm{N} 12$ & 0.344 & 5 & N57 & 0.344 & 5 & N73 & 0.394 & 1 & & & \\
\hline N17 & 0.344 & 5 & N59 & 0.344 & 5 & N74 & 0.394 & 1 & & & \\
\hline N18 & 0.344 & 5 & N63 & 0.344 & 5 & N75 & 0.394 & 1 & & & \\
\hline N19 & 0.344 & 5 & N64 & 0.344 & 5 & N77 & 0.394 & 1 & & & \\
\hline $\mathrm{N} 21$ & 0.344 & 5 & N65 & 0.344 & 5 & N78 & 0.394 & 1 & & & \\
\hline $\mathrm{N} 22$ & 0.344 & 5 & N66 & 0.344 & 5 & N79 & 0.394 & 1 & & & \\
\hline $\mathrm{N} 23$ & 0.344 & 5 & N67 & 0.344 & 5 & N70 & 0.394 & 1 & & & \\
\hline $\mathrm{N} 24$ & 0.344 & 5 & N44 & 0.344 & 5 & N9 & 0.402 & 1 & & & \\
\hline $\mathrm{N} 25$ & 0.344 & 5 & N13 & 0.344 & 5 & N10 & 0.402 & 1 & & & \\
\hline $\mathrm{N} 27$ & 0.344 & 5 & N51 & 0.345 & 5 & N11 & 0.402 & 1 & & & \\
\hline
\end{tabular}

Here the SE of the 105 binary representation of the amino acid $A_{12}$ is ranging 
from 0.257 to 0.619 with standard deviation 0.0503. Based on the SEs of the binary sequences all these 105 primary protein sequences of SARS-CoV2, five clusters $(\mathrm{C})$ are formed as presented in the Table 35.

The amino acid $A_{10}$ is present over the all the proteins except N99 with almost certainty since the SE of the spatial distributions is turned out to be less than 0.5, as shown in the Table 35. The SE of the smallest lengthy protein N99 is greater than 0.5 which imply the absence of the amino acid is spread over the protein with certainty.

\subsection{Shannon Entropy of $B_{13_{j}}$ for $j=1,2, \ldots 105$ and Classification}

For the amino acid $A_{13}(T)$ the SE for the 105 binary sequences $B_{13_{j}}$ for $j=$ $1,2, \ldots 105$ have been determined. The plot of the SE for the binary sequences has been plotted and corresponding histogram is also given in the Fig 35. The SE of the binary representations of ordering of the amino acid $A_{13}$ over all the primary protein sequences would reveal the amount of uncertainty of the presence or absence of the amino acid.
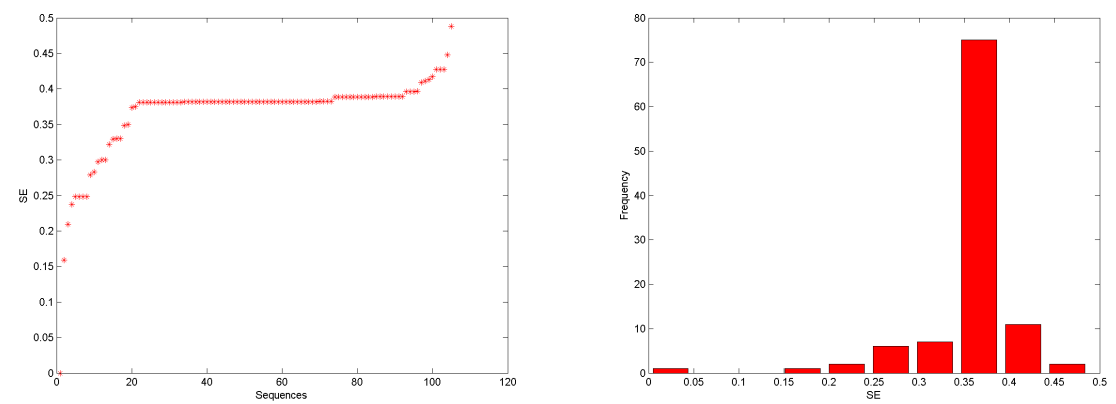

Figure 35: Plot of the SEs and corresponding histogram of all the binary sequences $B_{13_{j}}$ for $j=1,2, \ldots 105$ corresponding to the amino acid $A_{13}(T)$.

Here the $\mathrm{SE}$ of the 105 binary representation of the amino acid $A_{13}$ is ranging from 0 to 0.488 with standard deviation 0.0601. Based on the SEs of the binary sequences all these 105 primary protein sequences of SARS-CoV2, five clusters (C) are formed as presented in the Table 36. 
Table 36: SE of $105 B_{13_{j}}$ for $j=1,2, \ldots 105$ corresponding to the amino acid $A_{13}(T)$.

\begin{tabular}{|c|c|c|c|c|c|c|c|c|c|c|c|}
\hline Seq & SE & C & Seq & SE & C & Seq & SE & C & Seq & $\mathrm{SE}$ & C \\
\hline N99 & 0.000 & 3 & N35 & 0.381 & 2 & N59 & 0.382 & 2 & N94 & 0.389 & 2 \\
\hline N81 & 0.159 & 3 & N38 & 0.381 & 2 & N60 & 0.382 & 2 & N95 & 0.389 & 2 \\
\hline N82 & 0.210 & 1 & N63 & 0.381 & 2 & $\mathrm{~N} 62$ & 0.382 & 2 & N32 & 0.396 & 2 \\
\hline N15 & 0.237 & 1 & N26 & 0.382 & 2 & N64 & 0.382 & 2 & N36 & 0.396 & 2 \\
\hline N83 & 0.248 & 1 & N16 & 0.382 & 2 & N66 & 0.382 & 2 & N58 & 0.396 & 2 \\
\hline N84 & 0.248 & 1 & $\mathrm{~N} 21$ & 0.382 & 2 & $\mathrm{~N} 67$ & 0.382 & 2 & $\mathrm{~N} 102$ & 0.397 & 2 \\
\hline N85 & 0.248 & 1 & $\mathrm{~N} 22$ & 0.382 & 2 & $\mathrm{~N} 44$ & 0.382 & 2 & N7 & 0.409 & 5 \\
\hline N86 & 0.248 & 1 & $\mathrm{~N} 23$ & 0.382 & 2 & N13 & 0.382 & 2 & N87 & 0.411 & 5 \\
\hline $\mathrm{N} 103$ & 0.279 & 1 & $\mathrm{~N} 24$ & 0.382 & 2 & $\mathrm{~N} 12$ & 0.382 & 2 & N5 & 0.413 & 5 \\
\hline N68 & 0.283 & 1 & N30 & 0.382 & 2 & N14 & 0.382 & 2 & N4 & 0.417 & 5 \\
\hline N80 & 0.297 & 1 & N31 & 0.382 & 2 & N55 & 0.382 & 2 & N9 & 0.427 & 5 \\
\hline N96 & 0.300 & 1 & N33 & 0.382 & 2 & N61 & 0.382 & 2 & N10 & 0.427 & 5 \\
\hline N97 & 0.300 & 1 & N37 & 0.382 & 2 & N65 & 0.382 & 2 & N11 & 0.427 & 5 \\
\hline N8 & 0.322 & 1 & N39 & 0.382 & 2 & N69 & 0.389 & 2 & $\mathrm{~N} 2$ & 0.448 & 5 \\
\hline N105 & 0.329 & 1 & $\mathrm{~N} 40$ & 0.382 & 2 & N71 & 0.389 & 2 & N98 & 0.488 & 4 \\
\hline N104 & 0.330 & 1 & N41 & 0.382 & 2 & N72 & 0.389 & 2 & & & \\
\hline N1 & 0.330 & 1 & N42 & 0.382 & 2 & N73 & 0.389 & 2 & & & \\
\hline N100 & 0.349 & 2 & N43 & 0.382 & 2 & N74 & 0.389 & 2 & & & \\
\hline N3 & 0.350 & 2 & N45 & 0.382 & 2 & N75 & 0.389 & 2 & & & \\
\hline N6 & 0.374 & 2 & N46 & 0.382 & 2 & N76 & 0.389 & 2 & & & \\
\hline N101 & 0.375 & 2 & $\mathrm{~N} 47$ & 0.382 & 2 & N77 & 0.389 & 2 & & & \\
\hline N17 & 0.381 & 2 & N48 & 0.382 & 2 & N78 & 0.389 & 2 & & & \\
\hline N18 & 0.381 & 2 & N49 & 0.382 & 2 & N79 & 0.389 & 2 & & & \\
\hline N19 & 0.381 & 2 & N50 & 0.382 & 2 & N70 & 0.389 & 2 & & & \\
\hline $\mathrm{N} 20$ & 0.381 & 2 & N51 & 0.382 & 2 & N88 & 0.389 & 2 & & & \\
\hline $\mathrm{N} 25$ & 0.381 & 2 & N52 & 0.382 & 2 & N89 & 0.389 & 2 & & & \\
\hline $\mathrm{N} 27$ & 0.381 & 2 & N53 & 0.382 & 2 & N90 & 0.389 & 2 & & & \\
\hline $\mathrm{N} 28$ & 0.381 & 2 & N54 & 0.382 & 2 & N91 & 0.389 & 2 & & & \\
\hline $\mathrm{N} 29$ & 0.381 & 2 & N56 & 0.382 & 2 & N92 & 0.389 & 2 & & & \\
\hline N34 & 0.381 & 2 & N57 & 0.382 & 2 & N93 & 0.389 & 2 & & & \\
\hline
\end{tabular}

The amino acid $A_{13}(T)$ is absent in the protein sequence of N99 and consequently the binary representation $B_{13_{99}}$ of presence and absence of the amino acid is absolutely a sequence with zeros without any uncertainty $(\mathrm{SE}=0)$ as shown in the Table 36. The rest proteins belonging to other clusters have the 770 presence of the amino acid $A_{13}(T)$ with least amount of uncertainty as depicted in the Table 36.

\subsection{Shannon Entropy of $B_{14_{j}}$ for $j=1,2, \ldots 105$ and Classification}

For the amino acid $A_{14}(V)$ the SE for the 105 binary sequences $B_{14_{j}}$ for $j=$ $1,2, \ldots 105$ have been determined. The plot of the SE for the binary sequences 775 has been plotted and corresponding histogram is also given in the Fig 36. The SE of the binary representations of ordering of the amino acid $A_{14}$ over all 
the primary protein sequences would reveal the amount of uncertainty of the presence or absence of the amino acid.
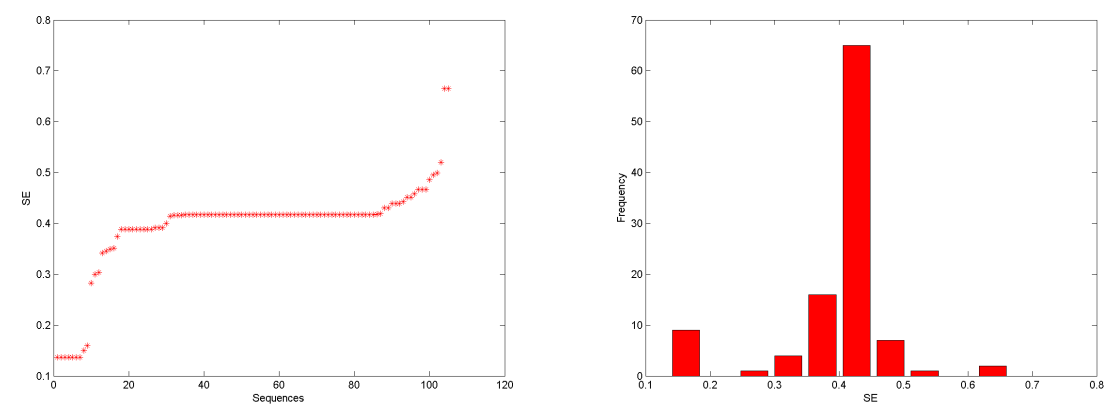

Figure 36: Plot of the SEs and corresponding histogram of all the binary sequences $B_{14_{j}}$ for $j=1,2, \ldots 105$ corresponding to the amino acid $A_{14}(V)$.

Here the SE of the 105 binary representation of the amino acid $A_{14}$ is ranging from 0.136 to 0.665 with standard deviation 0.0919. Based on the SEs of the binary sequences all these 105 primary protein sequences of SARS-CoV2, five clusters $(\mathrm{C})$ are formed as presented in the Table 37.

The essential amino acid $\mathrm{V}$ is present all over the 105 porteins and hence none of the binary representations has the zero SE. The SE of the $B_{1499}$ smallest lengthy protein including other proteins such as N74 and N77 of length 1273 is exactly 0.391 which imply the presence of the amino acid $A_{1} 4$ over the proteins is with good certainty. The proteins N96 and N97 having length 75 have the the maximum about of uncertainty (SE:0.665) as compared to other proteins. The rest proteins belonging to other clusters have the presence of the amino acid $A_{14}$ with certainty. 
Table 37: SE of $105 B_{14}$ for $j=1,2, \ldots 105$ corresponding to the amino acid $A_{14}(V)$.

\begin{tabular}{|c|c|c|c|c|c|c|c|c|c|c|c|}
\hline Seq & $\mathrm{SE}$ & C & Seq & $\mathrm{SE}$ & C & Seq & $\mathrm{SE}$ & C & Seq & $\mathrm{SE}$ & C \\
\hline N88 & 0.136 & 4 & $\mathrm{~N} 1$ & 0.414 & 5 & $\mathrm{~N} 42$ & 0.417 & 5 & N83 & 0.439 & 5 \\
\hline N89 & 0.136 & 4 & N13 & 0.416 & 5 & N43 & 0.417 & 5 & N86 & 0.439 & 5 \\
\hline N90 & 0.136 & 4 & $\mathrm{~N} 12$ & 0.416 & 5 & N45 & 0.417 & 5 & N7 & 0.443 & 5 \\
\hline N91 & 0.136 & 4 & $\mathrm{~N} 22$ & 0.417 & 5 & $\mathrm{~N} 46$ & 0.417 & 5 & N9 & 0.451 & 3 \\
\hline N93 & 0.136 & 4 & N32 & 0.417 & 5 & N47 & 0.417 & 5 & N11 & 0.451 & 3 \\
\hline N94 & 0.136 & 4 & N36 & 0.417 & 5 & N49 & 0.417 & 5 & N101 & 0.458 & 3 \\
\hline N95 & 0.136 & 4 & $\mathrm{~N} 26$ & 0.417 & 5 & N51 & 0.417 & 5 & N82 & 0.466 & 3 \\
\hline N92 & 0.150 & 4 & N14 & 0.417 & 5 & N52 & 0.417 & 5 & N84 & 0.466 & 3 \\
\hline N81 & 0.159 & 4 & N16 & 0.417 & 5 & N54 & 0.417 & 5 & N85 & 0.466 & 3 \\
\hline N68 & 0.283 & 1 & N17 & 0.417 & 5 & N55 & 0.417 & 5 & N80 & 0.485 & 3 \\
\hline N98 & 0.299 & 1 & N18 & 0.417 & 5 & N56 & 0.417 & 5 & N103 & 0.495 & 3 \\
\hline N8 & 0.303 & 1 & N19 & 0.417 & 5 & N57 & 0.417 & 5 & N104 & 0.499 & 3 \\
\hline N105 & 0.342 & 1 & $\mathrm{~N} 20$ & 0.417 & 5 & N60 & 0.417 & 5 & N15 & 0.520 & 3 \\
\hline N2 & 0.346 & 1 & $\mathrm{~N} 21$ & 0.417 & 5 & N62 & 0.417 & 5 & N96 & 0.665 & 2 \\
\hline N3 & 0.350 & 1 & $\mathrm{~N} 23$ & 0.417 & 5 & N64 & 0.417 & 5 & N97 & 0.665 & 2 \\
\hline N87 & 0.351 & 1 & $\mathrm{~N} 24$ & 0.417 & 5 & N66 & 0.417 & 5 & & & \\
\hline N6 & 0.374 & 1 & $\mathrm{~N} 25$ & 0.417 & 5 & N67 & 0.417 & 5 & & & \\
\hline N69 & 0.389 & 1 & $\mathrm{~N} 27$ & 0.417 & 5 & $\mathrm{~N} 44$ & 0.417 & 5 & & & \\
\hline N71 & 0.389 & 1 & $\mathrm{~N} 28$ & 0.417 & 5 & $\mathrm{~N} 48$ & 0.418 & 5 & & & \\
\hline N72 & 0.389 & 1 & N29 & 0.417 & 5 & N50 & 0.418 & 5 & & & \\
\hline N73 & 0.389 & 1 & N30 & 0.417 & 5 & N53 & 0.418 & 5 & & & \\
\hline N75 & 0.389 & 1 & N31 & 0.417 & 5 & N59 & 0.418 & 5 & & & \\
\hline N76 & 0.389 & 1 & N33 & 0.417 & 5 & N61 & 0.418 & 5 & & & \\
\hline N78 & 0.389 & 1 & N34 & 0.417 & 5 & N63 & 0.418 & 5 & & & \\
\hline N79 & 0.389 & 1 & N35 & 0.417 & 5 & N65 & 0.418 & 5 & & & \\
\hline N70 & 0.389 & 1 & N37 & 0.417 & 5 & N58 & 0.418 & 5 & & & \\
\hline N99 & 0.391 & 1 & N38 & 0.417 & 5 & $\mathrm{~N} 4$ & 0.419 & 5 & & & \\
\hline N74 & 0.391 & 1 & N39 & 0.417 & 5 & N5 & 0.430 & 5 & & & \\
\hline N77 & 0.391 & 1 & $\mathrm{~N} 40$ & 0.417 & 5 & N102 & 0.431 & 5 & & & \\
\hline N100 & 0.400 & 5 & N41 & 0.417 & 5 & N10 & 0.439 & 5 & & & \\
\hline
\end{tabular}

\subsection{Shannon Entropy of $B_{15_{j}}$ for $j=1,2, \ldots 105$ and Classification}

For the amino acid $A_{15}(W)$ the SE for the 105 binary sequences $B_{15_{j}}$ for $j=$ $1,2, \ldots 105$ have been determined. The plot of the SE for the binary sequences has been plotted and corresponding histogram is also given in the Fig 37 . The SE of the binary representations of ordering of the amino acid $A_{15}$ over all the primary protein sequences would reveal the amount of uncertainty of the presence or absence of the amino acid. 

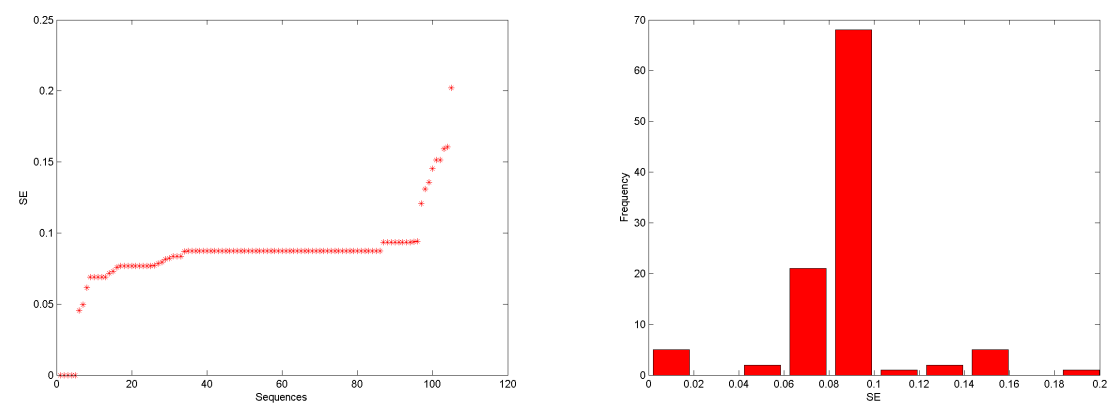

Figure 37: Plot of the SEs and corresponding histogram of all the binary sequences $B_{15_{j}}$ for $j=1,2, \ldots 105$ corresponding to the amino acid $A_{15}(W)$.

Table 38: SE of $105 B_{15_{j}}$ for $j=1,2, \ldots 105$ corresponding to the amino acid $A_{15}(W)$.

\begin{tabular}{|c|c|c|c|c|c|c|c|c|c|c|c|}
\hline Seq & $\mathrm{SE}$ & C & Seq & $\mathrm{SE}$ & C & Seq & $\mathrm{SE}$ & C & Seq & SE & C \\
\hline N80 & 0.000 & 1 & N32 & 0.084 & 2 & $\mathrm{~N} 43$ & 0.087 & 2 & N92 & 0.093 & 2 \\
\hline N87 & 0.000 & 1 & N36 & 0.084 & 2 & $\mathrm{~N} 45$ & 0.087 & 2 & N93 & 0.093 & 2 \\
\hline N96 & 0.000 & 1 & N58 & 0.084 & 2 & N46 & 0.087 & 2 & N94 & 0.093 & 2 \\
\hline N97 & 0.000 & 1 & N6 & 0.087 & 2 & N47 & 0.087 & 2 & N95 & 0.093 & 2 \\
\hline N99 & 0.000 & 1 & $\mathrm{~N} 26$ & 0.087 & 2 & $\mathrm{~N} 48$ & 0.087 & 2 & N7 & 0.094 & 2 \\
\hline N5 & 0.045 & 2 & N14 & 0.087 & 2 & N49 & 0.087 & 2 & N103 & 0.094 & 2 \\
\hline N15 & 0.050 & 2 & N16 & 0.087 & 2 & N50 & 0.087 & 2 & N68 & 0.121 & 5 \\
\hline N2 & 0.062 & 2 & N17 & 0.087 & 2 & N51 & 0.087 & 2 & N9 & 0.131 & 5 \\
\hline N82 & 0.069 & 2 & N18 & 0.087 & 2 & N52 & 0.087 & 2 & N1 & 0.136 & 5 \\
\hline N83 & 0.069 & 2 & N19 & 0.087 & 2 & N53 & 0.087 & 2 & N101 & 0.145 & 4 \\
\hline N84 & 0.069 & 2 & N20 & 0.087 & 2 & N54 & 0.087 & 2 & N10 & 0.152 & 4 \\
\hline N85 & 0.069 & 2 & N21 & 0.087 & 2 & N55 & 0.087 & 2 & N11 & 0.152 & 4 \\
\hline N86 & 0.069 & 2 & $\mathrm{~N} 22$ & 0.087 & 2 & N56 & 0.087 & 2 & N81 & 0.159 & 4 \\
\hline N104 & 0.072 & 2 & N23 & 0.087 & 2 & N57 & 0.087 & 2 & N105 & 0.161 & 4 \\
\hline N98 & 0.073 & 2 & N24 & 0.087 & 2 & N59 & 0.087 & 2 & N8 & 0.202 & 3 \\
\hline $\mathrm{N} 4$ & 0.076 & 2 & N25 & 0.087 & 2 & N60 & 0.087 & 2 & & & \\
\hline N69 & 0.077 & 2 & $\mathrm{~N} 27$ & 0.087 & 2 & $\mathrm{~N} 61$ & 0.087 & 2 & & & \\
\hline N71 & 0.077 & 2 & N28 & 0.087 & 2 & N62 & 0.087 & 2 & & & \\
\hline N72 & 0.077 & 2 & N29 & 0.087 & 2 & N63 & 0.087 & 2 & & & \\
\hline N73 & 0.077 & 2 & N30 & 0.087 & 2 & N64 & 0.087 & 2 & & & \\
\hline N74 & 0.077 & 2 & N31 & 0.087 & 2 & N65 & 0.087 & 2 & & & \\
\hline N75 & 0.077 & 2 & N33 & 0.087 & 2 & N66 & 0.087 & 2 & & & \\
\hline N77 & 0.077 & 2 & N34 & 0.087 & 2 & N67 & 0.087 & 2 & & & \\
\hline N78 & 0.077 & 2 & N35 & 0.087 & 2 & N44 & 0.087 & 2 & & & \\
\hline N79 & 0.077 & 2 & N37 & 0.087 & 2 & $\mathrm{~N} 13$ & 0.087 & 2 & & & \\
\hline N70 & 0.077 & 2 & N38 & 0.087 & 2 & $\mathrm{~N} 12$ & 0.087 & 2 & & & \\
\hline N100 & 0.079 & 2 & N39 & 0.087 & 2 & N88 & 0.093 & 2 & & & \\
\hline N102 & 0.079 & 2 & $\mathrm{~N} 40$ & 0.087 & 2 & N89 & 0.093 & 2 & & & \\
\hline N3 & 0.081 & 2 & N41 & 0.087 & 2 & N90 & 0.093 & 2 & & & \\
\hline N76 & 0.082 & 2 & $\mathrm{~N} 42$ & 0.087 & 2 & N91 & 0.093 & 2 & & & \\
\hline
\end{tabular}

Here the $\mathrm{SE}$ of the 105 binary representation of the amino acid $A_{15}$ is ranging 
from 0 to 0.202 with standard deviation 0.0919. Based on the SEs of the binary

the primary protein sequences would reveal the amount of uncertainty of the presence or absence of the amino acid.
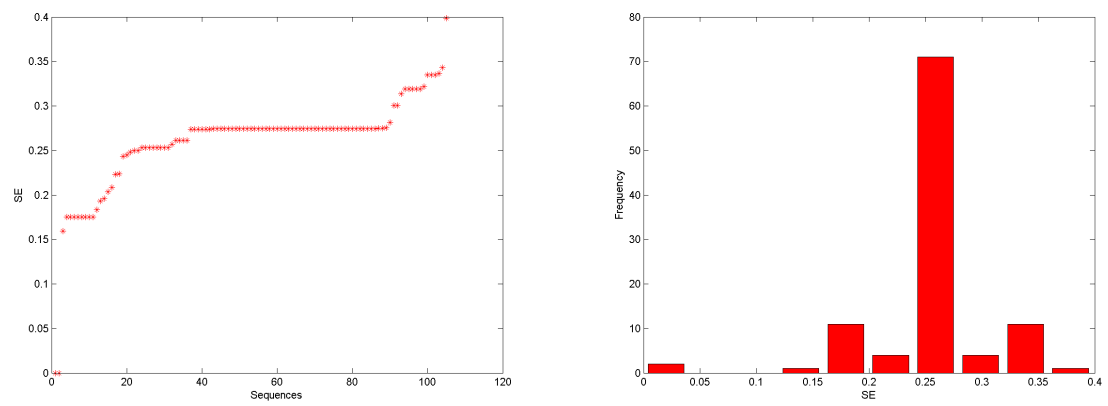

Figure 38: Plot of the SEs and corresponding histogram of all the binary sequences $B_{16}$ for $j=1,2, \ldots 105$ corresponding to the amino acid $A_{16}(Y)$.

Here the SE of the 105 binary representation of the amino acid $A_{16}$ is ranging from 0 to 0.398 with standard deviation 0.055. Based on the SEs of the binary sequences all these 105 primary protein sequences of SARS-CoV2, five clusters (C) are formed as presented in the Table 39. 
Table 39: SE of $105 B_{16}$ for $j=1,2, \ldots 105$ corresponding to the amino acid $A_{16}(Y)$.

\begin{tabular}{|c|c|c|c|c|c|c|c|c|c|c|c|}
\hline Seq & SE & C & Seq & SE & C & Seq & SE & C & Seq & $\mathrm{SE}$ & C \\
\hline N99 & 0.000 & 2 & N78 & 0.253 & 4 & N38 & 0.274 & 1 & N96 & 0.300 & 1 \\
\hline N103 & 0.000 & 2 & N79 & 0.257 & 4 & N39 & 0.274 & 1 & N97 & 0.300 & 1 \\
\hline N81 & 0.159 & 5 & N98 & 0.261 & 4 & $\mathrm{~N} 43$ & 0.274 & 1 & N5 & 0.314 & 3 \\
\hline N88 & 0.175 & 5 & N32 & 0.262 & 4 & $\mathrm{~N} 45$ & 0.274 & 1 & N82 & 0.319 & 3 \\
\hline N89 & 0.175 & 5 & N36 & 0.262 & 4 & $\mathrm{~N} 46$ & 0.274 & 1 & N83 & 0.319 & 3 \\
\hline N90 & 0.175 & 5 & N58 & 0.262 & 4 & $\mathrm{~N} 47$ & 0.274 & 1 & N84 & 0.319 & 3 \\
\hline N91 & 0.175 & 5 & $\mathrm{~N} 26$ & 0.274 & 1 & $\mathrm{~N} 48$ & 0.274 & 1 & N85 & 0.319 & 3 \\
\hline N92 & 0.175 & 5 & $\mathrm{~N} 22$ & 0.274 & 1 & N50 & 0.274 & 1 & N86 & 0.319 & 3 \\
\hline N93 & 0.175 & 5 & N25 & 0.274 & 1 & N51 & 0.274 & 1 & N101 & 0.322 & 3 \\
\hline N94 & 0.175 & 5 & N40 & 0.274 & 1 & N52 & 0.274 & 1 & N9 & 0.335 & 3 \\
\hline N95 & 0.175 & 5 & N41 & 0.274 & 1 & N53 & 0.274 & 1 & N10 & 0.335 & 3 \\
\hline N15 & 0.183 & 5 & $\mathrm{~N} 42$ & 0.274 & 1 & N54 & 0.274 & 1 & N11 & 0.335 & 3 \\
\hline N6 & 0.193 & 5 & N14 & 0.274 & 1 & N55 & 0.274 & 1 & N100 & 0.336 & 3 \\
\hline N3 & 0.196 & 5 & N16 & 0.274 & 1 & N56 & 0.274 & 1 & N7 & 0.343 & 3 \\
\hline N104 & 0.203 & 5 & N17 & 0.274 & 1 & N57 & 0.274 & 1 & N80 & 0.398 & 3 \\
\hline N68 & 0.208 & 5 & N18 & 0.274 & 1 & N59 & 0.274 & 1 & & & \\
\hline N102 & 0.223 & 4 & N19 & 0.274 & 1 & N60 & 0.274 & 1 & & & \\
\hline $\mathrm{N} 2$ & 0.224 & 4 & $\mathrm{~N} 20$ & 0.274 & 1 & N61 & 0.274 & 1 & & & \\
\hline N105 & 0.244 & 4 & N21 & 0.274 & 1 & N62 & 0.274 & 1 & & & \\
\hline N8 & 0.245 & 4 & $\mathrm{~N} 23$ & 0.274 & 1 & N63 & 0.274 & 1 & & & \\
\hline N87 & 0.248 & 4 & $\mathrm{~N} 24$ & 0.274 & 1 & N65 & 0.274 & 1 & & & \\
\hline N69 & 0.250 & 4 & $\mathrm{~N} 27$ & 0.274 & 1 & N66 & 0.274 & 1 & & & \\
\hline N70 & 0.250 & 4 & N28 & 0.274 & 1 & N67 & 0.274 & 1 & & & \\
\hline N71 & 0.253 & 4 & N29 & 0.274 & 1 & $\mathrm{~N} 44$ & 0.274 & 1 & & & \\
\hline N72 & 0.253 & 4 & N30 & 0.274 & 1 & $\mathrm{~N} 13$ & 0.275 & 1 & & & \\
\hline N73 & 0.253 & 4 & N31 & 0.274 & 1 & $\mathrm{~N} 12$ & 0.275 & 1 & & & \\
\hline N74 & 0.253 & 4 & N33 & 0.274 & 1 & $\mathrm{~N} 49$ & 0.275 & 1 & & & \\
\hline N75 & 0.253 & 4 & N34 & 0.274 & 1 & N64 & 0.275 & 1 & & & \\
\hline N76 & 0.253 & 4 & N35 & 0.274 & 1 & N1 & 0.275 & 1 & & & \\
\hline N77 & 0.253 & 4 & N37 & 0.274 & 1 & N4 & 0.281 & 1 & & & \\
\hline
\end{tabular}

The SE of the binary spatial representations of the proteins N99 and N103 is zero as the the amino acid does not present at all over these two proteins. Rest all the proteins have the amino acid $A_{16}$ presence with certainty as presented 820 in the Table 39.

\subsection{Shannon Entropy of $B_{17_{j}}$ for $j=1,2, \ldots 105$ and Classification}

For the amino acid $A_{17}(D)$ the SE for the 105 binary sequences $B_{17_{j}}$ for $j=$ $1,2, \ldots 105$ have been determined. The plot of the SE for the binary sequences has been plotted and corresponding histogram is also given in the Fig 39. The

${ }_{825} \mathrm{SE}$ of the binary representations of ordering of the amino acid $A_{17}$ over all the primary protein sequences would reveal the amount of uncertainty of the presence or absence of the amino acid. 

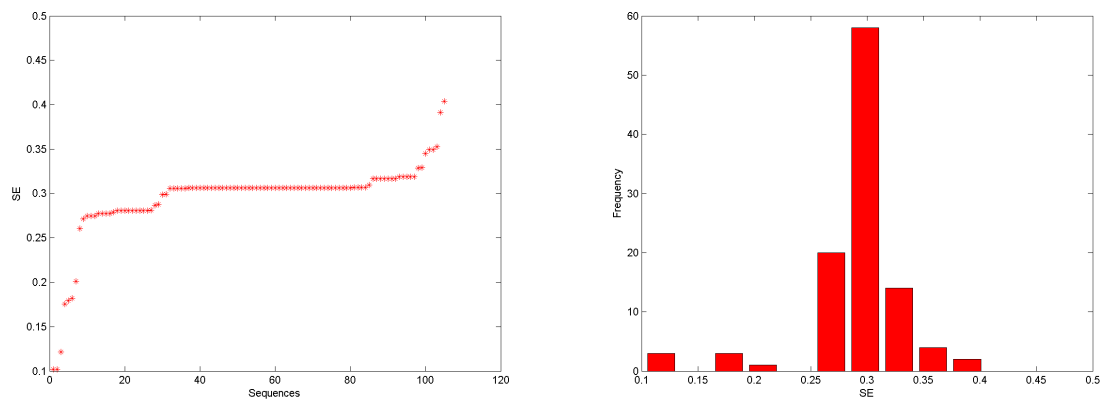

Figure 39: Plot of the SEs and corresponding histogram of all the binary sequences $B_{17_{j}}$ for $j=1,2, \ldots 105$ corresponding to the amino acid $A_{17}(D)$.

Table 40: SE of $105 B_{17_{j}}$ for $j=1,2, \ldots 105$ corresponding to the amino acid $A_{17}(D)$.

\begin{tabular}{|c|c|c|c|c|c|c|c|c|c|c|c|}
\hline Seq & $\mathrm{SE}$ & C & Seq & $\mathrm{SE}$ & C & Seq & $\mathrm{SE}$ & C & Seq & $\mathrm{SE}$ & C \\
\hline N96 & 0.102 & 5 & N98 & 0.299 & 1 & $\mathrm{~N} 42$ & 0.307 & 1 & N94 & 0.317 & 1 \\
\hline N97 & 0.102 & 5 & N29 & 0.306 & 1 & N45 & 0.307 & 1 & N95 & 0.317 & 1 \\
\hline N87 & 0.121 & 5 & $\mathrm{~N} 43$ & 0.306 & 1 & $\mathrm{~N} 47$ & 0.307 & 1 & N82 & 0.319 & 1 \\
\hline N80 & 0.176 & 2 & $\mathrm{~N} 46$ & 0.306 & 1 & $\mathrm{~N} 48$ & 0.307 & 1 & N83 & 0.319 & 1 \\
\hline N8 & 0.179 & 2 & N66 & 0.306 & 1 & N49 & 0.307 & 1 & N84 & 0.319 & 1 \\
\hline N101 & 0.182 & 2 & N67 & 0.306 & 1 & N50 & 0.307 & 1 & N85 & 0.319 & 1 \\
\hline N6 & 0.201 & 2 & N26 & 0.306 & 1 & N51 & 0.307 & 1 & N86 & 0.319 & 1 \\
\hline N7 & 0.260 & 3 & N14 & 0.307 & 1 & N52 & 0.307 & 1 & N103 & 0.328 & 1 \\
\hline N81 & 0.271 & 3 & N16 & 0.307 & 1 & N53 & 0.307 & 1 & N105 & 0.329 & 1 \\
\hline N9 & 0.275 & 3 & N17 & 0.307 & 1 & N54 & 0.307 & 1 & N1 & 0.345 & 4 \\
\hline N10 & 0.275 & 3 & N18 & 0.307 & 1 & N55 & 0.307 & 1 & N68 & 0.349 & 4 \\
\hline N11 & 0.275 & 3 & N19 & 0.307 & 1 & N56 & 0.307 & 1 & N3 & 0.350 & 4 \\
\hline N32 & 0.277 & 3 & $\mathrm{~N} 20$ & 0.307 & 1 & N57 & 0.307 & 1 & N104 & 0.353 & 4 \\
\hline N36 & 0.277 & 3 & $\mathrm{~N} 21$ & 0.307 & 1 & N59 & 0.307 & 1 & N99 & 0.391 & 4 \\
\hline N58 & 0.277 & 3 & $\mathrm{~N} 22$ & 0.307 & 1 & N60 & 0.307 & 1 & N100 & 0.404 & 4 \\
\hline N75 & 0.277 & 3 & $\mathrm{~N} 23$ & 0.307 & 1 & N61 & 0.307 & 1 & & & \\
\hline N5 & 0.279 & 3 & $\mathrm{~N} 24$ & 0.307 & 1 & $\mathrm{~N} 62$ & 0.307 & 1 & & & \\
\hline N69 & 0.281 & 3 & N25 & 0.307 & 1 & N63 & 0.307 & 1 & & & \\
\hline N71 & 0.281 & 3 & $\mathrm{~N} 27$ & 0.307 & 1 & N64 & 0.307 & 1 & & & \\
\hline N72 & 0.281 & 3 & $\mathrm{~N} 28$ & 0.307 & 1 & N65 & 0.307 & 1 & & & \\
\hline N73 & 0.281 & 3 & N30 & 0.307 & 1 & $\mathrm{~N} 44$ & 0.307 & 1 & & & \\
\hline N74 & 0.281 & 3 & N31 & 0.307 & 1 & $\mathrm{~N} 13$ & 0.307 & 1 & & & \\
\hline N76 & 0.281 & 3 & N33 & 0.307 & 1 & $\mathrm{~N} 12$ & 0.307 & 1 & & & \\
\hline N77 & 0.281 & 3 & N34 & 0.307 & 1 & N92 & 0.307 & 1 & & & \\
\hline N78 & 0.281 & 3 & N35 & 0.307 & 1 & N102 & 0.310 & 1 & & & \\
\hline N79 & 0.281 & 3 & N37 & 0.307 & 1 & N88 & 0.317 & 1 & & & \\
\hline N70 & 0.281 & 3 & N38 & 0.307 & 1 & N89 & 0.317 & 1 & & & \\
\hline N15 & 0.286 & 3 & N39 & 0.307 & 1 & N90 & 0.317 & 1 & & & \\
\hline N2 & 0.288 & 3 & $\mathrm{~N} 40$ & 0.307 & 1 & N91 & 0.317 & 1 & & & \\
\hline $\mathrm{N} 4$ & 0.299 & 1 & N41 & 0.307 & 1 & N93 & 0.317 & 1 & & & \\
\hline
\end{tabular}

Here the SE of the 105 binary representation of the amino acid $A_{17}$ is ranging 
from 0.102 to 0.404 with standard deviation 0.0448. Based on the SEs of the

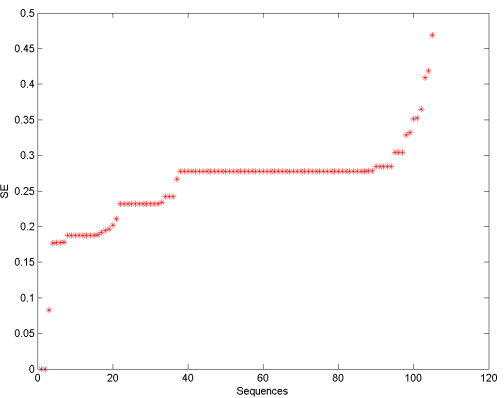

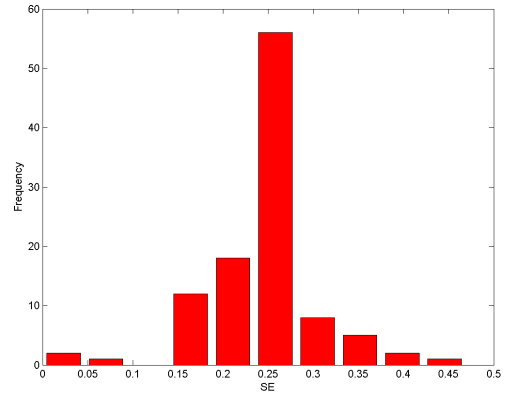

Figure 40: Plot of the SEs and corresponding histogram of all the binary sequences $B_{18_{j}}$ for $j=1,2, \ldots 105$ corresponding to the amino acid $A_{18}(D)$.

Here the SE of the 105 binary representation of the amino acid $A_{18}$ is ranging from 0 to 0.404 with standard deviation 0.0638. Based on the SEs of the binary 845 sequences all these 105 primary protein sequences of SARS-CoV2, five clusters (C) are formed as presented in the Table 41. 
Table 41: SE of $105 B_{18_{j}}$ for $j=1,2, \ldots 105$ corresponding to the amino acid $A_{18}(E)$.

\begin{tabular}{|c|c|c|c|c|c|c|c|c|c|c|c|}
\hline Seq & SE & C & Seq & SE & C & Seq & SE & C & Seq & $\mathrm{SE}$ & C \\
\hline N80 & 0.000 & 2 & N79 & 0.232 & 5 & $\mathrm{~N} 41$ & 0.277 & 1 & N83 & 0.285 & 1 \\
\hline N99 & 0.000 & 2 & N70 & 0.232 & 5 & $\mathrm{~N} 42$ & 0.277 & 1 & N84 & 0.285 & 1 \\
\hline N101 & 0.083 & 4 & N5 & 0.234 & 5 & $\mathrm{~N} 43$ & 0.277 & 1 & N85 & 0.285 & 1 \\
\hline N98 & 0.177 & 3 & N9 & 0.242 & 5 & $\mathrm{~N} 45$ & 0.277 & 1 & N86 & 0.285 & 1 \\
\hline N96 & 0.177 & 3 & N10 & 0.242 & 5 & $\mathrm{~N} 46$ & 0.277 & 1 & N32 & 0.304 & 1 \\
\hline N97 & 0.177 & 3 & N11 & 0.242 & 5 & $\mathrm{~N} 47$ & 0.277 & 1 & N36 & 0.304 & 1 \\
\hline $\mathrm{N} 105$ & 0.178 & 3 & N3 & 0.267 & 1 & $\mathrm{~N} 48$ & 0.277 & 1 & N58 & 0.304 & 1 \\
\hline N88 & 0.188 & 3 & N26 & 0.277 & 1 & N49 & 0.277 & 1 & N103 & 0.328 & 1 \\
\hline N89 & 0.188 & 3 & N16 & 0.277 & 1 & N50 & 0.277 & 1 & N4 & 0.332 & 1 \\
\hline N90 & 0.188 & 3 & N17 & 0.277 & 1 & N51 & 0.277 & 1 & N87 & 0.351 & 1 \\
\hline N91 & 0.188 & 3 & N18 & 0.277 & 1 & N52 & 0.277 & 1 & N 104 & 0.353 & 1 \\
\hline N92 & 0.188 & 3 & N19 & 0.277 & 1 & N53 & 0.277 & 1 & N81 & 0.365 & 1 \\
\hline N93 & 0.188 & 3 & N20 & 0.277 & 1 & N54 & 0.277 & 1 & N68 & 0.409 & 1 \\
\hline N94 & 0.188 & 3 & $\mathrm{~N} 21$ & 0.277 & 1 & N55 & 0.277 & 1 & N6 & 0.418 & 1 \\
\hline N95 & 0.188 & 3 & $\mathrm{~N} 22$ & 0.277 & 1 & N56 & 0.277 & 1 & N15 & 0.469 & 1 \\
\hline $\mathrm{N} 2$ & 0.188 & 3 & $\mathrm{~N} 23$ & 0.277 & 1 & N57 & 0.277 & 1 & & & \\
\hline N102 & 0.191 & 3 & N24 & 0.277 & 1 & N59 & 0.277 & 1 & & & \\
\hline N7 & 0.194 & 3 & $\mathrm{~N} 25$ & 0.277 & 1 & N60 & 0.277 & 1 & & & \\
\hline N1 & 0.196 & 3 & $\mathrm{~N} 27$ & 0.277 & 1 & N61 & 0.277 & 1 & & & \\
\hline N8 & 0.202 & 3 & $\mathrm{~N} 28$ & 0.277 & 1 & $\mathrm{~N} 62$ & 0.277 & 1 & & & \\
\hline N100 & 0.210 & 5 & $\mathrm{~N} 29$ & 0.277 & 1 & N63 & 0.277 & 1 & & & \\
\hline N69 & 0.232 & 5 & N30 & 0.277 & 1 & N64 & 0.277 & 1 & & & \\
\hline N71 & 0.232 & 5 & N31 & 0.277 & 1 & N65 & 0.277 & 1 & & & \\
\hline N72 & 0.232 & 5 & N33 & 0.277 & 1 & N67 & 0.277 & 1 & & & \\
\hline N73 & 0.232 & 5 & N34 & 0.277 & 1 & $\mathrm{~N} 44$ & 0.277 & 1 & & & \\
\hline N74 & 0.232 & 5 & N35 & 0.277 & 1 & $\mathrm{~N} 13$ & 0.278 & 1 & & & \\
\hline N75 & 0.232 & 5 & N37 & 0.277 & 1 & $\mathrm{~N} 12$ & 0.278 & 1 & & & \\
\hline N76 & 0.232 & 5 & N38 & 0.277 & 1 & N14 & 0.278 & 1 & & & \\
\hline N77 & 0.232 & 5 & N39 & 0.277 & 1 & N66 & 0.278 & 1 & & & \\
\hline N78 & 0.232 & 5 & $\mathrm{~N} 40$ & 0.277 & 1 & $\mathrm{~N} 82$ & 0.285 & 1 & & & \\
\hline
\end{tabular}

The amino acid $A_{18}(E)$ is absent in the proteins N80 and N99 (belong to the cluster 2) with length 13 and 38 respectively consequently the SE of these two proteins for its binary spatial representations $B_{18_{80}}$ and $B_{18_{99}}$. The other four clusters containing different proteins according to the closeness of the SE obtained for their spatial representations of the amino acids over the proteins. It is noted that the amino acid $A_{18}$ is present over all the 105 proteins with almost certainty $(H E s<0.5)$.

\subsection{Shannon Entropy of $B_{19_{j}}$ for $j=1,2, \ldots 105$ and Classification}

For the amino acid $A_{19}(K)$ the SE for the 105 binary sequences $B_{19_{j}}$ for $j=$ $1,2, \ldots 105$ have been determined. The plot of the SE for the binary sequences has been plotted and corresponding histogram is also given in the Fig 41. The 
SE of the binary representations of ordering of the amino acid $A_{19}$ over all the primary protein sequences would reveal the amount of uncertainty of the presence or absence of the amino acid.
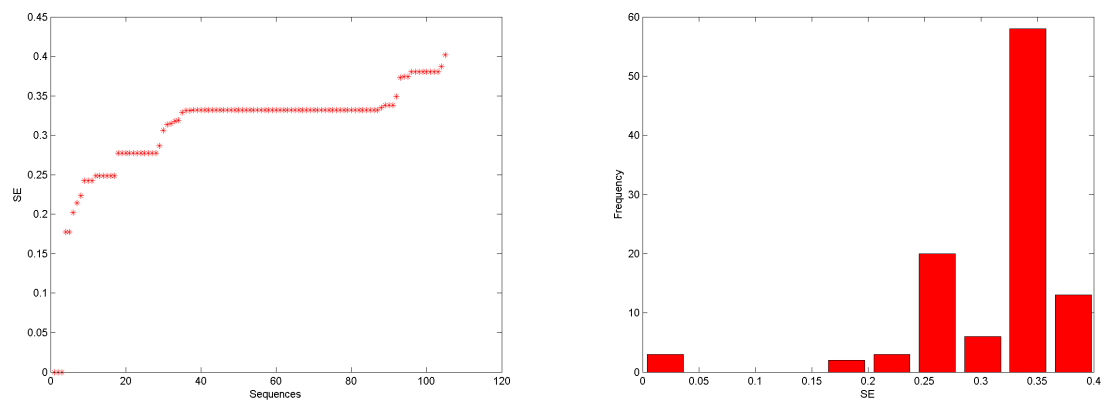

Figure 41: Plot of the SEs and corresponding histogram of all the binary sequences $B_{19_{j}}$ for $j=1,2, \ldots 105$ corresponding to the amino acid $A_{19}(K)$.

Here the $\mathrm{SE}$ of the 105 binary representation of the amino acid $A_{19}$ is ranging from 0 to 0.402 . Based on the SEs of the binary sequences all these 105 primary protein sequences of SARS-CoV2, five clusters (C) are formed as presented in the Table 42.

Every term of the binary representations $B_{19_{80}}, B_{19_{81}}$ and $B_{19_{99}}$ of lengths 38,43 and 13 respectively is zero and consequently the SE is turned out to be zero which implies the absence of the amino acid is without any uncertainty. The other proteins of the remaining clusters 1,2, 4 and 5 have the presence of the amino acid $A_{19}$ with almost certainty. 
Table 42: SE of $105 B_{19_{j}}$ for $j=1,2, \ldots 105$ corresponding to the amino acid $A_{19}(K)$.

\begin{tabular}{|c|c|c|c|c|c|c|c|c|c|c|c|}
\hline Seq & $\mathrm{SE}$ & C & Seq & $\mathrm{SE}$ & C & Seq & SE & C & Seq & $\mathrm{SE}$ & C \\
\hline $\mathrm{N} 80$ & 0.000 & 3 & N5 & 0.314 & 1 & N39 & 0.332 & 1 & N58 & 0.338 & 1 \\
\hline N81 & 0.000 & 3 & N1 & 0.315 & 1 & $\mathrm{~N} 40$ & 0.332 & 1 & N68 & 0.349 & 1 \\
\hline N99 & 0.000 & 3 & $\mathrm{~N} 2$ & 0.318 & 1 & $\mathrm{~N} 41$ & 0.332 & 1 & $\mathrm{~N} 4$ & 0.373 & 4 \\
\hline N96 & 0.177 & 2 & N87 & 0.319 & 1 & $\mathrm{~N} 42$ & 0.332 & 1 & N104 & 0.374 & 4 \\
\hline N97 & 0.177 & 2 & N105 & 0.329 & 1 & $\mathrm{~N} 43$ & 0.332 & 1 & N103 & 0.374 & 4 \\
\hline $\mathrm{N} 8$ & 0.202 & 2 & N54 & 0.331 & 1 & $\mathrm{~N} 45$ & 0.332 & 1 & N88 & 0.381 & 4 \\
\hline N7 & 0.214 & 2 & N57 & 0.331 & 1 & $\mathrm{~N} 46$ & 0.332 & 1 & N89 & 0.381 & 4 \\
\hline $\mathrm{N} 102$ & 0.223 & 2 & N12 & 0.332 & 1 & $\mathrm{~N} 47$ & 0.332 & 1 & N90 & 0.381 & 4 \\
\hline N9 & 0.242 & 5 & N26 & 0.332 & 1 & $\mathrm{~N} 48$ & 0.332 & 1 & N91 & 0.381 & 4 \\
\hline N10 & 0.242 & 5 & N14 & 0.332 & 1 & N 49 & 0.332 & 1 & N92 & 0.381 & 4 \\
\hline N11 & 0.242 & 5 & N16 & 0.332 & 1 & N50 & 0.332 & 1 & N93 & 0.381 & 4 \\
\hline N82 & 0.248 & 5 & N17 & 0.332 & 1 & N51 & 0.332 & 1 & N94 & 0.381 & 4 \\
\hline N83 & 0.248 & 5 & N18 & 0.332 & 1 & N52 & 0.332 & 1 & N95 & 0.381 & 4 \\
\hline N84 & 0.248 & 5 & N19 & 0.332 & 1 & N53 & 0.332 & 1 & N3 & 0.387 & 4 \\
\hline N85 & 0.248 & 5 & $\mathrm{~N} 20$ & 0.332 & 1 & N55 & 0.332 & 1 & N6 & 0.402 & 4 \\
\hline N86 & 0.248 & 5 & $\mathrm{~N} 21$ & 0.332 & 1 & N56 & 0.332 & 1 & & & \\
\hline N101 & 0.249 & 5 & $\mathrm{~N} 22$ & 0.332 & 1 & N59 & 0.332 & 1 & & & \\
\hline N69 & 0.277 & 5 & $\mathrm{~N} 23$ & 0.332 & 1 & N60 & 0.332 & 1 & & & \\
\hline N71 & 0.277 & 5 & N24 & 0.332 & 1 & N61 & 0.332 & 1 & & & \\
\hline N72 & 0.277 & 5 & N25 & 0.332 & 1 & $\mathrm{~N} 62$ & 0.332 & 1 & & & \\
\hline N73 & 0.277 & 5 & $\mathrm{~N} 27$ & 0.332 & 1 & N63 & 0.332 & 1 & & & \\
\hline N74 & 0.277 & 5 & $\mathrm{~N} 28$ & 0.332 & 1 & $\mathrm{~N} 64$ & 0.332 & 1 & & & \\
\hline N75 & 0.277 & 5 & N29 & 0.332 & 1 & N65 & 0.332 & 1 & & & \\
\hline N76 & 0.277 & 5 & N30 & 0.332 & 1 & N66 & 0.332 & 1 & & & \\
\hline N77 & 0.277 & 5 & N31 & 0.332 & 1 & $\mathrm{~N} 67$ & 0.332 & 1 & & & \\
\hline N78 & 0.277 & 5 & N33 & 0.332 & 1 & $\mathrm{~N} 44$ & 0.332 & 1 & & & \\
\hline N79 & 0.277 & 5 & N34 & 0.332 & 1 & $\mathrm{~N} 13$ & 0.332 & 1 & & & \\
\hline N70 & 0.278 & 5 & N35 & 0.332 & 1 & N98 & 0.335 & 1 & & & \\
\hline N15 & 0.286 & 5 & N37 & 0.332 & 1 & $\mathrm{~N} 32$ & 0.338 & 1 & & & \\
\hline N100 & 0.306 & 1 & N38 & 0.332 & 1 & N36 & 0.338 & 1 & & & \\
\hline
\end{tabular}

870

\subsection{Shannon Entropy of $B_{20_{j}}$ for $j=1,2, \ldots 105$ and Classification}

For the amino acid $A_{20}(R)$ the SE for the 105 binary sequences $B_{20_{j}}$ for $j=$ $1,2, \ldots 105$ have been determined. The plot of the SE for the binary sequences has been plotted and corresponding histogram is also given in the Fig 42. The SE of the binary representations of ordering of the amino acid $A_{20}$ over all the primary protein sequences would reveal the amount of uncertainty of the presence or absence of the amino acid. 

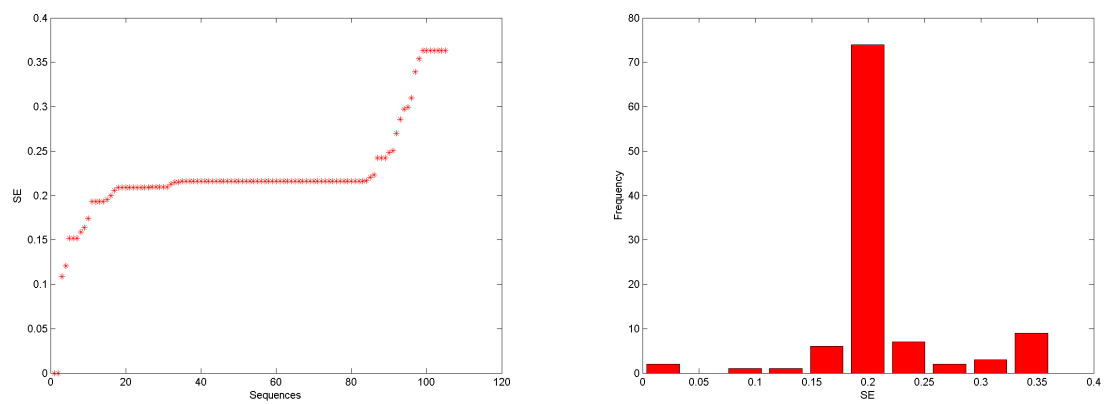

Figure 42: Plot of the SEs and corresponding histogram of all the binary sequences $B_{20}{ }_{j}$ for $j=1,2, \ldots 105$ corresponding to the amino acid $A_{20}(R)$.

Table 43: SE of $105 B_{20_{j}}$ for $j=1,2, \ldots 105$ corresponding to the amino acid $A_{20}(R)$.

\begin{tabular}{|c|c|c|c|c|c|c|c|c|c|c|c|}
\hline Seq & $\mathrm{SE}$ & C & Seq & $\mathrm{SE}$ & C & Seq & $\mathrm{SE}$ & C & Seq & $\mathrm{SE}$ & C \\
\hline N81 & 0.000 & 5 & N86 & 0.210 & 1 & $\mathrm{~N} 46$ & 0.216 & 1 & N1 & 0.250 & 1 \\
\hline N99 & 0.000 & 5 & N71 & 0.213 & 1 & $\mathrm{~N} 47$ & 0.216 & 1 & N100 & 0.270 & 1 \\
\hline $\mathrm{N} 2$ & 0.109 & 4 & N31 & 0.215 & 1 & $\mathrm{~N} 48$ & 0.216 & 1 & N5 & 0.286 & 3 \\
\hline N68 & 0.121 & 4 & N39 & 0.215 & 1 & N49 & 0.216 & 1 & N80 & 0.297 & 3 \\
\hline N9 & 0.152 & 4 & $\mathrm{~N} 26$ & 0.216 & 1 & N50 & 0.216 & 1 & N98 & 0.299 & 3 \\
\hline N10 & 0.152 & 4 & N14 & 0.216 & 1 & N51 & 0.216 & 1 & $\mathrm{~N} 15$ & 0.310 & 3 \\
\hline N11 & 0.152 & 4 & N16 & 0.216 & 1 & N52 & 0.216 & 1 & N8 & 0.339 & 3 \\
\hline N4 & 0.159 & 4 & N17 & 0.216 & 1 & N53 & 0.216 & 1 & N95 & 0.354 & 3 \\
\hline N103 & 0.164 & 4 & N18 & 0.216 & 1 & N55 & 0.216 & 1 & N88 & 0.363 & 3 \\
\hline N104 & 0.174 & 2 & N19 & 0.216 & 1 & N56 & 0.216 & 1 & N89 & 0.363 & 3 \\
\hline N32 & 0.193 & 2 & $\mathrm{~N} 20$ & 0.216 & 1 & N57 & 0.216 & 1 & N90 & 0.363 & 3 \\
\hline N36 & 0.193 & 2 & N21 & 0.216 & 1 & N59 & 0.216 & 1 & N91 & 0.363 & 3 \\
\hline N58 & 0.193 & 2 & $\mathrm{~N} 22$ & 0.216 & 1 & N60 & 0.216 & 1 & N92 & 0.363 & 3 \\
\hline N6 & 0.193 & 2 & $\mathrm{~N} 23$ & 0.216 & 1 & N61 & 0.216 & 1 & N93 & 0.363 & 3 \\
\hline N105 & 0.195 & 2 & $\mathrm{~N} 24$ & 0.216 & 1 & N62 & 0.216 & 1 & N94 & 0.363 & 3 \\
\hline N101 & 0.200 & 2 & N25 & 0.216 & 1 & N63 & 0.216 & 1 & & & \\
\hline N70 & 0.205 & 1 & $\mathrm{~N} 27$ & 0.216 & 1 & N64 & 0.216 & 1 & & & \\
\hline N69 & 0.209 & 1 & N28 & 0.216 & 1 & N65 & 0.216 & 1 & & & \\
\hline N72 & 0.209 & 1 & N29 & 0.216 & 1 & N66 & 0.216 & 1 & & & \\
\hline N73 & 0.209 & 1 & N30 & 0.216 & 1 & N67 & 0.216 & 1 & & & \\
\hline N74 & 0.209 & 1 & N33 & 0.216 & 1 & $\mathrm{~N} 44$ & 0.216 & 1 & & & \\
\hline N75 & 0.209 & 1 & N34 & 0.216 & 1 & $\mathrm{~N} 13$ & 0.216 & 1 & & & \\
\hline N76 & 0.209 & 1 & N35 & 0.216 & 1 & $\mathrm{~N} 12$ & 0.216 & 1 & & & \\
\hline N77 & 0.209 & 1 & N37 & 0.216 & 1 & N54 & 0.217 & 1 & & & \\
\hline N78 & 0.209 & 1 & N38 & 0.216 & 1 & N3 & 0.221 & 1 & & & \\
\hline N79 & 0.209 & 1 & $\mathrm{~N} 40$ & 0.216 & 1 & N102 & 0.223 & 1 & & & \\
\hline $\mathrm{N} 82$ & 0.210 & 1 & N41 & 0.216 & 1 & N7 & 0.242 & 1 & & & \\
\hline N83 & 0.210 & 1 & $\mathrm{~N} 42$ & 0.216 & 1 & N96 & 0.242 & 1 & & & \\
\hline N84 & 0.210 & 1 & $\mathrm{~N} 43$ & 0.216 & 1 & N97 & 0.242 & 1 & & & \\
\hline N85 & 0.210 & 1 & $\mathrm{~N} 45$ & 0.216 & 1 & N87 & 0.248 & 1 & & & \\
\hline
\end{tabular}

Here the SE of the 105 binary representation of the amino acid $A_{20}$ is ranging 
from 0 to 0.404 with standard deviation 0.0638. Based on the SEs of the binary sequences all these 105 primary protein sequences of SARS-CoV2, five clusters (C) are formed as presented in the Table 43.

The amino acid $A_{20}(R)$ does not present in the protein sequence $\mathrm{N} 81$ and N99 and consequently the SE is zero for the binary representations $B_{20_{80}}$ and $B_{20_{99}}$. The other proteins of the remaining clusters $1,2,4$ and 4 have the presence of the amino acid $A_{20}$ with almost certainty.

\subsection{A Collective Views of the SEs}

It needless to mention that the SE is would be zero if the binary representations $B_{i_{j}}$ such that the amino acid $A_{i}$ is absent throughput the protein $N j$. In fact that is what we have encountered throughout this study of SEs. It has been observed that the SE of the spatial distribution of the amino acids over some proteins is maximum for the smaller lengthy sequences such as N99, N80 etc. A surprising fact has been revealed that for some given amino acid $A_{i}$, the SE of some of the spatial distributions $B_{i_{j}}$ for some protein sequence $N j$ irrespective of their lengths is identical for many values of $j$. This essentially reports that the probability of the presence of the amino acid $A_{i}$ over those proteins is same.

Here we explore the correlation of amount uncertainty of the presence/absence of the amino acids over the proteins of SARS-CoV2 of the spatial representations. Following is the correlation matrix of ten amino acids A, C, F, G, $\mathrm{H}, \mathrm{I}, \mathrm{L}, \mathrm{M}, \mathrm{N}$ and $\mathrm{P}$ versus another ten amino acids $\mathrm{Q}, \mathrm{S}, \mathrm{T}, \mathrm{V}, \mathrm{W}, \mathrm{Y}, \mathrm{D}, \mathrm{E}, \mathrm{K}$ and R.

Table 44: Correlation matrix of SEs of the presence of the amino acids over the proteins

\begin{tabular}{|c|c|c|c|c|c|c|c|c|c|c|}
\hline $\mathbf{r}(\mathrm{SE})$ & $\mathbf{Q}$ & $\mathbf{S}$ & $\mathbf{T}$ & $\mathbf{V}$ & $\mathbf{W}$ & $\mathbf{Y}$ & $\mathbf{D}$ & $\mathbf{E}$ & $\mathbf{K}$ & $\mathbf{R}$ \\
\hline $\mathbf{A}$ & 0.321 & 0.290 & -0.019 & -0.367 & -0.143 & -0.491 & 0.192 & -0.481 & 0.073 & 0.126 \\
\hline $\mathbf{C}$ & -0.566 & -0.402 & 0.020 & 0.621 & -0.152 & 0.530 & -0.238 & 0.237 & -0.211 & -0.467 \\
\hline $\mathbf{F}$ & -0.300 & 0.037 & -0.552 & 0.267 & -0.252 & 0.181 & -0.253 & -0.261 & -0.840 & -0.539 \\
\hline $\mathbf{G}$ & 0.494 & 0.007 & 0.351 & -0.454 & 0.059 & -0.230 & 0.265 & -0.212 & 0.396 & 0.523 \\
\hline $\mathbf{H}$ & -0.279 & -0.427 & -0.112 & 0.223 & 0.363 & 0.359 & 0.172 & 0.565 & -0.019 & -0.284 \\
\hline $\mathbf{I}$ & -0.225 & -0.223 & -0.108 & 0.093 & 0.341 & 0.436 & -0.191 & 0.309 & -0.245 & -0.292 \\
\hline $\mathbf{L}$ & -0.606 & -0.086 & -0.234 & 0.355 & 0.132 & 0.016 & -0.516 & 0.184 & -0.424 & -0.356 \\
\hline $\mathbf{M}$ & -0.244 & -0.455 & 0.103 & -0.001 & 0.345 & 0.022 & 0.055 & 0.074 & 0.098 & -0.117 \\
\hline $\mathbf{N}$ & -0.039 & 0.010 & 0.220 & -0.021 & -0.227 & -0.089 & -0.024 & -0.424 & -0.032 & 0.116 \\
\hline $\mathbf{P}$ & 0.411 & -0.053 & 0.472 & -0.352 & -0.051 & 0.245 & 0.097 & -0.069 & 0.451 & 0.646 \\
\hline
\end{tabular}




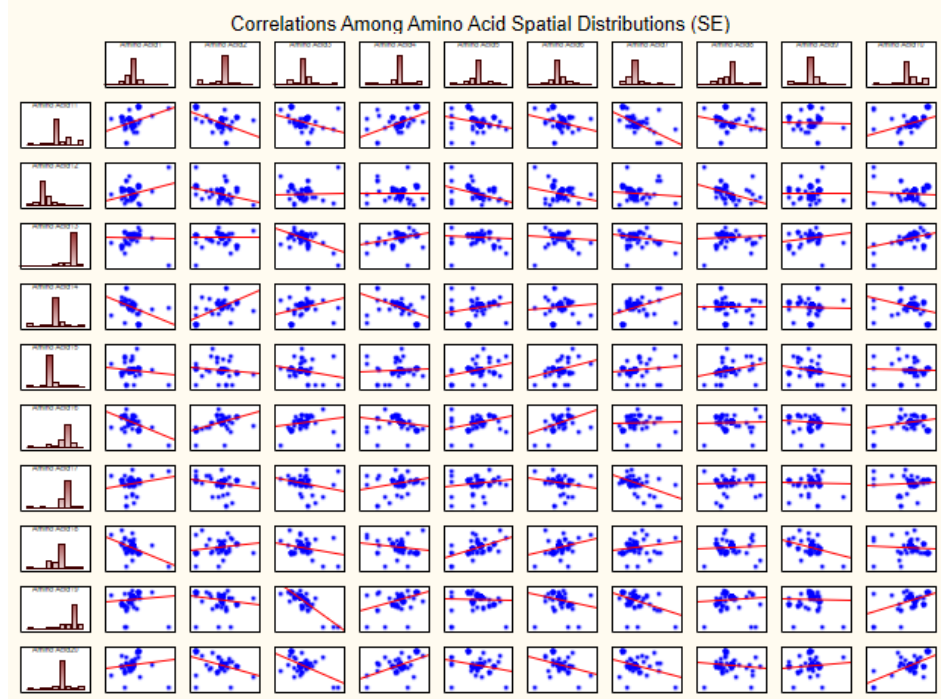

Figure 43: Plot of the correlation of the SEs of the amino acids distribution distinct pairwise.

900 of the amino acid $\mathrm{R}$ with the spatial distribution of the amino acid $\mathrm{P}$ is given below in the Fig. 44. 


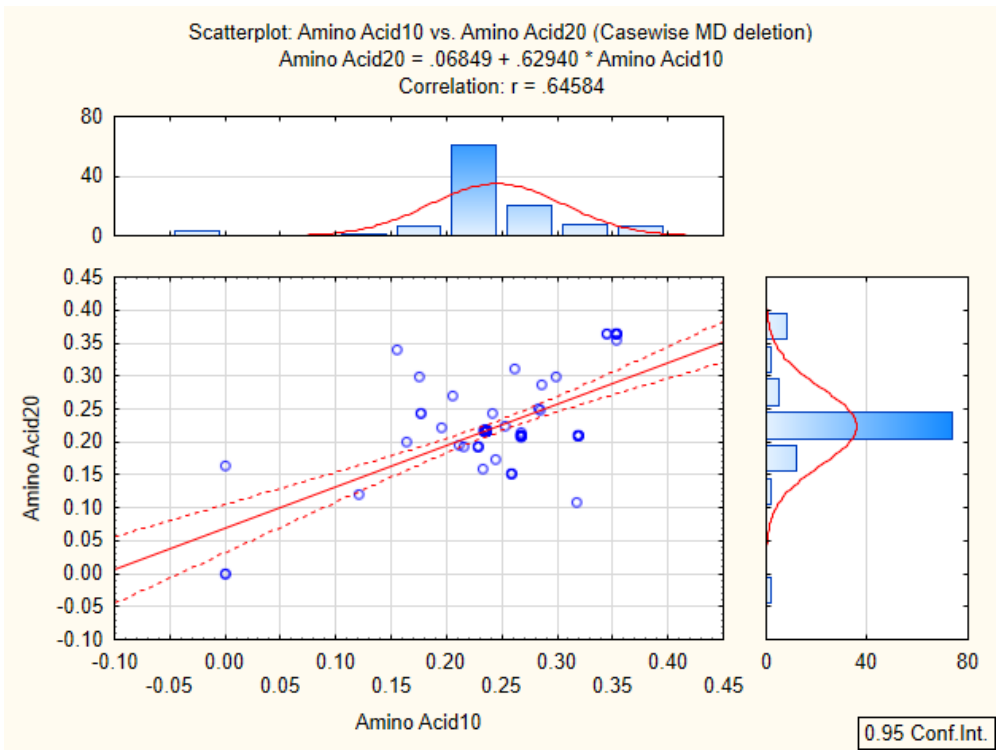

Figure 44: Plot of the correlation of the HEs of the amino acid $\mathrm{R}$ with that of $\mathrm{P}$.

Next we are moving towards the entropy of conservation of amino acids over the 105 SARS-CoV2 proteins in the following subsection.

\subsection{Amino Acid Conservation Shannon Entropy and Its Classification}

For each of the 105 protein sequences the amino acid conservation information have been determined through $\mathrm{HE}$ as described earlier. In the following Table 45, the Shannon entropy $\left(S E \_T 2\right)$ for each sequence and based on the SE, the formed clusters (C) are given. The plot of the SE over the 105 protein sequences with its histogram are given in the Fig. 45. 

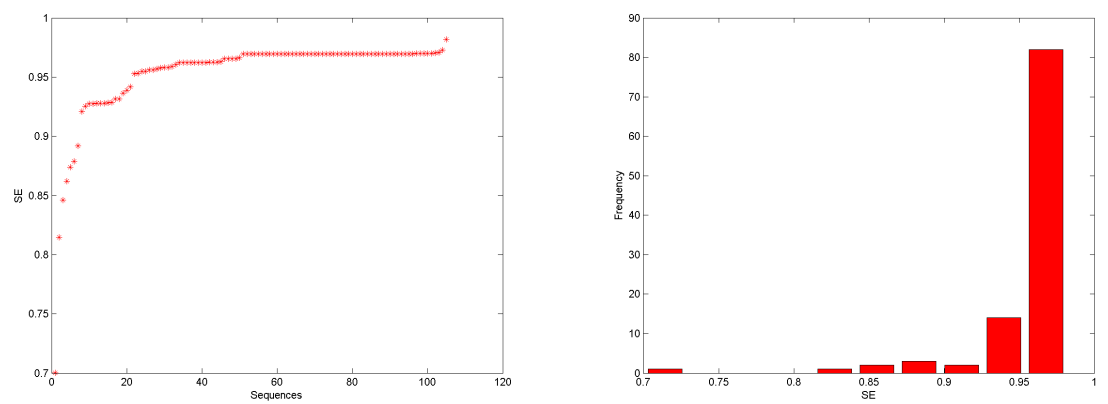

Figure 45: Plot of the SEs and corresponding histogram of all the protein sequences.

Table 45: Amino Acid Conservation Shannon Entropy

\begin{tabular}{|c|c|c|c|c|c|c|c|c|c|c|c|}
\hline Seq & SE_T2 & C & Seq & SE_T2 & C & Seq & SE_T2 & C & Seq & SE_T2 & C \\
\hline N99 & 0.700 & 4 & N11 & 0.957 & 7 & $\mathrm{~N} 13$ & 0.970 & 2 & N39 & 0.970 & 2 \\
\hline N81 & 0.815 & 6 & N10 & 0.958 & 7 & $\mathrm{~N} 23$ & 0.970 & 2 & N57 & 0.970 & 2 \\
\hline N97 & 0.846 & 6 & N84 & 0.958 & 7 & N37 & 0.970 & 2 & N16 & 0.970 & 2 \\
\hline N96 & 0.862 & 5 & N85 & 0.958 & 7 & N49 & 0.970 & 2 & $\mathrm{~N} 29$ & 0.970 & 2 \\
\hline N103 & 0.874 & 5 & N83 & 0.959 & 7 & N64 & 0.970 & 2 & N17 & 0.970 & 2 \\
\hline N80 & 0.879 & 5 & N4 & 0.961 & 8 & N66 & 0.970 & 2 & N18 & 0.970 & 2 \\
\hline N68 & 0.892 & 5 & N79 & 0.962 & 8 & N60 & 0.970 & 2 & N19 & 0.970 & 2 \\
\hline N15 & 0.921 & 9 & N70 & 0.962 & 8 & $\mathrm{~N} 12$ & 0.970 & 2 & N35 & 0.970 & 2 \\
\hline N3 & 0.925 & 9 & N69 & 0.962 & 8 & N65 & 0.970 & 2 & N38 & 0.970 & 2 \\
\hline N91 & 0.928 & 9 & N78 & 0.962 & 8 & N56 & 0.970 & 2 & N54 & 0.970 & 2 \\
\hline N94 & 0.928 & 9 & N75 & 0.962 & 8 & N41 & 0.970 & 2 & $\mathrm{~N} 21$ & 0.970 & 2 \\
\hline N90 & 0.928 & 9 & N74 & 0.962 & 8 & N55 & 0.970 & 2 & N44 & 0.970 & 2 \\
\hline N88 & 0.928 & 9 & N77 & 0.962 & 8 & N30 & 0.970 & 2 & $\mathrm{~N} 24$ & 0.970 & 2 \\
\hline N98 & 0.928 & 9 & N73 & 0.962 & 8 & N53 & 0.970 & 2 & N33 & 0.970 & 2 \\
\hline N89 & 0.928 & 9 & N72 & 0.962 & 8 & N59 & 0.970 & 2 & $\mathrm{~N} 28$ & 0.970 & 2 \\
\hline N92 & 0.929 & 9 & N71 & 0.963 & 8 & N40 & 0.970 & 2 & $\mathrm{~N} 27$ & 0.970 & 2 \\
\hline N95 & 0.931 & 1 & N5 & 0.963 & 8 & N43 & 0.970 & 2 & N52 & 0.970 & 2 \\
\hline N93 & 0.931 & 1 & N76 & 0.963 & 8 & N48 & 0.970 & 2 & N47 & 0.970 & 2 \\
\hline N87 & 0.936 & 1 & N58 & 0.965 & 8 & N50 & 0.970 & 2 & $\mathrm{~N} 62$ & 0.970 & 2 \\
\hline N8 & 0.939 & 3 & N36 & 0.965 & 8 & N51 & 0.970 & 2 & N34 & 0.970 & 2 \\
\hline N101 & 0.942 & 3 & N32 & 0.965 & 8 & $\mathrm{~N} 25$ & 0.970 & 2 & $\mathrm{~N} 22$ & 0.970 & 2 \\
\hline $\mathrm{N} 2$ & 0.953 & 7 & N105 & 0.965 & 8 & N26 & 0.970 & 2 & N67 & 0.970 & 2 \\
\hline N104 & 0.953 & 7 & $\mathrm{~N} 102$ & 0.966 & 8 & N45 & 0.970 & 2 & $\mathrm{~N} 20$ & 0.971 & 2 \\
\hline N9 & 0.955 & 7 & N100 & 0.970 & 2 & $\mathrm{~N} 46$ & 0.970 & 2 & N86 & 0.973 & 2 \\
\hline N7 & 0.955 & 7 & $\mathrm{~N} 42$ & 0.970 & 2 & N14 & 0.970 & 2 & N1 & 0.982 & 10 \\
\hline N82 & 0.956 & 7 & N61 & 0.970 & 2 & N31 & 0.970 & 2 & & & \\
\hline N6 & 0.956 & 7 & N63 & 0.970 & 2 & & & & & & \\
\hline
\end{tabular}

It is observed that the Shannon entropy of amino acid conservations along protein sequences of SARS-CoV2 are ranging from 0.7 to 0.982 which is closed to 1. Clearly, all the amino acids are uniformly distributed over the protein 
sequences since the uncertainty is maximum as the SE is nearly 1 . More than $50 \%$ of the proteins belong to the cluster 2 of SARS-CoV2 (54) having SE 0.970 which implies the amino acids are almost uniformly spread over the sequences. At last, the frequency analysis of the amino acids over the proteins is given in the following subsection.

In this section, we shall look into the frequencies of each of the amino acids in the 105 SARS-CoV2 proteins. At first a complete statistical comparison among all the amino acid frequencies over the 105 proteins is reported in the following Fig. 46 and Fig. 47. 

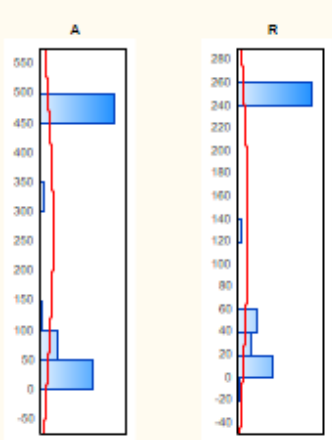

Graphical Summary (A, R, N, D, C, Q)
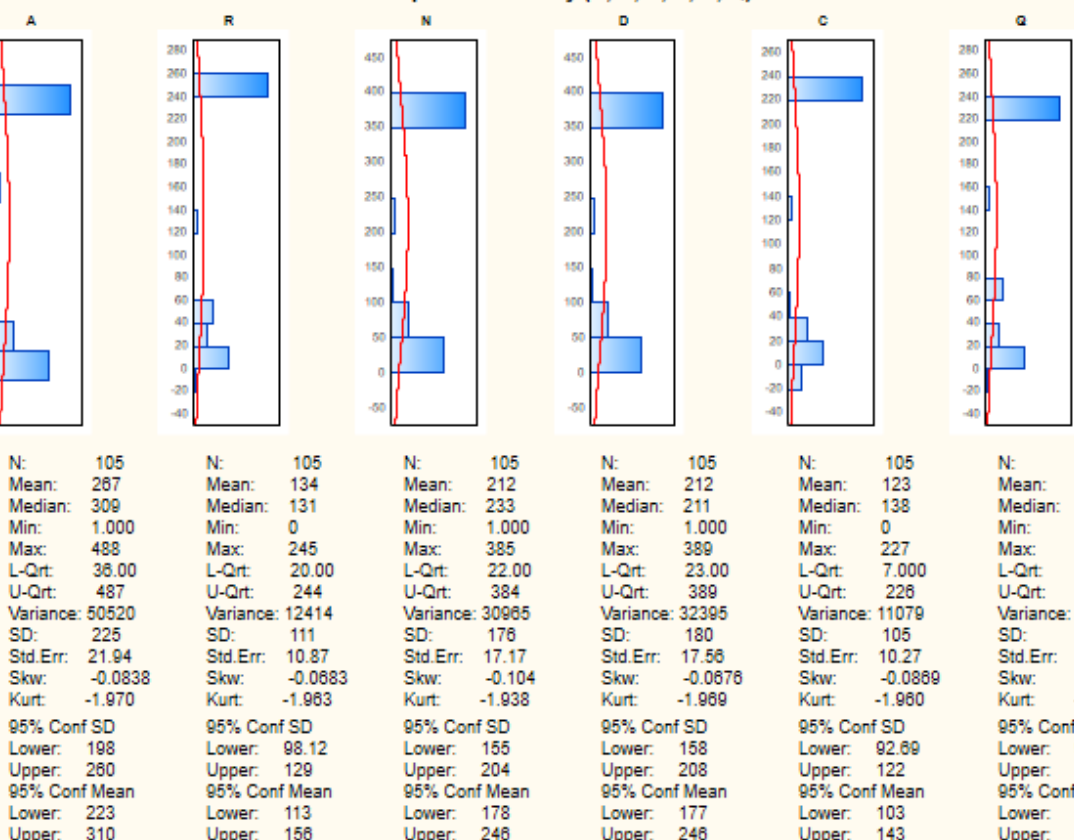

Median: 233

Max: $\quad 1.000 \quad$ Min: 1.000

$\begin{array}{ll}\text { Max: } & 385 \\ \text { L-Grt: } & 22.00\end{array}$

U-Qrt: $384 \quad$ L-Qrt: 23.00

Variance: 30965 Variance: 3239

SD: $\quad 178$

Std.Err: 17.17

$\begin{array}{ll}\text { Skw: } & -0.104 \\ \text { Kurt: } & -1.938\end{array}$

$95 \%$ Conf SD

$25 \%$ Conf SD
Lower. 155

Lower. $\quad 155$

95\% Conf Mean

Lower: 178

SD: $\quad 180$

$\begin{array}{ll}\text { Std.Err: } & 17.56 \\ \text { Skw: } & -0.0678\end{array}$

Kurt: -1.968

$95 \%$ Conf SD

Lower. 158

$85 \%$ Conf Mean

85\% Conf Mean
Lower: 177

Upper. 248

Upper. 248

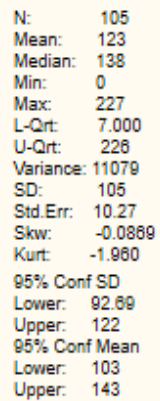

N.

$\begin{array}{lr}\text { N: } & 105 \\ \text { Mean: } & 135 \\ \text { Medin: } & 151\end{array}$

Median: 151

Min: $\quad{ }_{239}^{0}$

L-Qrt: $\quad 16.00$

U-Qrt: $\quad 239$

SD: $\quad 107$

$\begin{array}{ll}\text { Std. Err: } & 10.44 \\ \text { Skw: } & -0.121\end{array}$

Kurt: $\quad-1.816$

95\% Conf SD

Lower: 94.21

Upper. 124

Lower: 114

Upper. 155
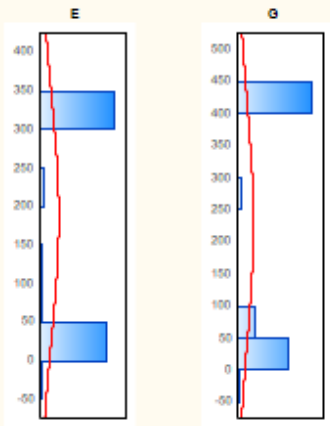

Graphical Summary (E, G, H, I, L, K)
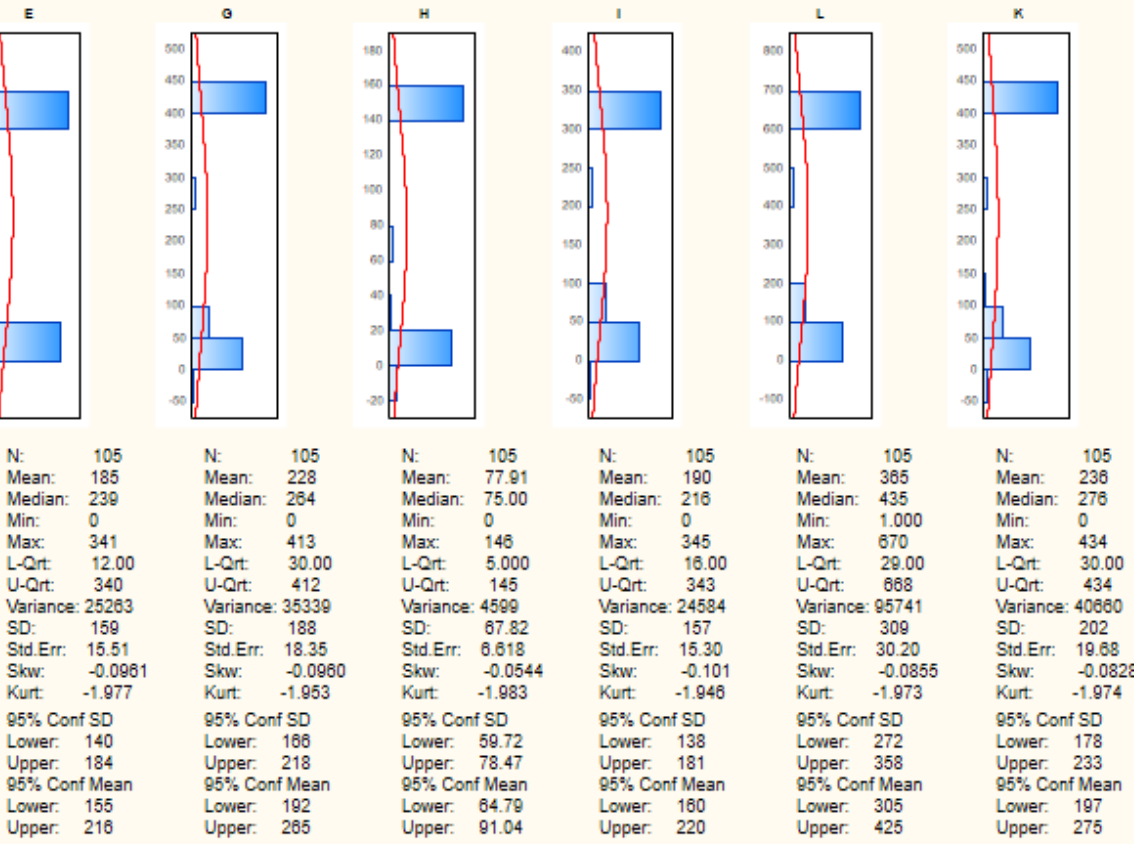

Figure 46: Comparative statistical details about frequencies of the amino acids over the proteins. 

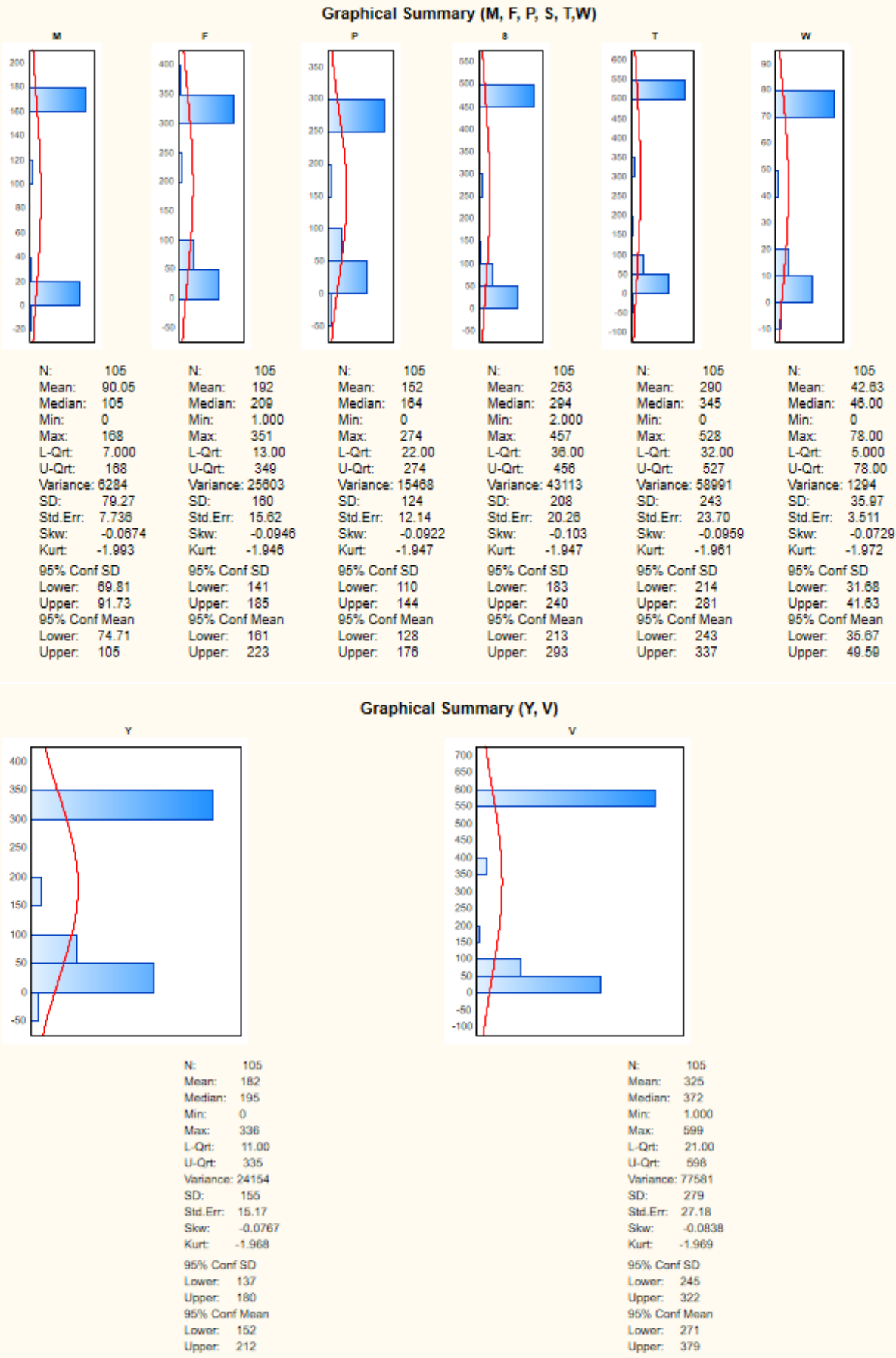

Figure 47: Comparative statistical details about frequencies of the amino acids over the proteins. 
Following a correlation among the frequency distribution of each of the amino acids over the 105 proteins of SARS-CoV2. The correlation coefficient corresponding to frequency distribution over the proteins is given in the Table 46 .

Table 46: Correlation matrix of the frequencies of the two amino acids pairwise

\begin{tabular}{|c|c|c|c|c|c|c|c|c|c|c|}
\hline & L & K & M & F & P & S & T & W & Y & V \\
\hline A & 0.999 & 1.000 & 0.996 & 0.997 & 0.998 & 0.998 & 0.999 & 0.997 & 0.998 & 0.998 \\
\hline $\mathbf{R}$ & 0.995 & 0.997 & 0.993 & 0.994 & 0.997 & 0.996 & 0.996 & 0.995 & 0.995 & 0.993 \\
\hline $\mathbf{N}$ & 0.996 & 0.996 & 0.990 & 0.999 & 0.998 & 0.999 & 0.998 & 0.993 & 0.997 & 0.996 \\
\hline $\mathbf{D}$ & 0.997 & 0.998 & 0.996 & 0.997 & 0.998 & 0.997 & 0.998 & 0.996 & 0.999 & 0.998 \\
\hline $\mathbf{C}$ & 0.998 & 0.996 & 0.994 & 0.999 & 0.995 & 0.996 & 0.998 & 0.993 & 0.999 & 0.999 \\
\hline $\mathbf{Q}$ & 0.989 & 0.992 & 0.982 & 0.993 & 0.998 & 0.997 & 0.994 & 0.987 & 0.989 & 0.988 \\
\hline $\mathbf{E}$ & 0.999 & 0.999 & 0.997 & 0.995 & 0.994 & 0.996 & 0.998 & 0.994 & 0.998 & 0.998 \\
\hline $\mathbf{G}$ & 0.997 & 0.998 & 0.992 & 0.997 & 0.999 & 0.999 & 0.999 & 0.995 & 0.996 & 0.995 \\
\hline $\mathbf{H}$ & 0.996 & 0.996 & 0.997 & 0.994 & 0.992 & 0.992 & 0.995 & 0.996 & 0.998 & 0.997 \\
\hline $\mathbf{I}$ & 0.998 & 0.996 & 0.991 & 0.999 & 0.997 & 0.998 & 0.998 & 0.996 & 0.998 & 0.998 \\
\hline
\end{tabular}

The corresponding correlation are also given pairwise in a matrix form in the Fig. 48.

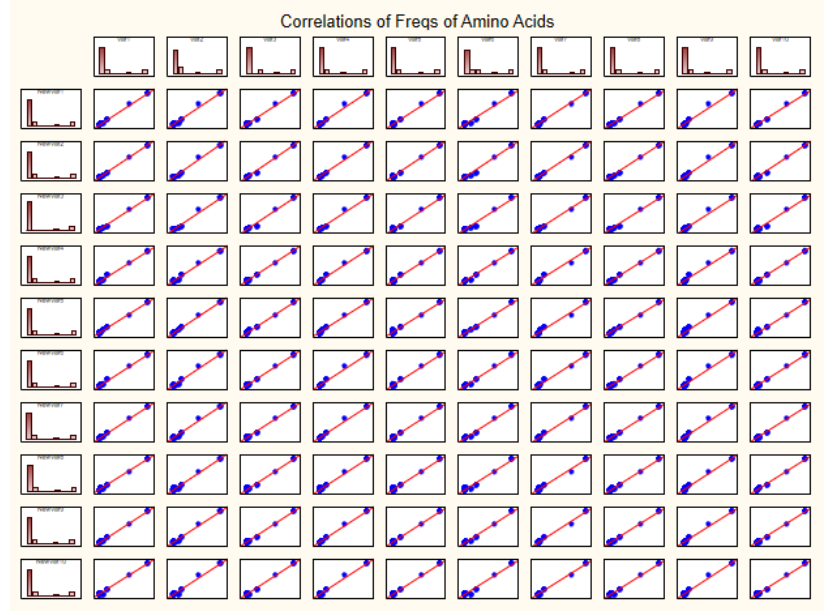

Figure 48: Correlation graphs for each of the amino acid frequencies.

It is observed that the correlation coefficient is very close to 1 which en- 
sures the existence of significant correlations of frequencies of each of the amino acids over the proteins. In fact the correlation coefficient between the frequency distributions corresponding to the amino acids A (Aliphatic) and K (Basic) is 1.

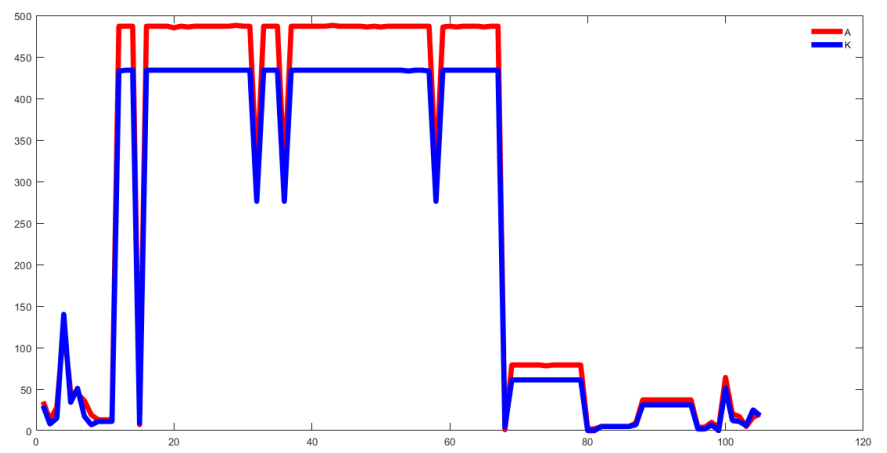

Figure 49: Frequency plots of the amino acids A and K over 105 proteins.

945

\section{Spatial Organization of Proteins of SARS-CoV}

In 2003, the SARS coronavirus (SARS-CoV) had caused an epidemic in China including other 22 countries [42, 43]. There are 14 protein sequences available in the NCBI database (taxid: 722424). The list of these protein (S1, $\mathrm{S} 2, \ldots \mathrm{S} 11)$ with their accessions is given here in the following Table 47. 
Table 47: List of SARS-CoV proteins with their Accession and length

\begin{tabular}{ccc}
\hline Accession & Seq & Length \\
\hline ACU31036 & S1 & 221 \\
ACU31045 & S2 & 63 \\
ACU31034 & S3 & 274 \\
ACU31035 & S4 & 76 \\
ACU31038 & S5 & 44 \\
ACU31041 & S6 & 70 \\
ACU31042 & S7 & 4189 \\
ACU31039 & S8 & 422 \\
ACU31037 & S9 & 122 \\
ACU31033 & S10 & 114 \\
ACU31040 & S11 & 98 \\
ACU31043 & S12 & 121 \\
ACU31044 & S13 & 6880 \\
ACU31032 & S14 & 1241 \\
\hline
\end{tabular}

It is noted that the protein with the accession ACU31032 (S14) is a spike protein of length 1241 as mentioned in the NCBI database. The spike protein (S-protein) is a large type I transmembrane protein of length not exceeding 1400 amino acids. The spike protein has its important function in the case of SARS$\mathrm{CoV}$ [4, 45]. Among all other proteins of SARS-CoV, spike protein is the main antigenic component which is responsible for inducing host immune responses, neutralizing antibodies and/or protective immunity against virus infection [46]. We therefore illuminate here the spatial representations of the amino acids over the the spike protein including other 13 proteins as mentioned in the Table 47 . The HE, SE and frequency distributions are given in the following and compared with the SARS-CoV2 proteins.

It is observed that the spatial representations of the presence of all the amino acids over the spike protein S14 follow the positive autocorrelation (positively 


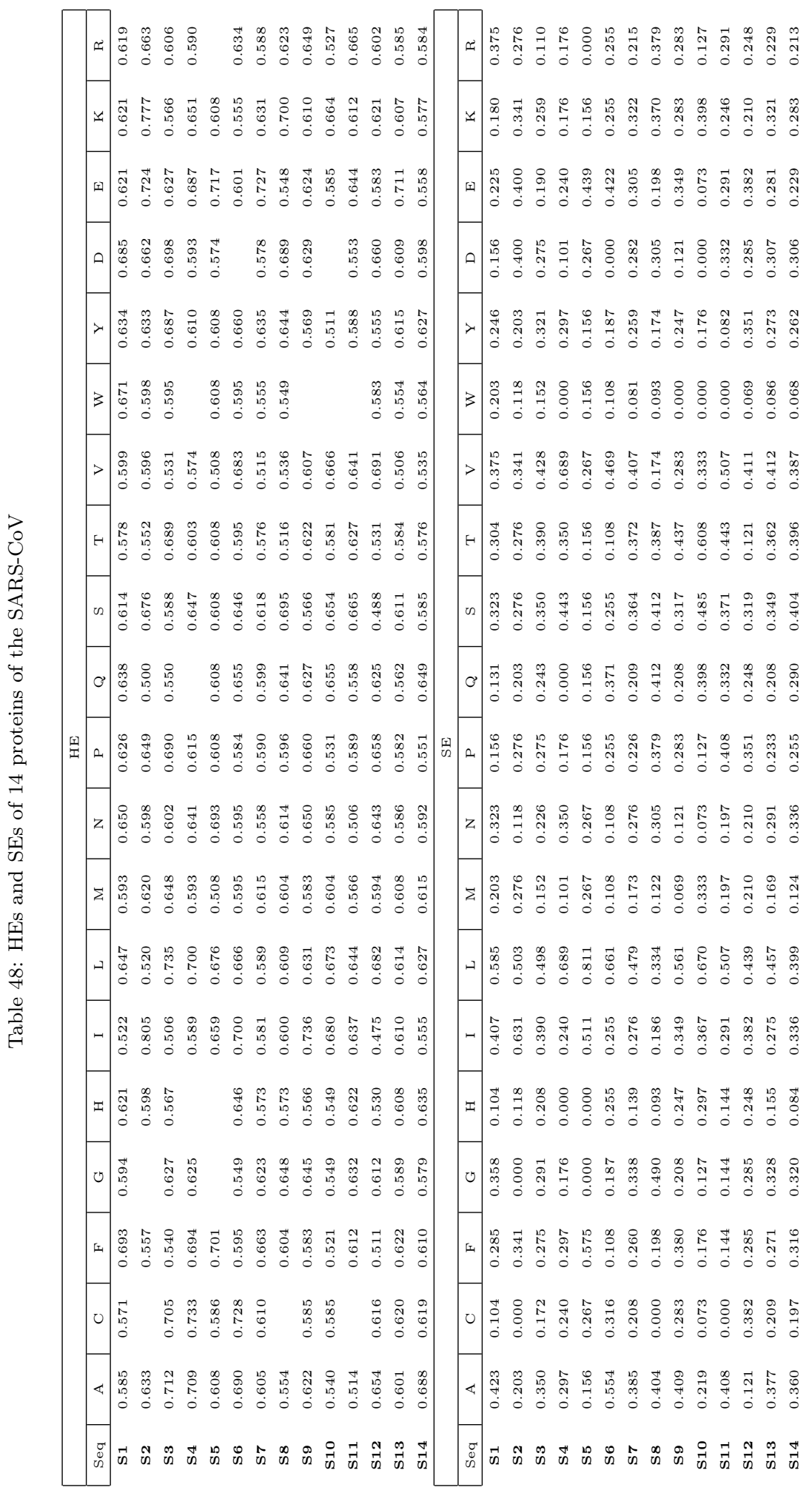


trending) as well as with least amount of uncertainty of presence of the amino acids. It seems that the presence of all the amino acids are necessary to make a

Table 49: Correlation matrix of the HEs (Pairwise)

\begin{tabular}{|c|c|c|c|c|c|c|c|c|c|c|}
\hline $\mathbf{r}$ & $\mathbf{Q}$ & $\mathbf{S}$ & $\mathbf{T}$ & $\mathbf{V}$ & $\mathbf{W}$ & $\mathbf{Y}$ & $\mathbf{D}$ & $\mathbf{E}$ & $\mathbf{K}$ & $\mathbf{R}$ \\
\hline $\mathbf{A}$ & -0.141 & -0.385 & 0.514 & 0.004 & -0.244 & 0.283 & 0.260 & -0.592 & -0.845 & -0.092 \\
\hline $\mathbf{C}$ & -0.706 & -0.101 & 0.814 & -0.288 & -0.316 & 0.535 & 0.307 & -0.046 & -0.752 & -0.077 \\
\hline $\mathbf{F}$ & 0.263 & 0.807 & -0.159 & -0.431 & 0.305 & 0.253 & -0.346 & 0.437 & 0.417 & 0.018 \\
\hline $\mathbf{G}$ & -0.503 & -0.159 & 0.409 & 0.083 & -0.052 & 0.257 & 0.285 & 0.313 & 0.091 & 0.264 \\
\hline $\mathbf{H}$ & 0.298 & 0.680 & 0.037 & -0.525 & 0.181 & 0.335 & -0.261 & -0.058 & -0.239 & -0.171 \\
\hline $\mathbf{I}$ & -0.256 & 0.723 & -0.039 & -0.806 & -0.497 & 0.190 & -0.758 & 0.696 & 0.120 & -0.694 \\
\hline $\mathbf{L}$ & -0.302 & -0.457 & 0.575 & 0.371 & 0.342 & 0.243 & 0.865 & -0.497 & -0.558 & 0.581 \\
\hline $\mathbf{M}$ & -0.654 & 0.264 & 0.908 & -0.583 & -0.286 & 0.796 & 0.138 & 0.096 & -0.758 & -0.144 \\
\hline $\mathbf{N}$ & 0.408 & -0.513 & -0.229 & 0.824 & 0.774 & -0.367 & 0.761 & -0.614 & 0.118 & 0.798 \\
\hline $\mathbf{P}$ & -0.392 & -0.418 & 0.456 & 0.457 & 0.412 & 0.153 & 0.854 & -0.164 & -0.143 & 0.712 \\
\hline
\end{tabular}

It is observed from the Table 49 that the correlation coefficient $(\mathrm{r})$ is 0.908 for the HEs of spatial representations of the amino acid $\mathrm{M}$ and $\mathrm{T}$ over all the 14 SARS-CoV proteins. Noted that over all the proteins the presence of the amino acid $\mathrm{M}$ and $\mathrm{T}$ are ensured. There are also other positive correlation exist as it can be seen in the Table 49 .

It is noted that the SE is turned out to be zero for the cases where the spatial distribution corresponding to an amino acid which is absent over a protein. The spatial distribution of amino acids over the proteins of SARS-CoV are all 
the 0.5 where the absence of amino acids dominates in terms of certainty.

The correlation coefficients of the SEs of the spatial distributions of the amino acids over the 14 SARS-CoV proteins are given in the Table 50.

Table 50: Correlation matrix of the SEs of the spatial distributions of amino acids

\begin{tabular}{|c|c|c|c|c|c|c|c|c|c|c|}
\hline $\mathbf{r}$ & $\mathbf{Q}$ & $\mathbf{S}$ & $\mathbf{T}$ & $\mathbf{V}$ & $\mathbf{W}$ & $\mathbf{Y}$ & $\mathbf{D}$ & $\mathbf{E}$ & $\mathbf{K}$ & $\mathbf{R}$ \\
\hline $\mathbf{A}$ & 0.245 & 0.109 & 0.119 & 0.123 & 0.032 & -0.190 & -0.273 & -0.094 & 0.108 & 0.500 \\
\hline $\mathbf{C}$ & -0.311 & -0.355 & -0.553 & 0.237 & -0.009 & 0.572 & -0.318 & 0.464 & -0.492 & -0.350 \\
\hline $\mathbf{F}$ & -0.589 & -0.554 & -0.270 & -0.287 & 0.297 & 0.164 & 0.281 & 0.399 & -0.428 & -0.490 \\
\hline $\mathbf{G}$ & 0.203 & 0.425 & 0.152 & -0.150 & 0.140 & 0.379 & 0.100 & -0.426 & 0.198 & 0.526 \\
\hline $\mathbf{H}$ & 0.566 & 0.151 & 0.173 & -0.128 & -0.247 & 0.108 & -0.391 & -0.124 & 0.430 & 0.117 \\
\hline $\mathbf{I}$ & -0.253 & -0.536 & -0.233 & -0.262 & 0.407 & -0.029 & 0.298 & 0.351 & -0.133 & -0.294 \\
\hline $\mathbf{L}$ & -0.363 & -0.363 & -0.190 & 0.229 & 0.030 & -0.245 & -0.594 & 0.214 & -0.474 & -0.591 \\
\hline $\mathbf{M}$ & 0.123 & -0.101 & 0.079 & -0.237 & 0.162 & -0.308 & 0.112 & -0.089 & 0.168 & -0.345 \\
\hline $\mathbf{N}$ & -0.468 & 0.145 & -0.080 & 0.188 & 0.268 & 0.309 & 0.342 & -0.176 & -0.391 & 0.060 \\
\hline $\mathbf{P}$ & 0.438 & 0.025 & -0.079 & -0.103 & -0.210 & -0.134 & 0.518 & 0.199 & 0.162 & 0.500 \\
\hline
\end{tabular}

It is observed that the correlations among the SEs of the spatial distributions of the amino acids over the proteins are not significantly up as tabulated in the Table 50. The highest positive correlation based on SEs of the spatial distributions of the amino acid $\mathrm{C}$ with that of $\mathrm{Y}$ is turned up as 0.572.

\section{Conclusions and Summary}

In this present study the spatial arrangement of amino acids over the SARSCoV2 proteins have been looked into through its autocorrelation by Hurst exponent and the amount of information of presence of the amino acids over the proteins through Shannon entropy are analysed. Also the frequency distribution of amino acids are also taken into consideration for categorizing the protein sequences. At the end, the features of the spatial distribution of 14 proteins of the SARS-CoV are also have been determined and seen significant difference with the former proteins of the SARS-CoV2. The study is a collection of information about the spatial distribution of the amino acids over the proteins of SARS-CoV2 as well as SARS-CoV. The difference noted in the section 4 would enable reader to distinguish the proteins of two different types of the CoVs. We 
1010 firmly believe that this spatial understanding of the presence and absence of each amino acids over the proteins would enable understanding the PPIs as well as identifying spike proteins in the case of SARS-CoV2. 


\section{References}

[1] C. P. E. R. E. Novel, et al., The epidemiological characteristics of an outbreak of 2019 novel coronavirus diseases (covid-19) in china, Zhonghua liu xing bing xue za zhi= Zhonghua liuxingbingxue zazhi 41 (2) (2020) 145.

[2] N. Zhu, D. Zhang, W. Wang, X. Li, B. Yang, J. Song, X. Zhao, B. Huang, W. Shi, R. Lu, et al., A novel coronavirus from patients with pneumonia in china, 2019, New England Journal of Medicine (2020).

[3] C. Huang, Y. Wang, X. Li, L. Ren, J. Zhao, Y. Hu, L. Zhang, G. Fan, J. Xu, X. Gu, et al., Clinical features of patients infected with 2019 novel coronavirus in wuhan, china, The Lancet 395 (10223) (2020) 497-506.

[4] C. Wang, P. W. Horby, F. G. Hayden, G. F. Gao, A novel coronavirus outbreak of global health concern, The Lancet 395 (10223) (2020) 470-473.

[5] S. Perlman, Another decade, another coronavirus (2020).

[6] Z.-W. Ye, S. Yuan, K.-S. Yuen, S.-Y. Fung, C.-P. Chan, D.-Y. Jin, Zoonotic origins of human coronaviruses, International Journal of Biological Sciences $16(10)(2020) 1686$.

[7] C. Ceraolo, F. M. Giorgi, Genomic variance of the 2019-ncov coronavirus, Journal of Medical Virology (2020).

[8] C. S. G. of the International, et al., The species severe acute respiratory syndrome-related coronavirus: classifying 2019-ncov and naming it sarscov-2, Nature Microbiology (2020) 1.

[9] K. G. Andersen, A. Rambaut, W. I. Lipkin, E. C. Holmes, R. F. Garry, The proximal origin of sars-cov-2, Nature Medicine (2020) 1-3.

[10] Y.-Z. Zhang, E. C. Holmes, A genomic perspective on the origin and emergence of sars-cov-2, Cell (2020). 
[11] X. Tang, C. Wu, X. Li, Y. Song, X. Yao, X. Wu, Y. Duan, H. Zhang, Y. Wang, Z. Qian, et al., On the origin and continuing evolution of sarscov-2, National Science Review (2020).

[12] E. L. Hatcher, S. A. Zhdanov, Y. Bao, O. Blinkova, E. P. Nawrocki, Y. Ostapchuck, A. A. Schäffer, J. R. Brister, Virus variation resourceimproved response to emergent viral outbreaks, Nucleic acids research 45 (D1) (2017) D482-D490.

[17] N. Goodacre, P. Devkota, E. Bae, S. Wuchty, P. Uetz, Protein-protein interactions of human viruses, in: Seminars in cell \& developmental biology, Vol. 99, Elsevier, 2020, pp. 31-39.

[18] X. Yang, S. Yang, Q. Li, S. Wuchty, Z. Zhang, Prediction of human-virus protein-protein interactions through a sequence embedding-based machine 
learning method, Computational and structural biotechnology journal 18 (2020) 153-161.

[19] S. Srinivasan, H. Cui, Z. Gao, M. Liu, S. Lu, W. Mkandawire, O. Narykov, M. Sun, D. Korkin, Structural genomics of sars-cov-2 indicates evolutionary conserved functional regions of viral proteins, Viruses 12 (4) (2020) 360.

[20] D. E. Gordon, G. M. Jang, M. Bouhaddou, J. Xu, K. Obernier, M. J. O'meara, J. Z. Guo, D. L. Swaney, T. A. Tummino, R. Huttenhain, et al., A sars-cov-2-human protein-protein interaction map reveals drug targets and potential drug-repurposing, BioRxiv (2020).

[21] R. Kolodny, D. Petrey, B. Honig, Protein structure comparison: implications for the nature of 'fold space', and structure and function prediction, Current opinion in structural biology 16 (3) (2006) 393-398.

[22] E. Krissinel, K. Henrick, Secondary-structure matching (ssm), a new tool for fast protein structure alignment in three dimensions, Acta Crystallographica Section D: Biological Crystallography 60 (12) (2004) 2256-2268.

[23] X. Pennec, N. Ayache, A geometric algorithm to find small but highly similar 3d substructures in proteins., Bioinformatics (Oxford, England) 14 (6) (1998) 516-522.

[24] Y.-S. Chiang, T. I. Gelfand, A. E. Kister, I. M. Gelfand, New classification of supersecondary structures of sandwich-like proteins uncovers strict patterns of strand assemblage, Proteins: Structure, Function, and Bioinformatics 68 (4) (2007) 915-921.

[25] M. I. GROMIHA, P. Ponnuswamy, Hydrophobic distribution and spatial arrangement of amino acid residues in membrane proteins, International journal of peptide and protein research 48 (5) (1996) 452-460.

[26] T. Kollár, I. Pálinkó, Z. Kónya, I. Kiricsi, Intercalating amino acid guests into montmorillonite host, Journal of Molecular Structure 651 (2003) 335340. 
[27] S. S. Hassan, R. K. Rout, V. Sharma, A quantitative genomic view of the coronaviruses: Sars-cov2 (2020).

[28] J. R. Brister, D. Ako-Adjei, Y. Bao, O. Blinkova, Ncbi viral genomes resource, Nucleic acids research 43 (D1) (2015) D571-D577.

[29] K. L. Schierhorn, F. Jolmes, J. Bespalowa, S. Saenger, C. Peteranderl, J. Dzieciolowski, M. Mielke, M. Budt, S. Pleschka, A. Herrmann, et al., Influenza a virus virulence depends on two amino acids in the n-terminal domain of its ns1 protein to facilitate inhibition of the rna-dependent protein kinase pkr, Journal of virology 91 (10) (2017) e00198-17.

[30] U. A. Ashfaq, T. Javed, S. Rehman, Z. Nawaz, S. Riazuddin, An overview of hcv molecular biology, replication and immune responses, Virology journal 8 (1) (2011) 161.

[31] W. Luytjes, L. S. Sturman, P. J. Bredenbee, J. Charite, B. A. van der Zeijst, M. C. Horzinek, W. J. Spaan, Primary structure of the glycoprotein e2 of coronavirus mhv-a59 and identification of the trypsin cleavage site, Virology 161 (2) (1987) 479-487.

[32] J. P. Banerjee, J. K. Das, P. P. Choudhury, S. Mukherjee, S. S. Hassan, P. Basu, The variations of human mirnas and ising like base pairing models, BioRxiv (2018) 319301.

[33] J. K. Das, P. P. Choudhury, N. Chaturvedi, M. Tayyab, S. S. Hassan, Ranking and clustering of drosophila olfactory receptors using mathematical morphology, Genomics 111 (4) (2019) 549-559.

[34] J. K. Das, P. P. Choudhury, A. Chaudhuri, S. S. Hassan, P. Basu, Analysis of purines and pyrimidines distribution over mirnas of human, gorilla, chimpanzee, mouse and rat, Scientific reports 8 (1) (2018) 1-19.

[35] M. Sánchez-Granero, M. Fernández-Martínez, J. Trinidad-Segovia, Introducing fractal dimension algorithms to calculate the hurst exponent of financial time series, The European Physical Journal B 85 (3) (2012) 86. 
[36] M. D. Kale, F. B. Butar, Fractal analysis of time series and distribution properties of hurst exponent, Ph.D. thesis, Sam Houston State University (2005).

[37] J. Mielniczuk, P. Wojdyłło, Estimation of hurst exponent revisited, Computational Statistics \& Data Analysis 51 (9) (2007) 4510-4525.

[38] J. Lin, Divergence measures based on the shannon entropy, IEEE Transactions on Information theory 37 (1) (1991) 145-151.

[39] B. J. Strait, T. G. Dewey, The shannon information entropy of protein sequences, Biophysical journal 71 (1) (1996) 148-155.

[40] L. R. Nemzer, Shannon information entropy in the canonical genetic code, Journal of theoretical biology 415 (2017) 158-170.

[41] G. Dovbeshko, L. Berezhinsky, Low frequency vibrational spectra of some amino acids, Journal of molecular structure 450 (1-3) (1998) 121-128.

[42] X. Xiao, S. Chakraborti, A. S. Dimitrov, K. Gramatikoff, D. S. Dimitrov, The sars-cov s glycoprotein: expression and functional characterization, Biochemical and biophysical research communications 312 (4) (2003) 11591164.

[43] G. Simmons, J. D. Reeves, A. J. Rennekamp, S. M. Amberg, A. J. Piefer, P. Bates, Characterization of severe acute respiratory syndrome-associated coronavirus (sars-cov) spike glycoprotein-mediated viral entry, Proceedings of the National Academy of Sciences 101 (12) (2004) 4240-4245.

[44] L. Du, Y. He, Y. Zhou, S. Liu, B.-J. Zheng, S. Jiang, The spike protein of sars-cov - a target for vaccine and therapeutic development, Nature Reviews Microbiology 7 (3) (2009) 226-236.

[45] Y. He, Y. Zhou, S. Liu, Z. Kou, W. Li, M. Farzan, S. Jiang, Receptorbinding domain of sars-cov spike protein induces highly potent neutralizing 
antibodies: implication for developing subunit vaccine, Biochemical and biophysical research communications 324 (2) (2004) 773-781.

${ }_{1150}$ [46] J. Cinatl, B. Morgenstern, G. Bauer, P. Chandra, H. Rabenau, H. Doerr, Treatment of sars with human interferons, The Lancet 362 (9380) (2003) 293-294. 
Table 51: 105 protein sequences of the SATS-CoV2 with their corresponding accessions

\begin{tabular}{|c|c|}
\hline $\begin{array}{l}\text { Sequence } \\
\text { Name }\end{array}$ & Accession ID \\
\hline N1 & YP_009725309 \\
\hline $\mathrm{N} 2$ & YP_009725306 \\
\hline N3 & YP_009725304 \\
\hline $\mathrm{N} 4$ & YP_009725299 \\
\hline N5 & YP_009725308 \\
\hline N6 & YP_009725298 \\
\hline N7 & YP_009725300 \\
\hline N8 & $\begin{array}{l}\text { YP_009724393, QIK50441, QIK50451, QIK50420, QIK50430, QIK02957, QIK02967, QIK02947, } \\
\text { QIJ96486, QIJ96476, QIJ96506, QIJ96526, QIJ96466, QIJ96496, QIJ96516, QII87785, QII87797, } \\
\text { QII87809, QII87821, QII57171, QII57271, QII57281, QII57341, QII57221, QII57261, QII57231, } \\
\text { QII57181, QII57163, QII57331, QII57211, QII57201, QII57321, QII57301, QII57311, QII57291, QII57191, } \\
\text { QIA98557, QII57241, QII57251, QHS34549, QIA98586, QIH55224, QIH45026, QIH45036, QIH45046, } \\
\text { QIH45056, QIG55997, QIE07454, QIE07464, QIE07474, QIE07484, QID98797, QID21051, QID21061, } \\
\text { QID21071, QIC53207, QIC53216, QIB84676, QIA98609, QIA98599, QHZ87585, QHZ87595, QIA20047, } \\
\text { QHZ00402, QHZ00382, QHZ00361, QHZ00392, QHW06052, QHW06062, QHW06042, QHU79197, } \\
\text { QHU36867, QHU36827, QHU36857, QHU36847, QHU36837, QHU79207, QHR84452, QHR63253, } \\
\text { QHR63263, QHR63273, QHR63283, QHR63293, QHO62114, QHQ82467, QHQ71966, QHQ71976, } \\
\text { QHO62109, QHO62880, QHN73813, QHN73798, QHO60597, QHD43419, }\end{array}$ \\
\hline N9 & QHZ00380 \\
\hline N10 & $\begin{array}{l}\text { YP_009724391, QIK50439, QIK50449, QIK50418, QIK50428, QIK02955, QIK02965, QIK02945, } \\
\text { QIJ96474, QIJ96484, QIJ96504, QIJ96524, QIJ96464, QIJ96494, QIJ96514, QII87795, QII87807, } \\
\text { QII87819, QII57169, QII57219, QII57269, QII57279, QII57339, QII57259, QII57229, QII57179, } \\
\text { QII57329, QII57209, QII57199, QII57319, QII57299, QII57309, QII57289, QII57189, QII57239, QII57249, } \\
\text { QHS34547, QIA98584, QIH55222, QIH45024, QIH45044, QIH45034, QIH45054, QIE07452, QIE07462, } \\
\text { QIE07472, QIE07482, QID98795, QID21049, QID21059, QID21069, QIC53214, QIB84674, QIA98607, } \\
\text { QIA98597, QHZ87583, QHZ87593, QIA20045, QHZ00400, QHZ00359, QHZ00390, QHW0606,, } \\
\text { QHW06050, QHW06040, QHU79195, QHU36825, QHU36865, QHU36855, QHU36845, QHU3683, } \\
\text { QHU79205, QHR63251, QHR63261, QHR63271, QHR63281, QHR63291, QHQ82465, QHQ71964, } \\
\text { QHO62878, QHN73811, QHN73796, QHO60595, QHD43417, }\end{array}$ \\
\hline N11 & QII87783,QIA98555,QIG55995,QIC53205,QHR84450,QHQ71974 \\
\hline N12 & QHZ87591 \\
\hline N13 & QII57277 \\
\hline N14 & QIE07480 \\
\hline N15 & YP_009725297 \\
\hline N16 & QHQ71962 \\
\hline N17 & QHW06058 \\
\hline N18 & QHZ00378 \\
\hline N19 & QII57287 \\
\hline $\mathrm{N} 20$ & QIJ96502 \\
\hline $\mathrm{N} 21$ & QII57187 \\
\hline $\mathrm{N} 22$ & QHZ00398 \\
\hline $\mathrm{N} 23$ & QII57167 \\
\hline $\mathrm{N} 24$ & QIH45022,QIH45032,QIH45042,QIH45052 \\
\hline $\mathrm{N} 25$ & QIH55220 \\
\hline
\end{tabular}


Table 52: 105 protein sequences of the SATS-CoV2 with their corresponding accessions

\begin{tabular}{|c|c|}
\hline N26 & QIK02963 \\
\hline N27 & QII57237 \\
\hline N28 & QIE07460 \\
\hline N29 & QHR63289 \\
\hline N30 & QHN73809 \\
\hline N31 & QIK50437,QIK50447 \\
\hline N32 & QIA20043 \\
\hline N33 & QIJ96512,QIG55993,QIA20042,QHQ82463 \\
\hline N34 & QIJ96522 \\
\hline N35 & QIE07470 \\
\hline N36 & YP_009725295,QII87793,QII87805,QII87817 \\
\hline N37 & QIK50426 \\
\hline N38 & QHQ71972 \\
\hline N39 & QIK02953 \\
\hline N40 & QIK02943 \\
\hline N41 & QII87792,QII87804 \\
\hline N42 & QII87816 \\
\hline N43 & QID21067 \\
\hline N44 & QHZ00388 \\
\hline N45 & $\begin{array}{l}\text { YP_009724389, QIK50416, QIJ96482, QIJ96462, QII57337, QII57217, QII57257, QII57227, QII57327, } \\
\text { QII57207, QII57197, QII57297, QII57307, QII57247, QIE07450, QID21047, QID21057, QIC53222, } \\
\text { QIB84672, QIA98595, QHZ00357, QHU79193, QHU36853, QHU36833, QHU79203, QHR84448, } \\
\text { QHR63259, QHR63279, QHO62111, QHO62106, QHN73794, QHO60603, QHD43415 }\end{array}$ \\
\hline N46 & QHR63249 \\
\hline N47 & QIA98553 \\
\hline N48 & QID98793 \\
\hline N49 & QIA98605 \\
\hline N50 & QII57177 \\
\hline N51 & QHU36823 \\
\hline N52 & QIJ96472 \\
\hline N53 & QHU36863 \\
\hline N54 & QHR63269 \\
\hline N55 & QHU36843 \\
\hline N56 & QII57165 \\
\hline N57 & QII57267 \\
\hline N58 & QII 87781 \\
\hline N59 & QII 87780 \\
\hline N60 & QIC53203 \\
\hline N61 & QHS34545 \\
\hline N62 & QIJ96492 \\
\hline N63 & QIA98582 \\
\hline N64 & QII57317 \\
\hline N65 & QHW06048,QHW06038 \\
\hline N66 & QHZ87581 \\
\hline N67 & QHO62876 \\
\hline
\end{tabular}


Table 53: 105 protein sequences of the SATS-CoV2 with their corresponding accessions

\begin{tabular}{|c|c|}
\hline $\begin{array}{l}\text { Sequence } \\
\text { Name }\end{array}$ & Accession ID \\
\hline N68 & $\begin{array}{l}\text { YP_009724394, QIK50442, QIK50452, QIK50421, QIK50431, QIK02958, QIK02968, QIK02948, } \\
\text { QIJ96477, QIJ96487, QIJ96507, QIJ96527, QIJ96467, QIJ96497, QIJ96517, QII87786, QII87798, } \\
\text { QII87810, QII87822, QII57272, QII57172, QII57222, QII57282, QII57342, QII57262, QII57232, QII57182, } \\
\text { QII57302, QII57332, QII57212, QII57202, QII57322, QII57312, QII57292, QII57192, QIA9855, } \\
\text { QII57242, QII57252, QHS34550, QIA98587, QIH55225, QIH45027, QIH45037, QIH45047, QIH45057, } \\
\text { QIG55998, QIE07455, QIE07465, QIE07475, QIE07485, QID98798, QID21052, QID21062, QID21072, } \\
\text { QIC53208, QIC53217, QIB84677, QIA98610, QIA98600, QHZ87586, QHZ87596, QIA20048, QHZ00403, } \\
\text { QHZ00383, QHZ00362, QHZ00393, QHW06053, QHW06063, QHW06043, QHU79198, QHU36828, } \\
\text { QHU36868, QHU36858, QHU36848, QHU36838, QHU79208, QHR84453, QHR63254, QHR63264, } \\
\text { QHR63274, QHR63284, QHR63294, QHQ82468, QHQ71967, QHQ71977, QHO62881, QHN73814, } \\
\text { QHN73799, QHO60598, QHD43420 }\end{array}$ \\
\hline N69 & QIA20044 \\
\hline N70 & QHS34546 \\
\hline N71 & QHR84449 \\
\hline N72 & QIC53204 \\
\hline N73 & $\begin{array}{l}\text { YP_009724390, QIK50438, QIK50448, QIK50417, QIK02954, QIK02964, QIK02944, QIJ96483, } \\
\text { QIJ96473, QIJ96503, QIJ96523, QIJ96463, QIJ96513, QII87782, QII87794, QII87806, QII87818, } \\
\text { QII57218, QII57268, QII57168, QII57338, QII57258, QII57228, QII57178, QII57161, QII57328, QII57208, } \\
\text { QII57198, QII57318, QII57298, QII57308, QII57288, QII57188, QIA98554, QII57248, QII57238, } \\
\text { QIH55221, QIH45023, QIH45033, QIH45053, QIH45043, QIG55994, QIE07451, QIE07461, QIE07471, } \\
\text { QIE07481, QID98794, QID21048, QID21058, QID21068, QIC53213, QIB84673, QIA98606, QIA98596, } \\
\text { QHZ87582, QHZ87592, QHZ00399, QHZ00358, QHZ00389, QHW06049, QHW06039, QHU79194, } \\
\text { QHU36864, QHU36854, QHU36824, QHU36844, QHU36834, QHU79204, QHR63250, QHR63260, } \\
\text { QHR63270, QHR63280, QHR63290, QHO62112, QHQ82464, QHQ71963, QHQ71973, QHO62107, } \\
\text { QHO62877, QHN73810, QHN73795, QHO60594, QHD43416 }\end{array}$ \\
\hline N74 & QIA98583 \\
\hline N75 & QIK50427 \\
\hline N76 & QHZ00379 \\
\hline N77 & QIJ96493 \\
\hline N78 & QII57278 \\
\hline N79 & QHW06059 \\
\hline N80 & $\begin{array}{l}\text { YP_009725255, QIK50446, QIK50456, QIK50425, QIK50436, QIK02962, QIK02972, QIK02952, } \\
\text { QIJ96481, QIJ96491, QIJ96511, QIJ96531, QIJ96471, QIJ96501, QIJ96521, QII87791, QII87803, } \\
\text { QII87815, QII87827, QII57176, QII57226, QII57276, QII57286, QII57346, QII57266, QII57236, QII57186, } \\
\text { QII57336, QII57216, QII57206, QII57326, QII57306, QII57316, QII57296, QII57196, QIA98562, } \\
\text { QII57246, QII57256, QHS34554, QIA98591, QIH55229, QIH45031, QIH45041, QIH45051, QIH45061, } \\
\text { QIG56002, QIE07459, QIE07469, QIE07479, QIE07489, QID98802, QID21056, QID21066, QID21076, } \\
\text { QIC53212, QIB84681, QIA98614, QIA98603, QIA20053, QHZ87590, QHZ87600, QHZ00407, QHZ00387, } \\
\text { QHZ00366, QHZ00397, QHW06057, QHW06067, QHW06047, QHU79202, QHU36872, QHU36862, } \\
\text { QHU36832, QHU36852, QHU36842, QHU79212, QHR84457, QHQ82472, QHQ71981, QHQ71971, } \\
\text { QHO62885, QHN73818, QHO60602, QHI42199, }\end{array}$ \\
\hline N81 & $\begin{array}{l}\text { YP_009725318, YP_009725296, QIK50433, QII87788, QII87800, QII87812, QII87824, QIC53219, } \\
\text { QIA20050, QHR63256, QHR63266, QHR63276, QHR63286, QHR63296 }\end{array}$ \\
\hline N82 & QID21074 \\
\hline N83 & QHZ87588,QHQ71969 \\
\hline
\end{tabular}


Table 54: 105 protein sequences of the SATS-CoV2 with their corresponding accessions

\begin{tabular}{|c|c|}
\hline $\begin{array}{l}\text { Sequence } \\
\text { Name }\end{array}$ & Accession ID \\
\hline N84 & $\begin{array}{l}\text { YP_009724396, QIK50444, QIK50454, QIK50423, QIK50434, QIK02960, QIJ96479, } \\
\text { QIJ96489, QIJ96509, QIJ96529, QIJ96469, QIJ96499, QIJ96519, QII87789, QII57174, } \\
\text { QII57274, QII57284, QII57344, QII57224, QII57264, QII57234, QII57184, QII57304, } \\
\text { QII57334, QII57214, QII57204, QII57324, QII57314, QII57294, QII57194, QIA98560, } \\
\text { QII57244, QII57254, QHS34552, QIG56000, QIE07457, QIE07467, QIE07487, QID98800, } \\
\text { QID21064, QIC53210, QIC53220, QIB84679, QIA98612, QHZ87598, QHZ00405, QHZ00385, } \\
\text { QHZ00364, QHZ00395, QHW06055, QHW06065, QHW06045, QHU36870, QHU36860, } \\
\text { QHU36830, QHU36850, QHU36840, QHR84455, QHR63257, QHR63267, QHR63277, } \\
\text { QHR63287, QHR63297, QHQ71979, QHD43422 }\end{array}$ \\
\hline N85 & $\begin{array}{l}\text { QIK02970, QIK02950, QII87801, QII87813, QII87825, QIA98589, QIH55227, QIH45029, } \\
\text { QIH45039, QIH45059, QIH45049, QIE07477, QID21054, QIA98601, QIA20051, QHU79200, } \\
\text { QHU79210, QHQ82470, QHN73816, QHN73801, QHO60600 }\end{array}$ \\
\hline N86 & QHO62883 \\
\hline N87 & $\begin{array}{l}\text { YP_009724395, QIK50443, QIK50453, QIK50422, QIK50432, QIK02959, QIK02969, } \\
\text { QIK02949, QIJ96478, QIJ96488, QIJ96508, QIJ96528, QIJ96468, QIJ96498, QIJ96518, } \\
\text { QII87787, QII87799, QII87811, QII87823, QII57223, QII57173, QII57273, QII57283, } \\
\text { QII57343, QII57263, QII57233, QII57183, QII57303, QII57333, QII57213, QII57203, } \\
\text { QII57323, QII57313, QII57293, QII57193, QIA98559, QII57243, QII57253, QHS34551, } \\
\text { QIA9858,, QIH55226, QIH45028, QIH45058, QIH45038, QIH45048, QIG55999, QIE07456, } \\
\text { QIE07466, QIE07476, QIE07486, QID98799, QID21053, QID21063, QID21073, QIC53209, } \\
\text { QIC53218, QIB84678, QIA98611, QIA98604, QIA20049, QHZ87587, QHZ87597, QHZ00404, } \\
\text { QHZ00384, QHZ00363, QHZ00394, QHW06054, QHW06064, QHW06044, QHU79199, } \\
\text { QHU36869, QHU36859, QHU36829, QHU36849, QHU36839, QHU79209, QHR84454, } \\
\text { QHR63255, QHR63265, QHR63275, QHR63285, QHR63295, QHQ82469, QHQ71968, } \\
\text { QHQ71978, QHO62882, QHN73815, QHN73800, QHO60599, QHD43421 }\end{array}$ \\
\hline N88 & QHZ00406,QHW06056,QHW06046 \\
\hline N89 & QID21055 \\
\hline N90 & $\begin{array}{l}\text { YP_009724397, QIK50445, QIK50455, QIK50424, QIK50435, QIK02961, QIK02971, } \\
\text { QIK02951, QIJ96490, QIJ96480, QIJ96510, QIJ96470, QIJ96500, QIJ96520, QII87790, } \\
\text { QII87802, QII87814, QII87826, QII57175, QII57225, QII57275, QII57285, QII57345, } \\
\text { QII57265, QII57235, QII57185, QII57164, QII57335, QII57215, QII57205, QII57325, } \\
\text { QII57315, QII57295, QII57195, QIA98561, QII57245, QII57255, QHS34553, QIA98590, } \\
\text { QIH55228, QIH45030, QIH45040, QIH45060, QIG56001, QIE07468, QIE07478, QIE07488, } \\
\text { QID98801, QID21065, QID21075, QIC53211, QIC53221, QIB84680, QIA98613, QIA98602, } \\
\text { QHZ87589, QHZ87599, QIA20052, QHZ00386, QHZ00365, QHZ00396, QHW06066, } \\
\text { QHU79201, QHU36831, QHU36871, QHU36861, QHU36851, QHU36841, QHU79211, } \\
\text { QHR84456, QHR63258, QHR63268, QHR63278, QHR63288, QHR63298, QHO62115, } \\
\text { QHQ82471, QHQ71970, QHQ71980, QHO62110, QHN73817, QHN73802, QHO60601, } \\
\text { QHD43423 }\end{array}$ \\
\hline
\end{tabular}


Table 55: 105 protein sequences of the SATS-CoV2 with their corresponding accessions

\begin{tabular}{|c|c|}
\hline $\begin{array}{l}\text { Sequence } \\
\text { Name }\end{array}$ & Accession ID \\
\hline N91 & QIE07458 \\
\hline N92 & QIH45050 \\
\hline N93 & QHO62884 \\
\hline N94 & QII57305 \\
\hline N95 & QIJ96530 \\
\hline N96 & QHZ00381 \\
\hline N97 & $\begin{array}{l}\text { YP_009724392, QIK50440, QIK50450, QIK50419, QIK50429, QIK02956, QIK02966, } \\
\text { QIK02946, QIJ96485, QIJ96475, QIJ96505, QIJ96525, QIJ96465, QIJ96495, QIJ96515, } \\
\text { QII87784, QII87796, QII87808, QII87820, QII57170, QII57220, QII57280, QII57270, } \\
\text { QII57340, QII57260, QII57230, QII57180, QII57300, QII57162, QII57330, QII57210, } \\
\text { QII57200, QII57320, QII57310, QII57290, QII57190, QIA98556, QII57240, QII57250, } \\
\text { QHS34548, QIA98585, QIH55223, QIH45025, QIH45035, QIH45045, QIH45055, QIG55996, } \\
\text { QIE07453, QIE07463, QIE07473, QIE07483, QID98796, QID21050, QID21060, QID21070, } \\
\text { QIC53206, QIC53215, QIB84675, QIA98608, QIA98598, QIA20046, QHZ87584, QHZ87594, } \\
\text { QHZ00401, QHZ00360, QHZ00391, QHW06051, QHW06061, QHW06041, QHU79196, } \\
\text { QHU36866, QHU36856, QHU36826, QHU36846, QHU36836, QHU79206, QHR84451, } \\
\text { QHR63252, QHR63262, QHR63272, QHR63282, QHR63292, QHO62113, QHQ82466, } \\
\text { QHQ71965, QHQ71975, QHO62108, QHO62879, QHN73812, QHN73797, QHO60596, } \\
\text { QHD43418 }\end{array}$ \\
\hline N98 & YP_009725305 \\
\hline N99 & YP_009725312 \\
\hline N100 & YP_009725307 \\
\hline N101 & YP_009725302 \\
\hline N102 & YP_009725301 \\
\hline N103 & YP_009725303 \\
\hline N104 & YP_009725310 \\
\hline N105 & YP_009725311 \\
\hline
\end{tabular}

